\title{
Anteroposterior Jaw Position and Pharyngeal Airway Morphology in Young Adult Patients: A CBCT Study
}

Martin C. Avey

Follow this and additional works at: https://researchrepository.wvu.edu/etd

\section{Recommended Citation}

Avey, Martin C., "Anteroposterior Jaw Position and Pharyngeal Airway Morphology in Young Adult Patients: A CBCT Study" (2016). Graduate Theses, Dissertations, and Problem Reports. 5133.

https://researchrepository.wvu.edu/etd/5133

This Thesis is protected by copyright and/or related rights. It has been brought to you by the The Research Repository @ WVU with permission from the rights-holder(s). You are free to use this Thesis in any way that is permitted by the copyright and related rights legislation that applies to your use. For other uses you must obtain permission from the rights-holder(s) directly, unless additional rights are indicated by a Creative Commons license in the record and/ or on the work itself. This Thesis has been accepted for inclusion in WVU Graduate Theses, Dissertations, and Problem Reports collection by an authorized administrator of The Research Repository @ WVU. For more information, please contact researchrepository@mail.wvu.edu. 


\title{
Anteroposterior Jaw Position and Pharyngeal Airway Morphology in Young Adult Patients: A CBCT Study
}

\author{
Martin C. Avey, D.M.D. \\ Thesis submitted \\ to the School of Dentistry \\ at West Virginia University \\ in partial fulfillment of the requirements for the degree of \\ Master of Science in \\ Orthodontics
}

Timothy Tremont, D.M.D., Chair

Peter Ngan, D.M.D.

Chris Martin, D.D.S.

Richard Jurevic, D.D.S., Ph.D.

Department of Orthodontics

Morgantown, West Virginia

2016

Keywords: Airway, Craniofacial, CBCT, Cone Beam, Sleep Apnea Copyright 2016 Martin C. Avey, D.M.D. 


\title{
ABSTRACT \\ Anteroposterior Jaw Position and Pharyngeal Airway Morphology in Young Adult Patients: A CBCT Study
}

\author{
Martin C. Avey, D.M.D.
}

Background and Objectives: Much previous attention has been paid in the orthodontic literature to craniofacial skeletal patterns and morphology of the upper airway and their association with obstructive sleep apnea (OSA). However, the majority of 3D airway investigations in recent years have analyzed the relationship of the airway with various anteroposterior (AP) skeletal patterns using traditional 2D cephalometric landmarks and measurements, such as SNA and SNB. The Six Elements of Orofacial Harmony is a diagnostic and treatment philosophy that proposes a more accurate and clinically relevant approach to evaluating the position of teeth and jaws. Element II specifically assesses AP position of the jaws relative to a reproducible landmark, the goal anterior limit line (GALL). The specific aim of this study was to utilize cone-beam computed tomography (CBCT) to investigate pharyngeal airway morphology relative to various AP jaw positions as described by Element II. Experimental Design and Methods: A sample of $86 \mathrm{CBCT}$ scans of pre-treatment orthodontic patients aged 18-30 from the private practice of Dr. Thomas Shipley was used for this study. IRB-approval was obtained, and a letter of permission was obtained from Dr. Shipley to use the records from his office. Exclusion criteria included history of orthodontic treatment, complex open bite with divergent occlusal planes, craniofacial/developmental deformity, adenoid hypertrophy, history of tonsillectomy/adenoidectomy, and poor image quality or artifacts. Pre-treatment CBCT scans were de-identified and DICOM files were analyzed using Dolphin Imaging 11.5 software. CBCT slices were used to extract a 2D lateral cephalogram for each subject. Subjects were then divided into groups based on craniofacial variables classified by the Six Elements (experimental) and traditional cephalometric measurements (control). Dolphin 3D was utilized to measure each subject's lower pharyngeal airway volume (AV), airway length (AL), and minimum crosssectional area (mCA). These airway dimensions, as well as calculated mean cross-sectional area (MCA) and uniformity percentage (U\%), were compared between groups for each craniofacial variable. Data was analyzed using one-way ANOVA and unequal variances t-tests to determine statistical significance of the results. Results: In the optimal Mx-GALL group, the average AV $\left(23296.1+/-1095.6 \mathrm{~mm}^{3}\right)$ and MCA $\left(332.3+/-16.4 \mathrm{~mm}^{2}\right)$ were significantly higher $(\mathrm{p}=0.011$ and 0.023 ) than every other position group. No other craniofacial variable groups had statistically significant differences in airway dimensions. Conclusions: The anteroposterior position of the maxilla relative to GALL has a significant correlation with lower pharyngeal airway size and shape. Subjects with an optimally positioned maxilla had airways with a significantly higher volume and larger average axial area than subjects in every other group for maxillary position. This is a novel and clinically relevant finding that can have a significant influence on surgical and non-surgical treatment planning. 


\section{ACKNOWLEDGEMENTS}

I would like to acknowledge the support and assistance I have received during the undertaking of this thesis and throughout my orthodontic residency. I would never have been able to accomplish this project without your help, and I thank you.

Dr. Tim Tremont, for serving as my thesis advisor and chair of my committee. You have provided guidance, thought-provoking conversation, and unwavering confidence in my abilities. Your mentorship has been invaluable to me. Thank you.

Dr. Peter Ngan, for your feedback and wisdom throughout my thesis project. You have dedicated your life to the education and inspiration of future orthodontists and the search for truth in our profession through evidence and research. You have been a wonderful chairman and I owe you a great debt of gratitude for allowing me to realize my professional dreams. Thank you.

Dr. Chris Martin, for serving on my thesis committee and being a constant presence during my orthodontic education. Thank you.

Dr. Rick Jurevic, for serving on my thesis committee and offering your perspectives and feedback to build a solid research foundation. Thank you.

Dr. Thomas Shipley, for graciously allowing access to your office and your patient database. Your dedication to improving our understanding of orthodontics is greatly appreciated. Thank you.

Dr. Erdogen Gunel and Stefan Avey, for your time and effort in preparing and interpreting the statistical analyses conducted during this project. Thank you.

Dr. Tim Glass and Dr. Jason Lawrence - my classmates and my great friends, for your insight, company, and fellowship these past three years. I couldn't imagine going through the program with a better group of guys and I know we will all have amazing careers and lasting friendships. Thanks guys.

Nick, Travis, Jen, Lance, Nicole, and Deepa - my former co-residents, for being great friends and teachers. You all taught me many things while we were in school together and I am grateful for the chance to have spent that time with you. Thank you.

Uyen, Marina, DoBin, MacKenzie, Tyler, and Amer - my fellow residents, for being eager learners and dedicated students. You have reminded me that the future of our profession is bright and I wish you all the best of luck in your careers ahead. Thank you.

Katie - my wife and my partner, for always being by my side. None of this is possible without you. I love you. Thank you. 


\section{TABLE OF CONTENTS}

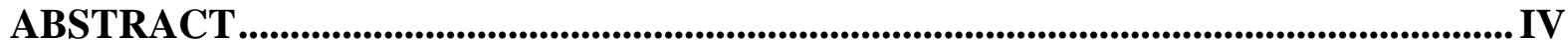

ACKNOWLEDGEMENTS ..................................................................................................II

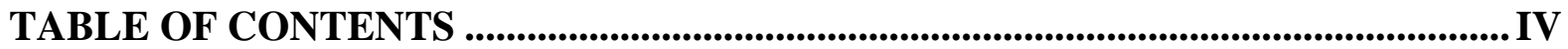

LIST OF TABLES ...............................................................................................................................VII

LIST OF FIGURES .......................................................................................................................... VIII

CHAPTER 1: INTRODUCTION................................................................................................1

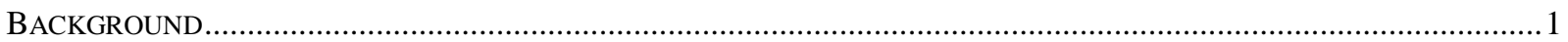

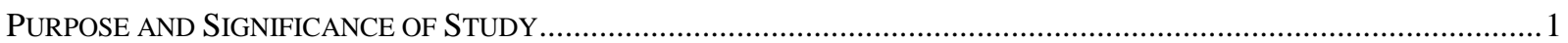

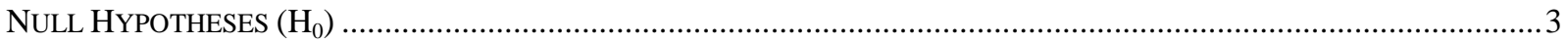

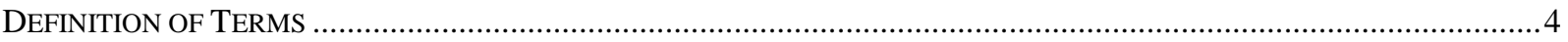

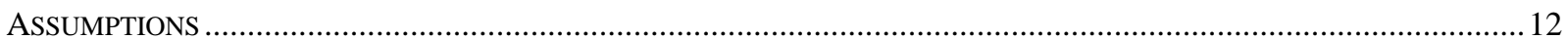

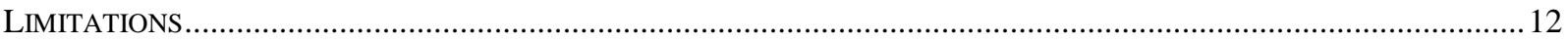

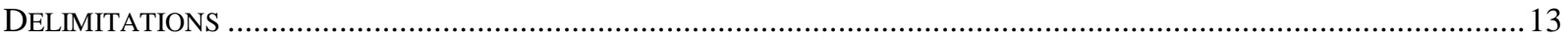

CHAPTER 2: REVIEW OF THE LITERATURE.....................................................14

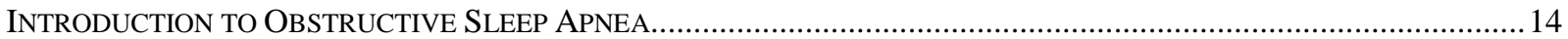

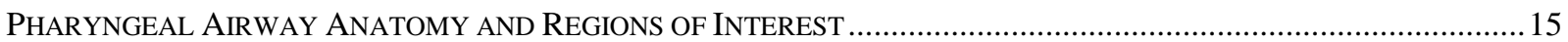

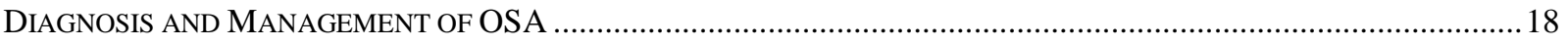

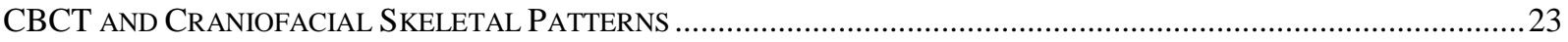

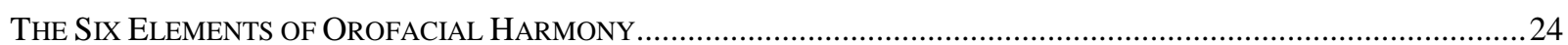

CHAPTER 3: EXPERIMENTAL DESIGN AND METHODS..............................................26

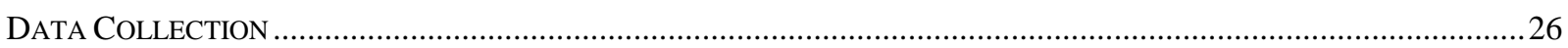

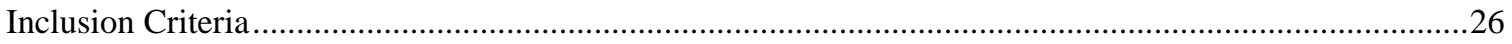

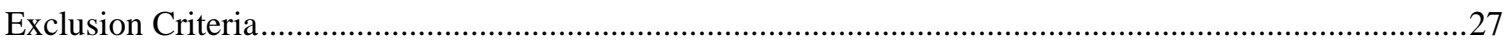

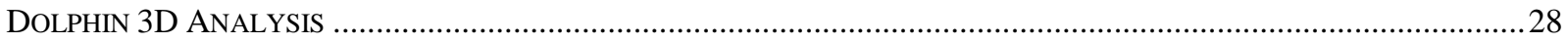

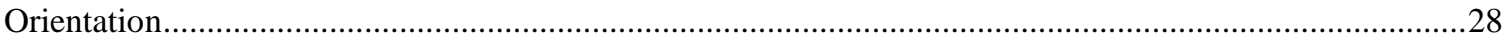

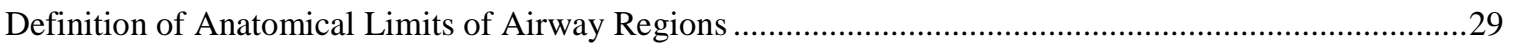

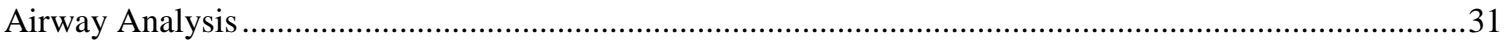




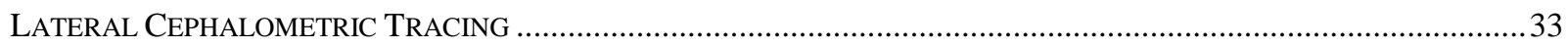

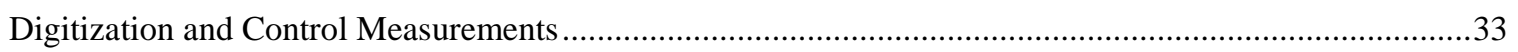

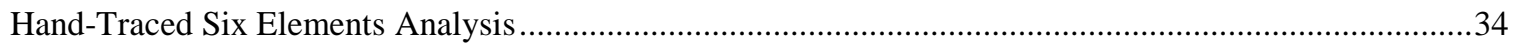

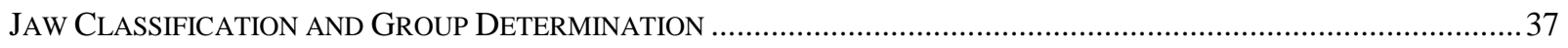

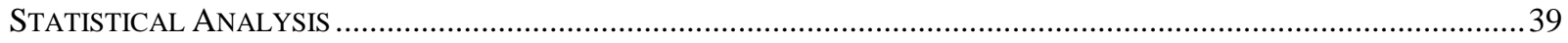

CHAPTER 4: RESULTS ...................................................................................................40

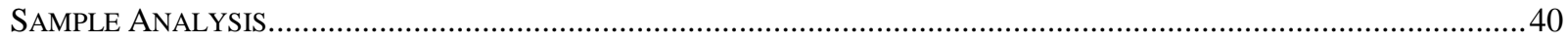

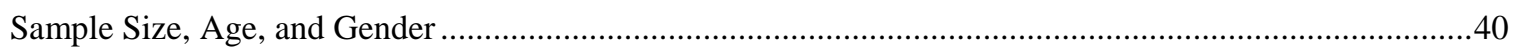

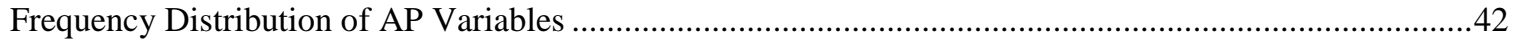

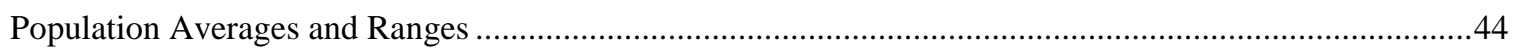

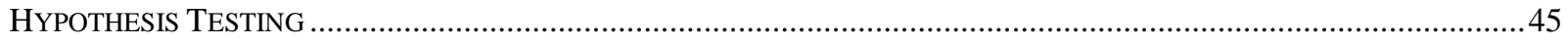

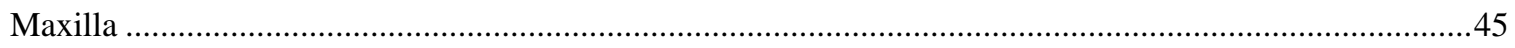

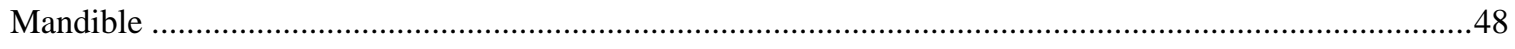

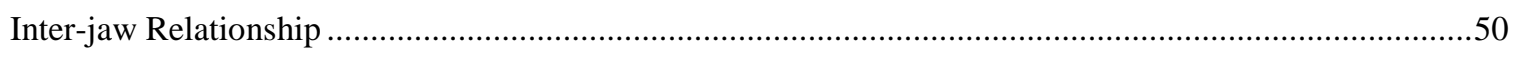

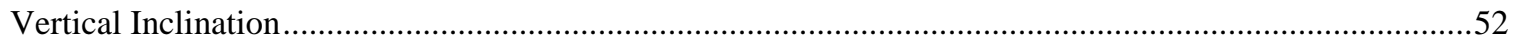

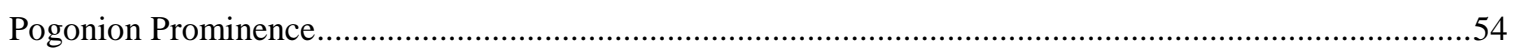

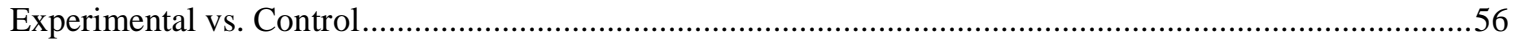

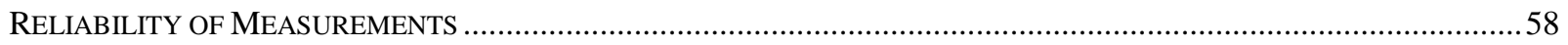

CHAPTER 5: DISCUSSION ..........................................................................................................59

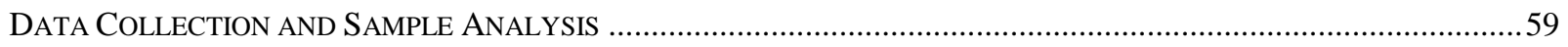

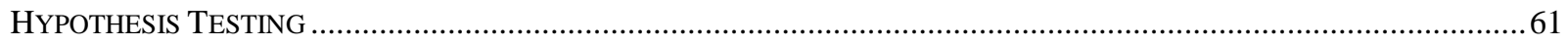

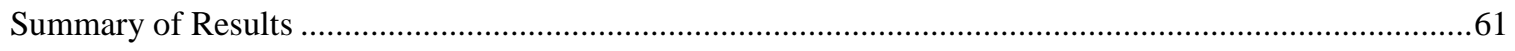

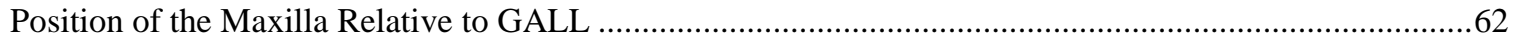

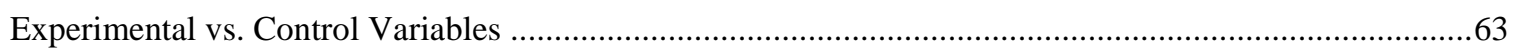

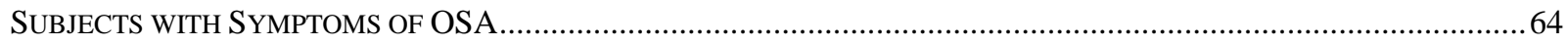

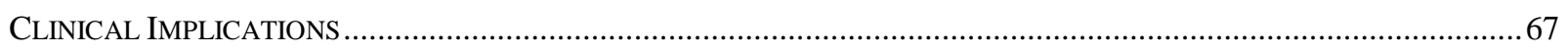

CHAPTER 6: SUMMARY AND CONCLUSIONS ...................................................68

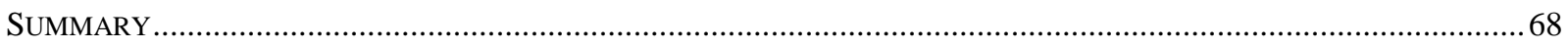

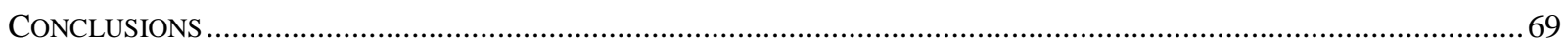


CHAPTER 7: RECOMMENDATIONS FOR FUTURE RESEARCH.............................70

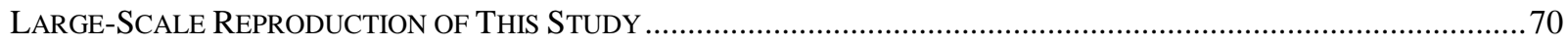

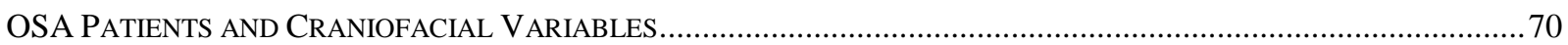

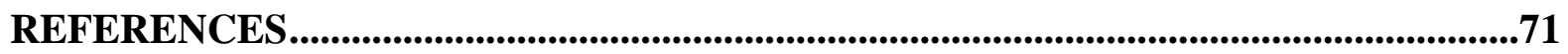

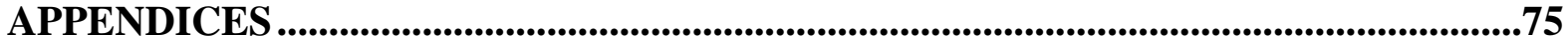

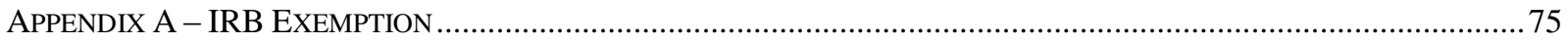

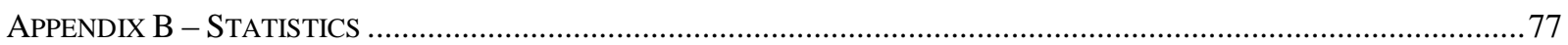

Raw Data

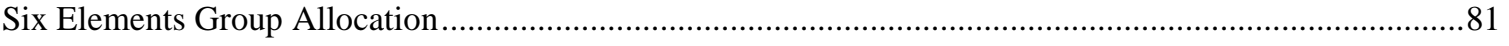

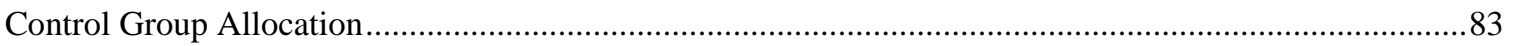

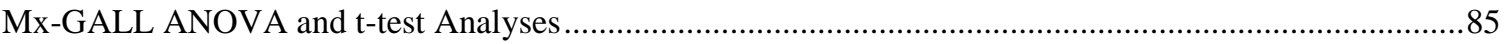




\section{LIST OF TABLES}

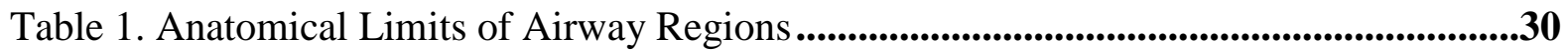

Table 2. Craniofacial Variable Groups ...........................................................................................38

Table 3. Population Measures for Craniofacial (A, B) and Airway (C) Variables................44

Table 4. Mx-GALL Group Means and ANOVA Results .........................................................46

Table 5. Md-GALL Group Means and ANOVA Results .........................................................48

Table 6. Mx-Md Group Means and ANOVA Results ............................................................50

Table 7. Means and ANOVA Results for MPI (A) and OPI (B) ..................................................52

Table 8. Means and ANOVA Results for Pog (A) and EPP (B) ................................................54

Table 9. Statistical Results for Experimental (A) and Control (B) Craniofacial Variables.....56 


\section{LIST OF FIGURES}

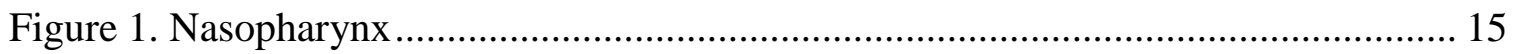

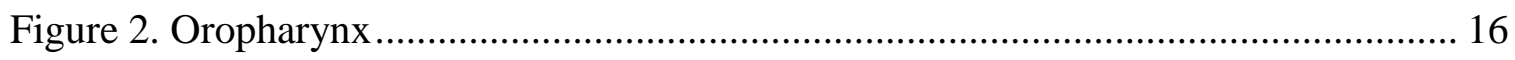

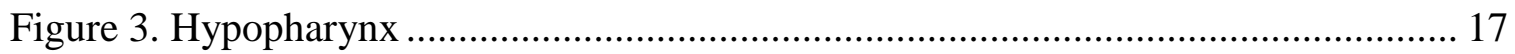

Figure 4. Polysomnographs of a Normal Patient (A) and a Patient with OSA (B) ......... 19

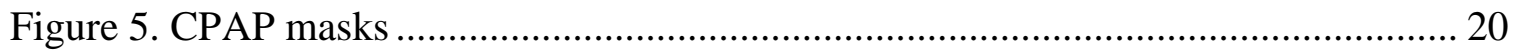

Figure 6. Various MRAs used for the management of OSA ......................................... 21

Figure 7. Airway volume before and after MMA surgery ............................................ 22

Figure 8. Comparison of Surgical Procedures with CPAP, by \% reduction in AHI (3)... 22

Figure 9. 2D and 3D CBCT rendering of the pharyngeal airway (19) …….................. 23

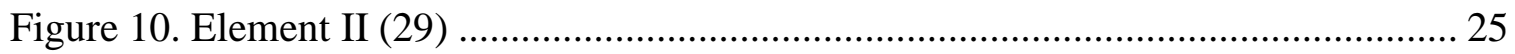

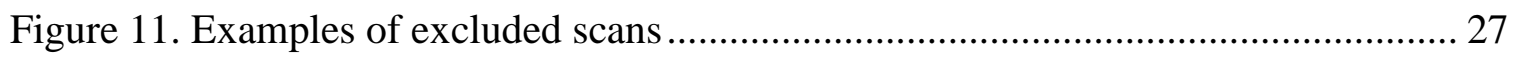

Figure 12. Sagittal (A) and Frontal (B) Orientation .................................................... 28

Figure 13. Airway Clipping Borders and Seed Points .................................................... 31

Figure 14. Completed Airway Analysis.................................................................. 32

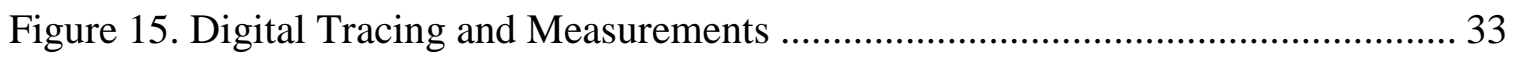

Figure 16. Andrews Tracing Template ………………............................................... 34

Figure 17. Consecutively Completed Hand-Traced Analyses ......................................... 36

Figure 19. Age Distribution (A) and Correlation with Airway Size and Shape (B, C) .... 41

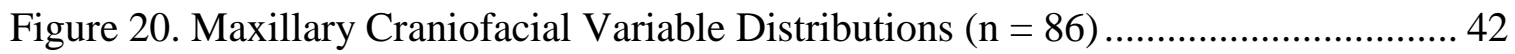

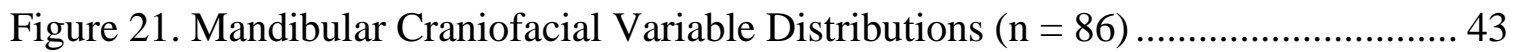

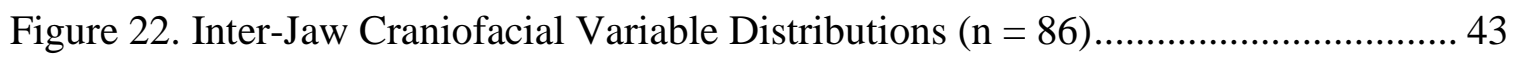

Figure 23. Mx-GALL Group vs. Airway Volume (AV) and t-test Results ...................... 46

Figure 24. Mx-GALL Group vs. Mean Cross-sectional Area (MCA) and t-test Results. 47

Figure 25. Md-GALL Group Comparison for AV and MCA ………………………..... 49

Figure 26. Mx-Md Group Comparison for AV, AL, mCA and MCA............................. 51

Figure 27. OPI Group Comparison for AV and MCA ……….................................... 53

Figure 28. EPP Group Comparison for Airway Volume (AV) ……………………...... 55

Figure 29. Comparison of Mx-GALL (left) and SNA (right) Groups for AV and MCA. 57

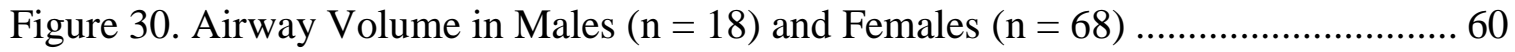

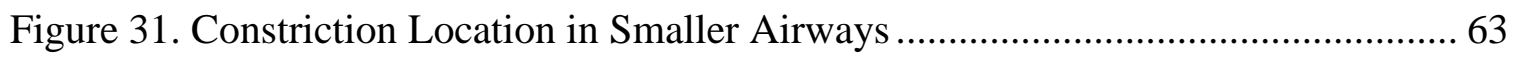

Figure 32. Subject \#196, Before and After MMA Procedure.......................................... 65 


\section{CHAPTER 1: INTRODUCTION}

\section{Background}

Much previous attention has been paid in the orthodontic literature to craniofacial skeletal patterns and morphology of the upper airway and their association with obstructive sleep apnea (OSA). However, the majority of 3D airway investigations in recent years have analyzed the relationship of the airway with various anteroposterior (AP) skeletal patterns using traditional 2D cephalometric landmarks and measurements, such as SNA and SNB. The Six Elements of Orofacial Harmony is a diagnostic and treatment philosophy that has attempted to provide a more accurate and clinically relevant determination of the position of teeth and jaws. Element II specifically deals with AP position of the jaws relative to a reproducible landmark, the goal anterior limit line (GALL).

\section{Purpose and Significance of Study}

The purpose of this study was to investigate, utilizing CBCT imaging, the association between pharyngeal airway morphology and AP jaw position as described by the Six Elements of Orofacial Harmony. An airway study using this method of jaw classification has not been documented in the current literature, and may elucidate new findings to expand knowledge of normal skeletal morphology and disorders such as OSA. Furthermore, no study has been undertaken to compare traditional angular measurements for craniofacial skeletal patterns to the Six Elements methods in terms of correlation with airway morphology.

Skeletal surgical procedures involving maxillary and mandibular advancement (MMA) for management of OSA have been shown to be highly therapeutic and are the preferred surgical 
procedures in adults $(1 ; 2 ; 3)$. However, when MMA is performed primarily for airway improvement - telegnathic surgery (3), and not primarily to correct malocclusions - orthognathic surgery, no clear guidelines are presently followed to determine the anterior functional and esthetic limit of the two-jaw advancement. This lack of reliable landmarks frequently leads to poor esthetic results in patients undergoing telegnathic surgery, depending primarily on the skills and discretion of individual surgeons. Since the GALL line has been well established as a reliable landmark for the esthetic position of the jaws $(4 ; 5)$, there may also be a functional range of AP jaw position with respect to pharyngeal airway that has a relationship with GALL. Can the GALL line become a truly universal landmark for achieving the goals of both telegnathic and orthognathic surgery? What parameters might be established for future MMA procedures to provide the maximum improvement to pharyngeal airway dimensions? 


\section{Null Hypotheses $\left(\mathrm{H}_{0}\right)$}

The following null hypotheses were developed to test the significance of craniofacial variables from the Six Elements of Orofacial Harmony, and traditional cephalometric controls, which are commonly associated with airway dimensions and are likely to be altered during a MMA procedure for OSA.

1. There are no significant differences in airway dimensions among the four anteroposterior groups for the position of the maxilla relative to $\boldsymbol{G A L L}$ (Severely Deficient, Deficient, Optimal, Excessive) in this sample of untreated young adult orthodontic patients.

2. There are no significant differences in airway dimensions among the four anteroposterior groups for the position of the mandible relative to GALL (Severely Deficient, Deficient, Optimal, Excessive) in this sample of untreated young adult orthodontic patients.

3. There are no significant differences in airway dimensions among the four anteroposterior groups for inter-jaw relationship (Category I, Category II, Category II - Severe, Category III) in this sample of untreated young adult orthodontic patients.

4. There are no significant differences in airway dimensions among the groups for the vertical inclination of the jaws relative to GALL (MPI and OPI) in this sample of untreated young adult orthodontic patients.

5. There are no significant differences in airway dimensions among the groups for skeletal pogonion prominence (Pog or EPP) in this sample of untreated young adult orthodontic patients.

6. There are no significant differences in airway dimensions between corresponding Six Element groups and control groups in this sample of untreated young adult orthodontic patients. 


\section{Definition of Terms}

- $\quad 2 \mathrm{D}$ - Two Dimensional (2-Dimensional)

- Refers to objects that are rendered visually on paper, film or on screen in two planes (X and $\mathrm{Y}$; width and height). Two-dimensional structures or images are used to simulate $3 \mathrm{D}$ objects. In the computer, a 2D drawing program can be used to illustrate a 3D object; however, in order to interactively rotate an object in all axes, it must be created as a 3D drawing in a 3D drawing program.

- $\quad 3 D$ - Three Dimensional (3-Dimensional)

- Refers to objects that are rendered visually on paper, film or on screen in three planes (X, Y and Z). 3D images are true representations of 3D objects.

- $\mathrm{ANB}$

- Cephalometric angle formed between point A, nasion, and point $\mathrm{B}$. This angle is used to demonstrate the sagittal skeletal relationship between maxilla and mandible. Normative value is $2^{\circ}$.

- $\mathrm{C} 3 \mathrm{ai} / \mathrm{C} 4 \mathrm{ai}$

- Abbreviation denoting the anterior inferior limit of the third or fourth cervical vertebrae, respectively. In this study, C3ai is the hard tissue delineation for the inferior border of the oropharynx and superior border of the hypopharynx. C4ai is the hard tissue delineation for the lower border of the hypopharyngeal airway and the upper airway as a whole. 
- Category I skeletal pattern

- Inter-jaw relationship of the maxilla and mandible, measured relative to GALL, in which jaws are coupled or within $1 \mathrm{~mm}$ of each other.

- Category II skeletal pattern

- Inter-jaw relationship of the maxilla and mandible, measured relative to GALL, in which the mandible is posterior to the maxilla by $2 \mathrm{~mm}$ or greater.

- Category II - Severe is a subcategory in which the mandible is posterior to the maxilla by $6 \mathrm{~mm}$ or greater.

- Category III skeletal pattern

○ Inter-jaw relationship of the maxilla and mandible, measured relative to GALL, in which the mandible is anterior to the maxilla by $2 \mathrm{~mm}$ or greater.

\section{- Central Sleep Apnea}

- Cessation of breathing due to the central nervous system failing to send a signal to the muscles to enact breathing. Causes of this type of sleep apnea include head trauma, stroke, and tumor.

- Cephalometric analysis

- An analysis made on a radiograph of the head (cephalometric radiograph) comprised of referents and landmarks used to describe relationships of skeletal and dental components, usually compared to a norm.

- Cephalometric radiograph

- A radiograph of the head made with reproducible relationships between the x-ray source, the subject, and the film. 
- Class I skeletal pattern

$\circ$ Denoting an ANB angle $0^{\circ}$ to $4^{\circ}$.

- Class II skeletal pattern

$\circ$ Denotes an ANB angle $>4^{\circ}$.

- Class III skeletal pattern

$\circ$ Denotes an ANB angle $<0^{\circ}$.

- Computed tomography (CT)

- A series of radiographs (flat, two-dimensional grayscale images) that are analyzed and rendered via computer to produce a three-dimensional volumetric or surface mapped image.

- Cone Beam Computed Tomography (CBCT)

- A computed tomography scan utilizing an x-ray beam in the shape of a cone to provide images of bony structures. Data is captured by a flat receiver that detects pulses of cone shaped beam radiation. The result is a stack of two-dimensional grayscale images of the anatomy which can be rendered into volumetric data to visualize anatomical structures in three dimensions. Also known as Cone Beam Volumetric Tomography (CBVT)

- Digital Imaging and Communications in Medicine (DICOM)

- DICOM is a standard for handling, storing, printing, and transmitting medical images. It includes a file format in which data from volumetric radiographs are stored. 
- Element I

O Optimal Arch (Shape and Lengths). Exists when the roots are centered over basal bone, the crowns are so inclined that the occlusal surfaces can interface optimally, the contact areas abut, and the core line depth does not exceed $2.5 \mathrm{~mm}$.

- $\quad$ Element II

O Optimal antero-posterior (AP) Jaws. The AP jaw positions when the incisors are actually or hypothetically Element I, inter-arch relationship is Key I and the FA Point of each maxillary central incisor is on the Goal Anterior Limit Line (GALL).

- Effective Pogonion Prominence (EPP)

- Novel measurement calculated by the addition of pogonion prominence and mandibular position relative to GALL. EPP describes the position of the hard tissue chin in space relative to a stable landmark and eliminates measurement bias of the hypothetically optimal lower incisor position in the mandibular symphysis.

- Forehead Anterior Limit Line (FALL)

- A line, parallel to the frontal plane of the head, which passes through the forehead facial axis (FFA) point.

- Forehead Facial Axis (FFA)

- A midsagittal point on the forehead that represents the midpoint of the inferior and superior borders of the clinical forehead (glabella and hairline).

- Frankfort Horizontal Plane (FHP)

- A horizontal plane represented on lateral cephalograms by a line connecting the inferior margin of the orbit and the superior margin of the auditory meatus. 
- Goal Anterior Limit Line (GALL)

○ According to Andrews, a line that parallels the head's frontal plane and represents the optimal anterior border for a maxilla when measured from the FA Point of a maxillary incisor that is actually or hypothetically Element I. It passes through the FFA Point when the cant of the forehead is 7 degrees or less. For each degree the forehead is canted more than 7 degrees, the GALL is $0.6 \mathrm{~mm}$ anterior to the FFA Point, but never beyond glabella unless the patient insists. Recent unpublished research by Mitchell in 2015 was able to show the average distance from glabella to GALL is less than a quarter of millimeter, and is coincident with glabella in over $80 \%$ of patients. Thus, for the purposes of this study, all subject GALL lines have been set at glabella.

- Hypopharynx

- The lowermost portion of the pharyngeal airway, extending from the transverse plane through C3ai superiorly to a transverse plane through C4ai inferiorly. This region includes the epiglottis.

- Landmark

- A fixed, reproducible (anatomical) point of reference on a radiograph.

- Mandibular Plane (MP)

- A plane constructed from the most anterior inferior portion of the mandible, termed menton, and the most inferior posterior border of the mandible termed gonion. 
- Mandibular Plane Inclination (MPI)

- Vertical inclination of the mandibular plane, relative to a plane perpendicular to GALL.

- Maxillo-mandibular Advancement (MMA)

- Surgical procedure consisting of advancement of the hard tissues of the maxilla and mandible, with or without genioplasty, for the purposes of esthetics, jaw function, and/or obstructive sleep apnea.

- MP-SN

- Cephalometric angle formed between the sella-nasion line, and mandibular plane. This angle is used to demonstrate the vertical skeletal relationship between anterior cranial base and mandibular border. Normative value is $32-35^{\circ}$.

- NAP

- Cephalometric angle formed between nasion, point A, and hard-tissue pogonion. This angle is used to demonstrate the relative sagittal skeletal chin prominence. Normative value is $180^{\circ}$.

- Nasopharynx

- The uppermost portion of the pharyngeal airway, extending from the transverse plane through PNS inferiorly to the frontal plane through PNS anteriorly. This region includes adenoid tissues.

- Obstructive Sleep Apnea

- A sleep disorder that occurs when a person's breathing is interrupted during sleep. It is caused by a narrowing or blocking of the airway due to the collapse of soft tissues surrounding the pharynx. 
- Occlusal Plane Inclination (OPI)

- Vertical inclination of the occlusal plane, relative to a plane perpendicular to GALL.

- OP-SN

- Cephalometric angle formed between the sella-nasion line, and occlusal plane.

This angle is used to demonstrate the vertical skeletal relationship between anterior cranial base and the angular orientation of the dentition. Normative value is $12-15^{\circ}$.

- Oropharynx

- Includes the oral cavity, beginning with the back portion of the mouth and extending rearward to the base of the tongue. The oropharynx in this study extends superiorly to PNS and inferiorly to C3ai, and can be further divided into velopharynx and glossopharynx.

- Pogonion Prominence (Pog)

- Measurement of the position of the hard tissue pogonion, relative to a line perpendicular to the occlusal plane and passing through the FA point of an optimally position lower incisor - aka Will's Plane.

- Posterior Nasal Spine (PNS)

- Midsagittal point of the maxillary bone that is the posterior terminus of the hard palate and the anterior-superior border of the velopharynx. 
- SNA

○ Cephalometric angle formed between sella, nasion, and point A. This angle is used to demonstrate the sagittal skeletal relationship between anterior cranial base and maxilla. Normative value is $82^{\circ}$.

- $\mathrm{SNB}$

- Cephalometric angle formed between sella, nasion, and point $\mathrm{B}$. This angle is used to demonstrate the sagittal skeletal relationship between anterior cranial base and mandible. Normative value is $80^{\circ}$.

- SN Inclination (SNI)

- Calculation of the inclination of the anterior cranial base relative to a plane perpendicular to GALL. Derived by subtracting MPI from MP-SN.

- Telegnathic Surgery

- Referring to craniofacial surgery to advance both jaws (MMA) for the primary purpose of increasing the pharyngeal airway size (3).

- U1-FALL Judgment (formerly: FALL/DALL Judgment)

- Clinical judgment of patient's pre-treatment upper incisor facial axis (FA) point relative to the frontal plane of the head running through the forehead facial axis (FFA) point. Judged with the patient in adjusted natural head position and expressed as a positive or negative value in millimeters.

- Velopharynx

- Extends from the hard palate to the inferior tip of the soft palate. Includes the uvula and the uppermost segment of the posterior pharyngeal wall. In this investigation, the superior border is a transverse plane running through PNS. 


\section{Assumptions}

1. The CBCT scans included in this study are of sufficient quality with no patient movement contributing to the introduction of radiographic artifacts.

2. The operator in this study has a working knowledge of computer technology.

3. Landmarks can be accurately identified using cone-beam computed tomography technology.

4. CBCT scans on subjects are taken in centric relation as opposed to maximum intercuspation.

5. CBCT scans on subjects were taken prior to initiation of any type of orthodontic, orthopedic, or surgical treatment.

6. CBCT scan can be used to accurately orient, extract, and digitize 1:1 a 2D lateral cephalogram for use in a hand-traced Six Elements analysis.

\section{Limitations}

1. There are gender, ethnicity, and medical history differences among the subjects.

2. All U1-FALL judgments were performed clinically by Dr. Thomas Shipley and recorded in subject charts.

3. Some scans may contain minor artifacts depending on patient movement and machine calibration.

4. Measurements are limited to the researcher's ability to accurately manipulate the CBCT images.

5. One researcher will make all measurements and determine all airway dimensions 
from the CBCT images.

6. The pharyngeal airway is a dynamic structure, and the actions of the breathing and swallowing as well as normal muscle tone can lead to inherently variable airway measurements from CBCT scans that only represent a snapshot of the subjects' anatomical motion.

\section{Delimitations}

1. Ages of the subjects comprising the sample is limited to young adult patients ages 1830.

2. The study is limited to prospective orthodontic patients in the database of CBCT scans in the orthodontic practice of Dr. Thomas Shipley in Peoria, AZ.

3. All GALL landmarks in this study were constructed to coincide with glabella.

4. Due to time constraints and limited impact on airway collapsibility, this study is not investigating nasopharyngeal airway measurements and is limited to oropharyngeal and hypopharyngeal measurements only.

5. Jaw classification is limited to AP position of the maxilla and mandible, the inclination of the occlusal plane and mandibular plane, and the prominence of the hard tissue pogonion. These variables are those that are typically altered by MMA surgical procedures for OSA. 


\section{CHAPTER 2: REVIEW OF THE LITERATURE}

\section{Introduction to Obstructive Sleep Apnea}

Proper respiratory function is one of the basic processes essential to human life. Because of the role that respiration, along with mastication and deglutination, can play on functional growth and development of the craniofacial complex (6), the interest in studying the upper airway has been present in orthodontics for many decades. It has been shown that dysfunctional breathing patterns, such as mouth breathing, can be contributing factors to the development of malocclusions $(7 ; 8)$. Sleep-related breathing disorders are a group of disorders that cause abnormal respiration during sleep, and include both obstructive and central sleep apnea, as well as obesity hypoventilation syndrome and other sleep-related hypoventilations (9). Of these, obstructive sleep apnea (OSA) is overwhelmingly the most common disorder and has been associated with several systemic diseases including cardiovascular diseases and metabolic syndrome. Over $75 \%$ of severe OSA patients go untreated and are estimated to have four times higher morbidity than non-OSA cohorts. In patients with OSA, portions of the pharyngeal airway become increasingly collapsible during sleep, which causes periods of partial hypoventilation (hypopnea) or complete cessation of airflow (apnea). This is followed by drops in arterial oxygen saturation, and ultimately, arousal from sleep (10). OSA is becoming an increasingly recognized problem in the dental and medical community because of the impact it can have on the daily quality of life of patients who fail to attain restful sleep. 


\section{Pharyngeal Airway Anatomy and Regions of Interest}

Morphology of the pharyngeal air passage and its relationship to airway collapsibility and OSA has been widely studied in medical and dental research. The upper airway anatomically consists of the nasal cavity, pharynx, and finally the larynx. A recent systematic review (11) defines three distinct regions of the pharyngeal airway that border the nasal cavity and entrance to the larynx: the nasopharynx, oropharynx, and hypopharynx.

\section{Figure 1. Nasopharynx}

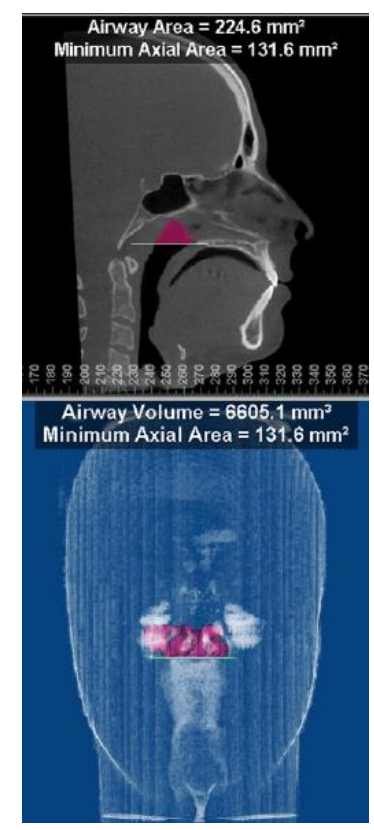

The nasopharynx is the region superior to the hard palate, posterior to the posterior nasal spine (PNS), and extending to the posterior pharyngeal wall in the area of the adenoid tissues (Figure 1). The nasopharynx is not typically associated with airway collapse in adults, but may cause reduced airflow or alterations in breathing patterns in cases of adenoid hypertrophy or other obstructions to nasal breathing, especially in children and adolescents (7). 


\section{Figure 2. Oropharynx}

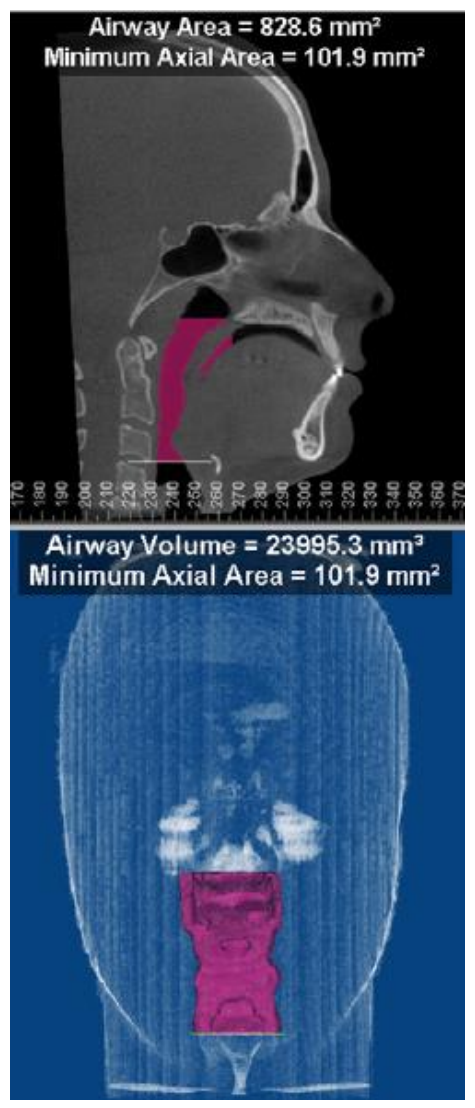

The oropharynx is the largest and most variable region of the pharyngeal airway. Its borders are the soft palate and tongue anteriorly, and the pharyngeal walls laterally and posteriorly (Figure 2). The superior border of oropharyngeal airway is at the level of the PNS and the inferior border is at the tip of the epiglottis. However, due to the variable position of the epiglottis, the oropharynx can be more consistently defined by setting the inferior border at the level of the most anterior-inferior aspect of the third cervical vertebra (C3ai). The oropharynx has also been described as having two distinct subregions with unique functional morphology, the velopharynx (or retropalatal) and the glossopharynx (or retroglossal) (12). Both the soft palate (velum) and tongue can contribute to airway obstruction in this region. 


\section{Figure 3. Hypopharynx}

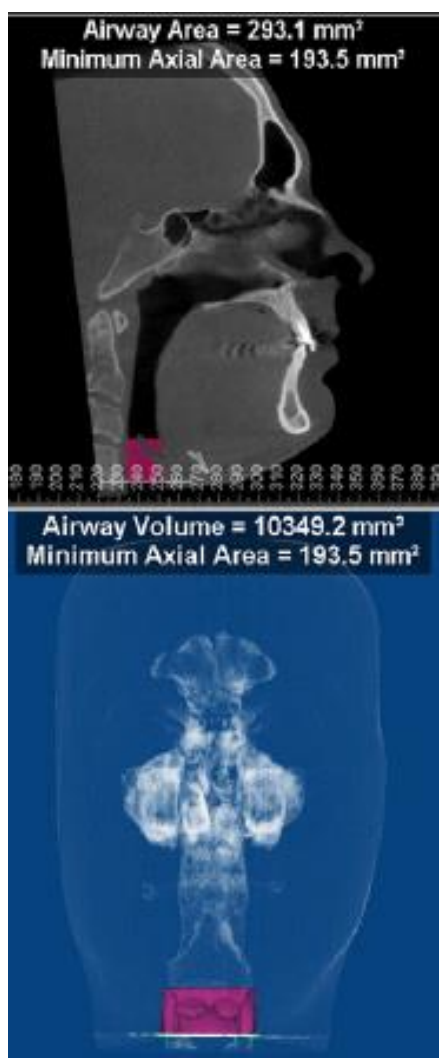

The hypopharynx is the most inferior region of the oropharyngeal airway, located immediately superior to the base of the epiglottis and entrance into the trachea and larynx (Figure 3). Again, due to the variability of anatomy, the inferior border of the hypopharynx can be defined at the level of the most anterior-inferior aspect of the fourth cervical vertebra (C4ai). The superior border of the hypopharynx is coincident with the inferior border of the oropharynx, at the level of third cervical vertebra (C3ai). The hypopharynx is frequently the location of the minimum cross-sectional area (mCA) for the pharyngeal airway and therefore susceptible to collapse. The hypopharynx is also highly sensitive to impingement from surrounding anatomy, such as the base of the tongue, hyoid musculature, and cervical adipose tissue. This is one reason obesity is a significant risk factor for OSA (9). 
The pharyngeal airway changes in size and shape over time, growing throughout adolescence, and is ever-changing during adulthood due to the effects of aging and environmental factors such as weight gain. After age 30, average airway volume begins to decrease and airway length begins to increase gradually due to aging, increasing the collapsibility of the pharyngeal airway, especially in men $(13 ; 14)$. Collapsibility of the pharyngeal airway is the key morphological factor in the determining the risk of sleep disturbances such as obstructive sleep apnea (OSA).

\section{Diagnosis and Management of OSA}

Obstructive sleep apnea can present with a myriad of symptoms, the most common of which are snoring, witnessed apneas, and excessive daytime sleepiness. Snoring is the hallmark symptom of OSA, with over $95 \%$ of OSA patients experiencing habitual snoring (9). Witnessed apneas or nocturnal choking events, evidenced by a bed partner or video recording, and excessive daytime sleepiness, determined by questionnaires such as the Epworth Sleepiness Scale, are very strong evidence indicating a diagnosis of OSA. Also, objective signs such as obesity, retrognathia, airway constriction (as seen with diagnostic imaging), and comorbidities such as cardiovascular disease and diabetes should be considered when diagnosing OSA (9).

However, the definitive diagnostic criterion for OSA is the apnea/hypopnea index (AHI), which is a measure of apneic event per hour of sleep based on the results of a polysomnogram (PSG) sleep study (Fig 4A,B). According to the American Academy of Sleep Medicine, the severity of OSA can be defined by the AHI. An AHI of less than 5 is considered below the threshold of an OSA diagnosis, 5-15 events per hour is indicative of mild OSA, 15-30 events per hour is moderate OSA, and greater than 30 apneic or hypopneic events per hour of sleep 
indicates a case of severe OSA (9). A PSG study can provide other information relevant to OSA severity, such as percent oxygen desaturation and respiratory disturbance index (RDI), which includes minor respiratory-event related arousals (RERAs) that do not meet the criteria for hypopnea. While these additional measures provide useful information, the AHI score is the definitive classification of OSA.

Figure 4. Polysomnographs of a Normal Patient (A) and a Patient with OSA (B) Normal Polysomnograph

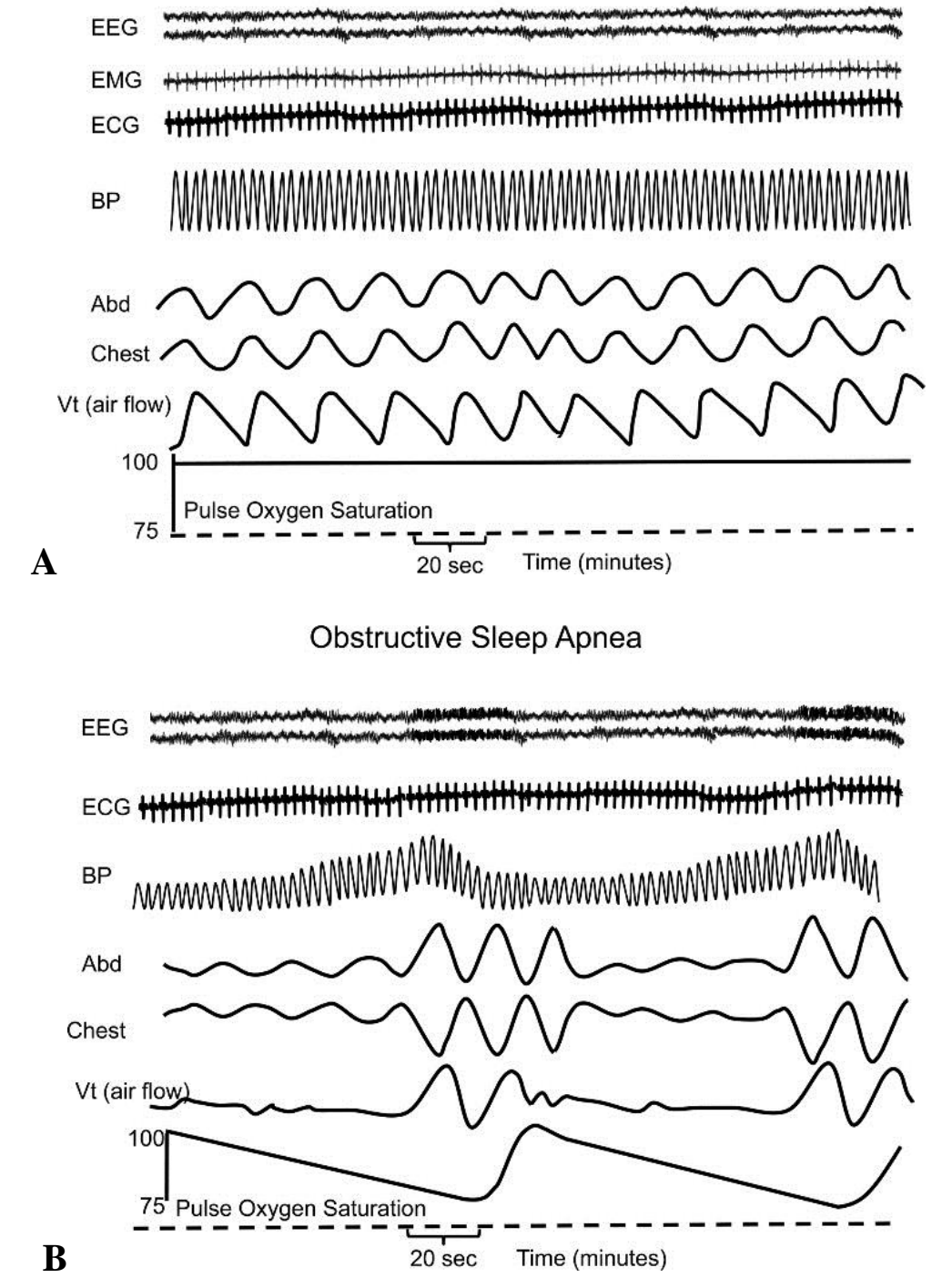


Management of OSA requires a multifactorial approach, as there are several treatment modalities with varying efficacy, acceptability, and individuals may respond differently to certain treatments. Currently, continuous positive airway pressure (CPAP) machines are the first line of treatment for moderate to severe OSA.

\section{Figure 5. CPAP masks}
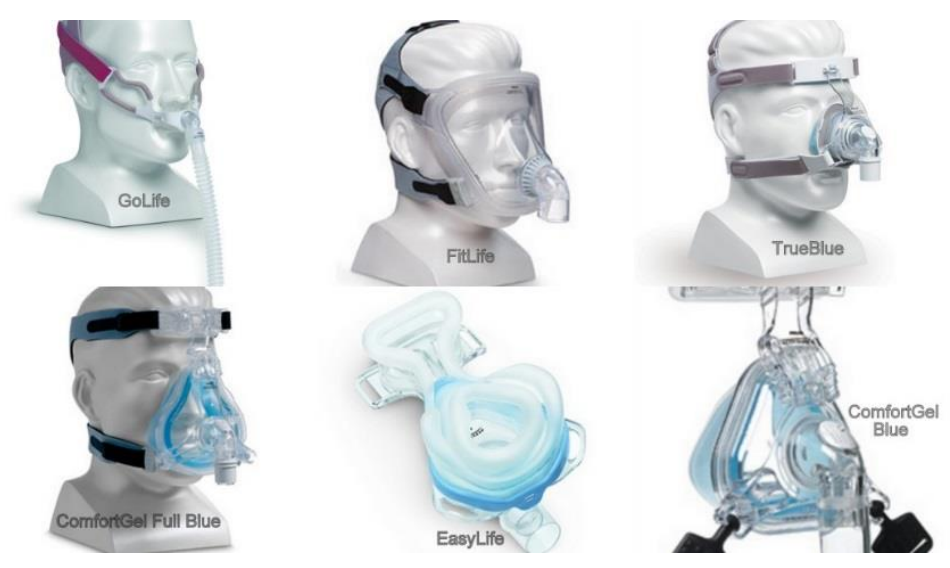

CPAP is highly efficacious due to its action of applying pneumatic air pressure in the upper airway that counteracts the collapsible nature of the pharynx in OSA patients. Most patients that will accept CPAP therapy will see marked improvement in AHI $(<5)$ and noticeably improved sleep quality (9). However, the machine and nasal or naso-oral mask may be difficult to tolerate during sleep for some patients, and significantly high non-compliance rates ranging from $46-83 \%$ for CPAP have been reported in the literature (9).

Other treatment modalities for managing OSA include conservative therapies such as lifestyle modification and oral appliances. Lifestyle changes such as weight loss, positional sleep changes, tobacco cessation, and limitation of alcohol consumption can have significant benefit to OSA severity, but these methods are highly patient-dependent and therefore can be 
inconsistent. Oral appliances that serve to reposition the mandible, and therefore the base of the tongue, more anteriorly during sleep are known as mandibular repositioning appliances (MRAs). There are numerous commercially available types of MRAs (Figure 6), which are typically prescribed by dentists and orthodontists. However, there are no significant differences in efficacy across appliance types, and the decision of which MRA to use typically boils down to doctor preference and patient comfort.

Figure 6. Various MRAs used for the management of OSA
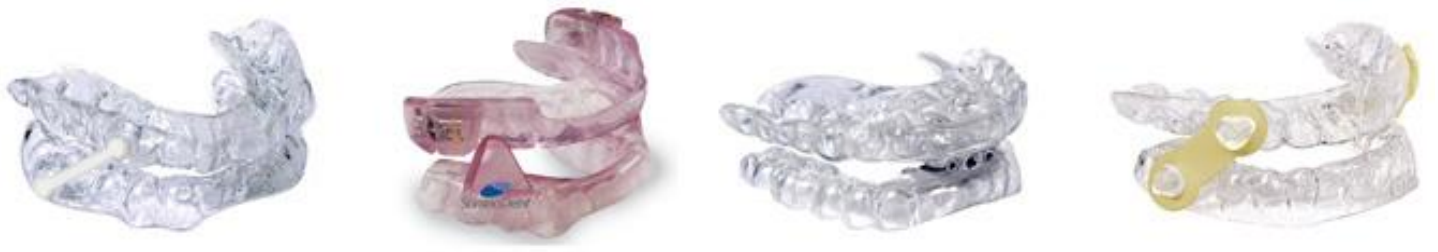

While MRAs have not been shown to be as successful as CPAP for decreasing sleeprelated breathing disturbances, patients will typically prefer MRAs over CPAP for sleep comfort when similar improvements in symptoms are experienced (9).

Patients with moderate to severe OSA, for whom CPAP and other conservative therapies have been unsuccessful, may choose to undergo surgical treatment of upper airway. Surgeries performed include intrapharyngeal and extrapharyngeal soft tissue procedures, and hard tissue surgeries involving mandibular advancement or two-jaw maxillomandibular advancement (MMA) (3). Of these, MMA has been shown to be the most effective at increasing airway volume (Figure 7) and reducing AHI $(2 ; 15)$, and is comparable to the gold standard of CPAP (Figure 8) (3) 
Figure 7. Airway volume before and after MMA surgery
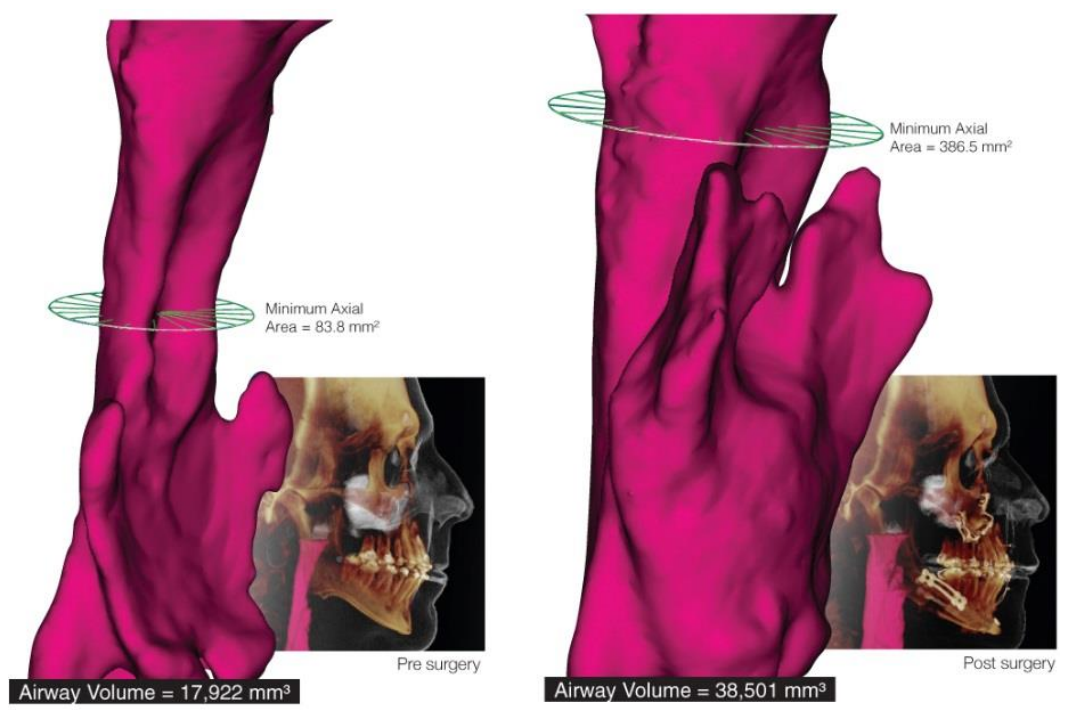

Figure 8. Comparison of Surgical Procedures with CPAP, by \% reduction in AHI (3)

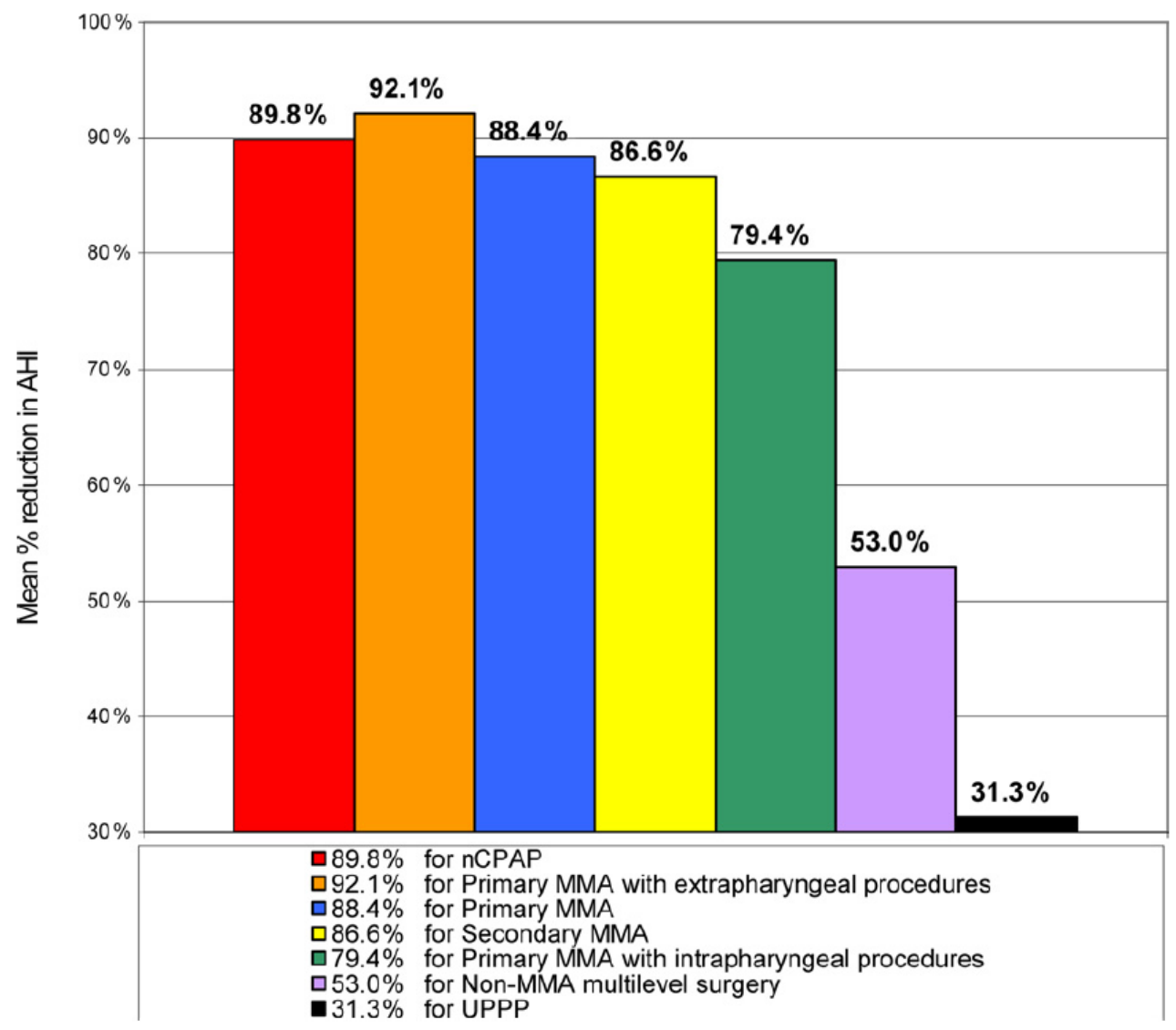




\section{CBCT and Craniofacial Skeletal Patterns}

Many recent investigations have been able to use cone-beam computed tomography (CBCT) in order to accurately study the upper airway in three dimensions, with minimal invasiveness to the patient $(16 ; 17 ; 18)$.

\section{Figure 9. 2D and 3D CBCT rendering of the pharyngeal airway (19)}

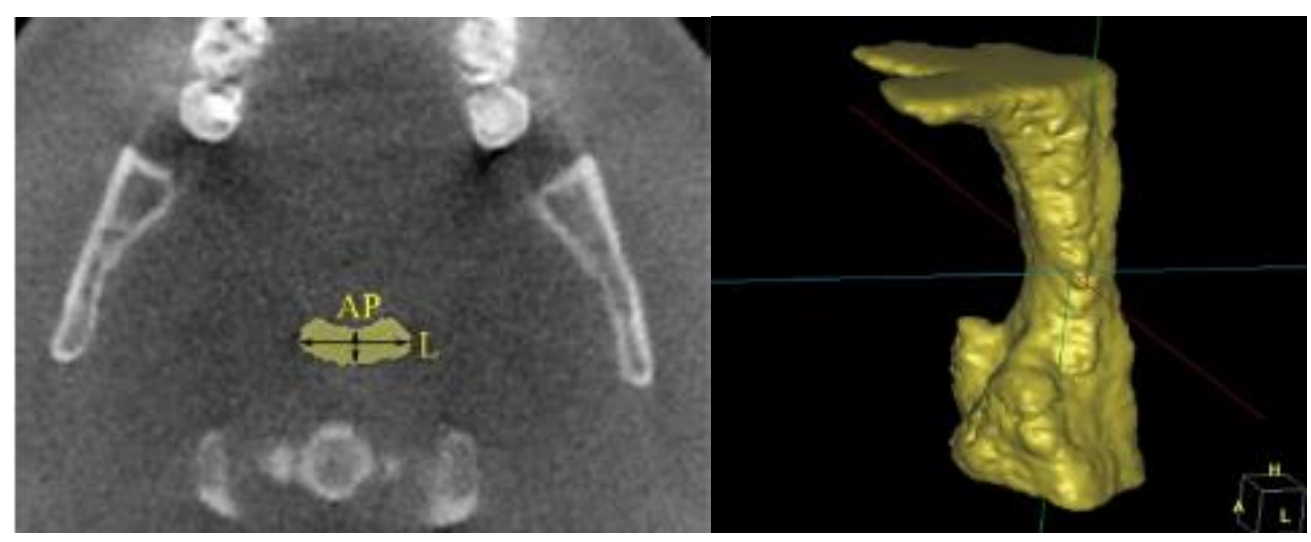

Several studies have shown that certain morphological factors of the pharyngeal airway that are measured with CBCT analysis (Figure 9), such as volume, minimal cross-sectional area, length, and lateral dimension, correlate well with presence and severity of $\operatorname{OSA}(20 ; 21 ; 19)$. While CBCT and other medical imaging such as MRI scans have been able to elucidate many morphological aspects of the upper airway and provide more information for surgical procedures, their usefulness in accurate modeling and prediction of the behavior of the pharynx during sleep and sleep-related breathing disturbances has many limitations. Among those reported in nearly all recent studies are changes in the airway due to position (standing vs. supine), consciousness (awake vs. asleep), and swallowing and breathing dynamics of the tongue, epiglottis and soft palate. These confounding variables are noted limitations of this study 
as well, but should not discourage further investigation of the airway in orthodontics due to the increasing availability of 3D imaging for prospective orthodontic patients.

It has also been shown in the orthodontic literature that different anteroposterior (AP) craniofacial skeletal patterns (Class I, Class II, Class III) as well as vertical patterns (hyperdivergence) show significant differences in airway morphology $(22 ; 23 ; 24 ; 25)$. However, nearly every CBCT study involving upper airway morphology in orthodontics has used traditional 2-dimensional lateral cephalometric landmarks and measurements, such as SNA and SNB, in order to classify subjects by AP skeletal pattern. The amount of variance with the length and inclination of the anterior cranial base relative to the true horizontal plane of the skull greatly affects these angles' ability to describe jaw relationship. This inherent error has been well documented $(26 ; 27 ; 28)$, and as such, many of the previous conclusions drawn about different craniofacial groups relative to pharyngeal airway may be inaccurate or incomplete.

\section{The Six Elements of Orofacial Harmony}

The Six Elements of Orofacial Harmony (29) is a diagnostic and treatment philosophy that proposes a simple, accurate, and clinically relevant method to assess and plan the position of the teeth and jaws. The six characteristics include arch development, jaws AP, jaws transverse, jaws vertically, pogonion prominence, and inter-arch occlusion. Element II deals specifically with the description of the AP position of the maxilla and mandible relative to a reproducible landmark, the goal anterior limit line (GALL) (Figure 10). 


\section{Figure 10. Element II (29)}

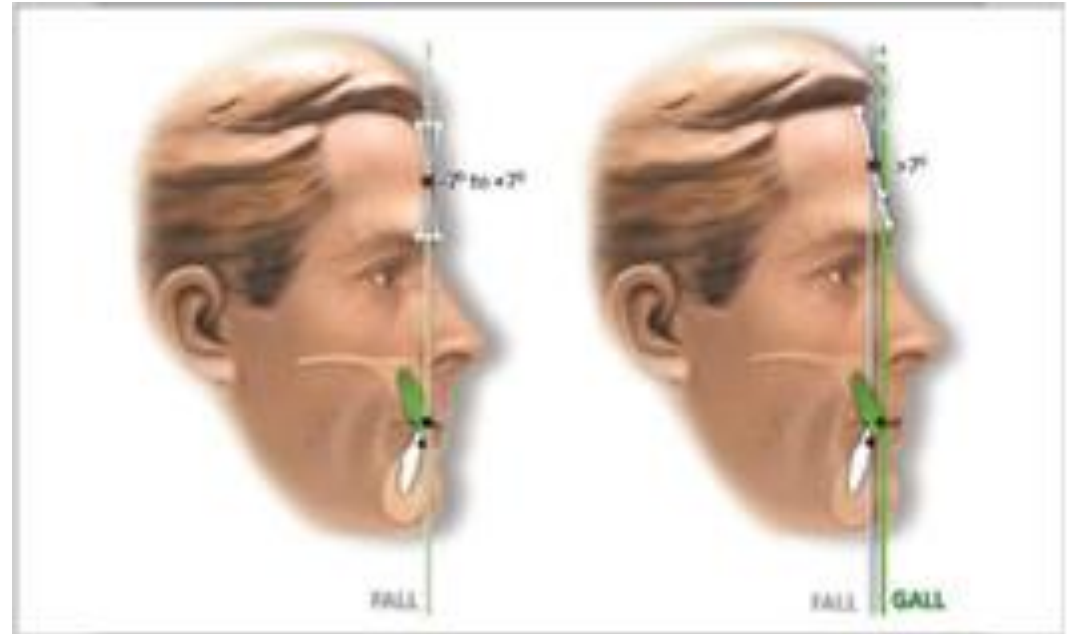

Using this evaluation, each jaw can be clearly and accurately measured as being optimal, deficient, or excessive based on the AP distance from the GALL. This method also allows a simple quantification of inter-jaw discrepancy by comparing maxilla to mandible (30). 


\section{CHAPTER 3: EXPERIMENTAL DESIGN AND METHODS}

\section{Data Collection}

A sample of 86 prospective orthodontic patients from the private practice Dr. Thomas Shipley in Peoria, AZ was used for this study. The sample consists of CBCT scans taken with the i-CAT 3D Cone Beam Dental Imaging System. Each scan was taken with technical specifications of a full field of view of $170 \mathrm{~mm}^{3}$, power of $120 \mathrm{KV}$, and exposure of $5 \mathrm{~mA}$ for 7 seconds. All subjects have had pre-treatment CBCT scans completed with upright head posture and jaws positioned in centric relation (CR) rather than maximum intercuspation (MICP). Subject ages were limited to 18-30 years old. The goal of this limitation was to include a large sample size of orthodontic patients possessing adult dentition and relatively stable upper airway $(2 ; 14)$.

All subject CBCT scans were de-identified before analysis and assigned a subject number from 001 to 251. IRB-exempt approval was obtained from West Virginia University (see Appendix A).

\section{Inclusion Criteria}

Subjects were included by the following criteria $(\mathrm{n}=251)$ :

1. Full field of view CBCT scans of $170 \mathrm{~mm}^{3}$, including all pertinent anatomy vertically from forehead facial axis (FFA) point to hard tissue menton

2. Patient aged $18-30$ years at the time of pre-treatment CBCT scan

3. U1-FALL Clinical Judgment recorded in patient chart

4. No history of previous treatment recorded in patient chart 


\section{Exclusion Criteria}

Subjects were excluded by the following criteria $(n=86)$ :

1. Poor image quality, artifacts, or missing C4ai (Figure 11A)

2. Craniofacial syndrome or developmental deformity

3. Adeno-tonsillar hypertrophy or history of tonsillectomy/adenoidectomy

4. Complex open bite with separate, diverging occlusal planes (Figure 11B)

Figure 11. Examples of excluded scans
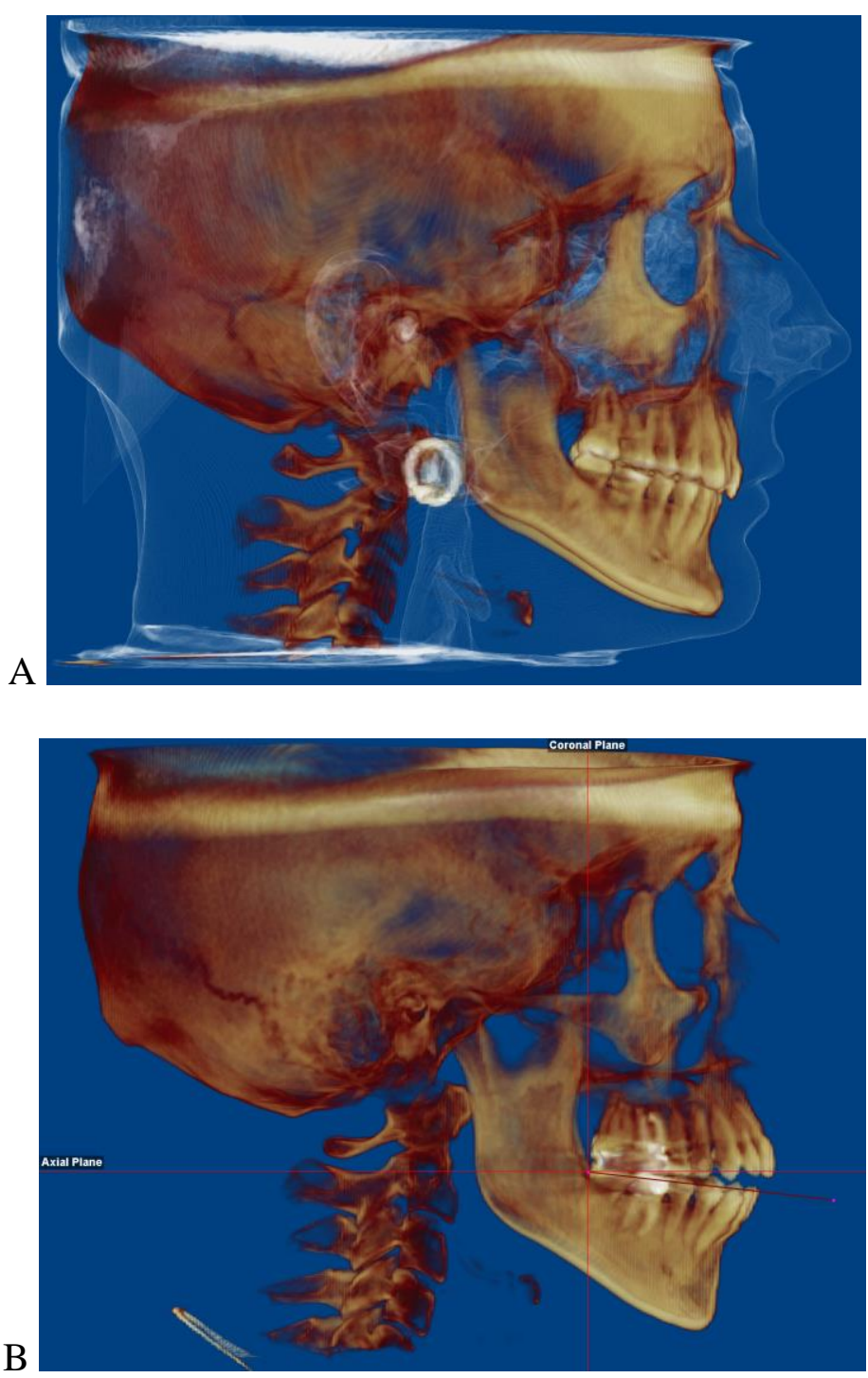


\section{Dolphin 3D Analysis}

\section{Orientation}

All DICOM files were uploaded into Dolphin Imaging 11.5 software. Using the Dolphin 3D module, 3D volumetric renderings were oriented to adjusted natural head position using the orientation tool. Initially, from the lateral perspective, lateral wall of the orbits were aligned, and head inclination was adjusted to coincide the recorded U1-FALL judgment (Figure 12A). From the frontal perspective, the clipping feature was then used to remove the anterior-most portions of the skull and dentition, leaving a clear view of skeletal midline structures: ethmoidal crest, vomer bone, anterior nasal spine, incisive foramen, and genial tubercle. The midsagittal plane was then aligned using a best fit line passing through these structures (Figure 12B). The clipped structures were restored and the final head orientation was saved and used for all future measurements and analysis for each subject.

\section{Figure 12. Sagittal (A) and Frontal (B) Orientation}
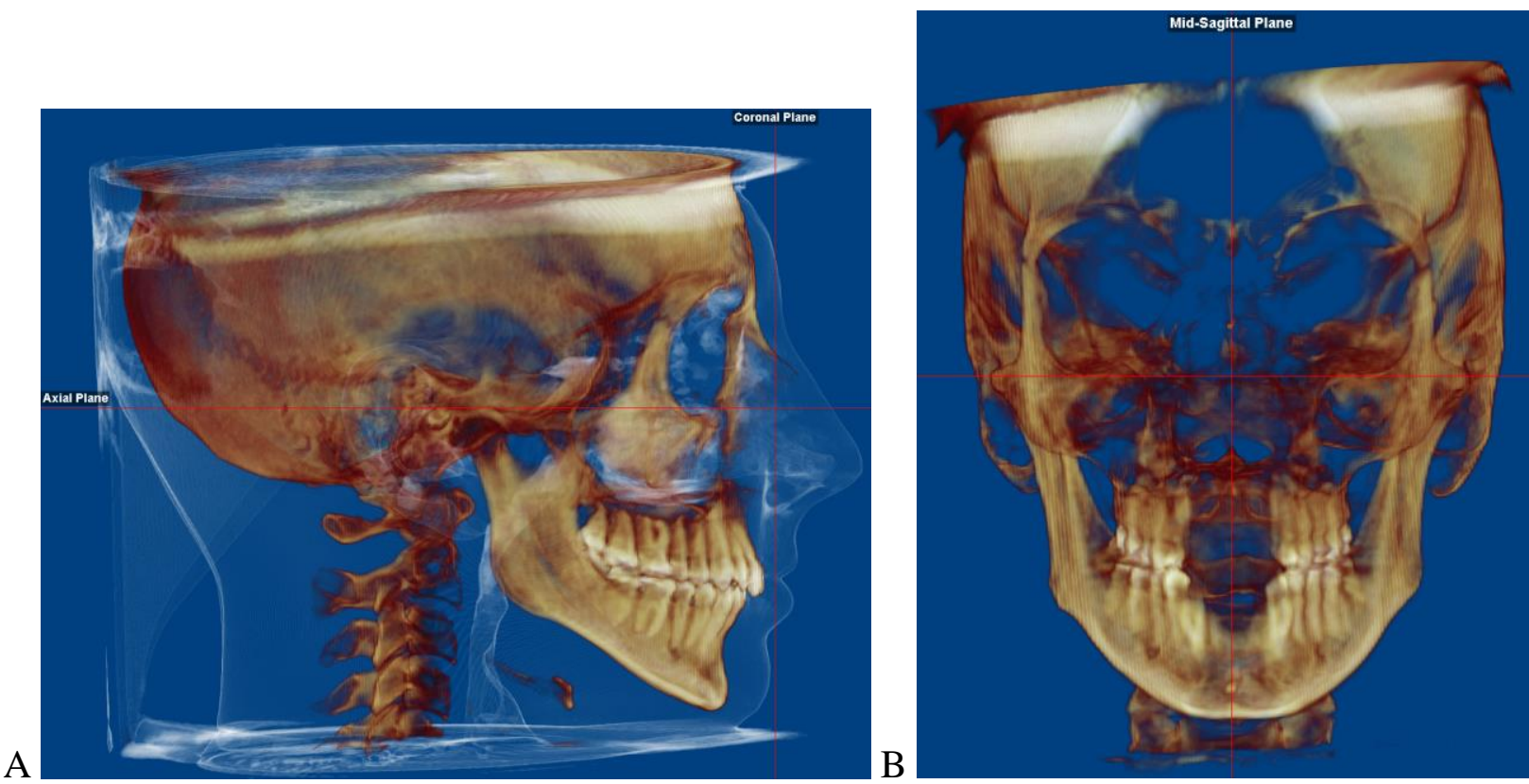


\section{Definition of Anatomical Limits of Airway Regions}

Dolphin 3D was utilized to measure each subject's lower pharyngeal airway volume $(\mathrm{AV})$, airway length (AL), and minimum cross-sectional area (mCA), as well as calculated variables mean cross-sectional area (MCA) and uniformity percentage (U\%). Anatomical and technical considerations for CBCT airway analysis were adapted from recommendations of a recent systematic review validation study (11) in order to facilitate comparable airway measurements and future systematic reviews. Identical regional definitions of the pharyngeal airway were utilized, with the exception of Frankfort Horizontal Plane (FHP) as the transverse reference line. Since FHP has significant variation with respect to the true horizontal plane of the face, planes perpendicular to the GALL line (GALL-perpd) or parallel to the GALL line (GALL-parll) will be used for all borders in this study (Table 1). 
Table 1. Anatomical Limits of Airway Regions

\begin{tabular}{|c|c|c|c|}
\hline Region & Subregion & Limits & Anatomical Border \\
\hline \multirow{8}{*}{ Oropharynx } & \multirow{4}{*}{ Velopharynx } & Superior & GALL-perpd through PNS \\
\hline & & Anterior & GALL-parll through PNS \\
\hline & & Posterior/Lateral & Soft tissue pharyngeal walls \\
\hline & & Inferior & Tip of soft palate \\
\hline & \multirow{4}{*}{ Glossopharynx } & Superior & Tip of soft palate \\
\hline & & Anterior & GALL-parll through PNS \\
\hline & & Posterior/Lateral & Soft tissue pharyngeal walls \\
\hline & & Inferior & GALL-perpd through C3ai \\
\hline \multirow{4}{*}{\multicolumn{2}{|c|}{ Hypopharynx }} & Superior & GALL-perpd through C3ai \\
\hline & & Anterior & GALL-parll through PNS \\
\hline & & Posterior/Lateral & Soft tissue pharyngeal walls \\
\hline & & Inferior & GALL-perpd through C4ai \\
\hline
\end{tabular}


Airway Analysis

Using the Dolphin 3D Sinus/Airway tool, lower pharyngeal airway clipping borders were created in the sagittal view according to the anatomical limits listed in Table 1. Seed points were then added in all three planar views to populate air space outwards to clipping borders or soft tissue limits (Figure 13). Slice sensitivity was set to 60, in order to maximize fill of air space and minimize digital artifacts.

\section{Figure 13. Airway Clipping Borders and Seed Points}

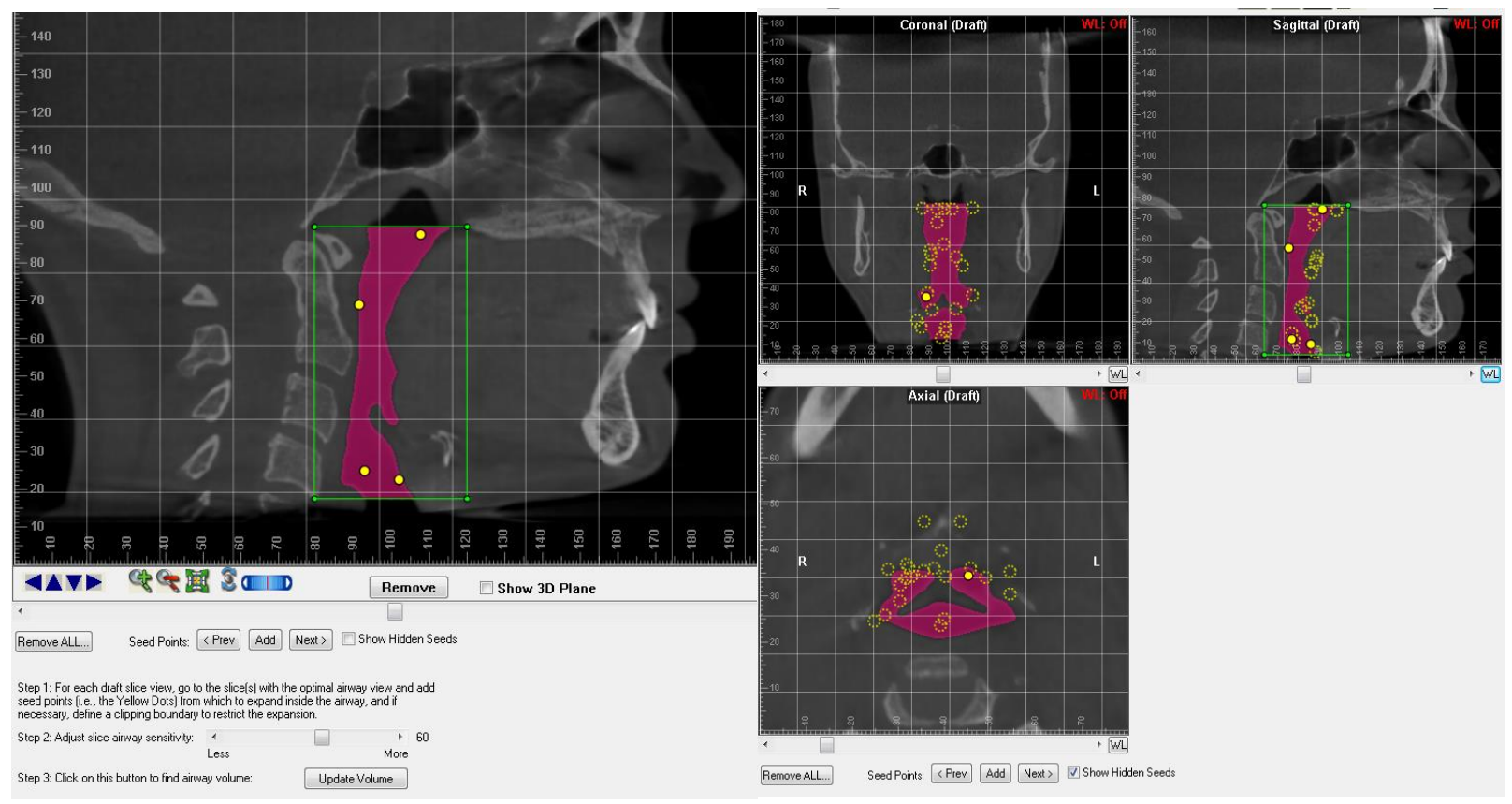

Dolphin 3D software automatically calculated airway volume (AV) and minimum crosssectional area (mCA), also called minimum axial area. Airway length (AL) was measured manually by aligning ruler bars at the superior and inferior borders of the airway. 


\section{Figure 14. Completed Airway Analysis}
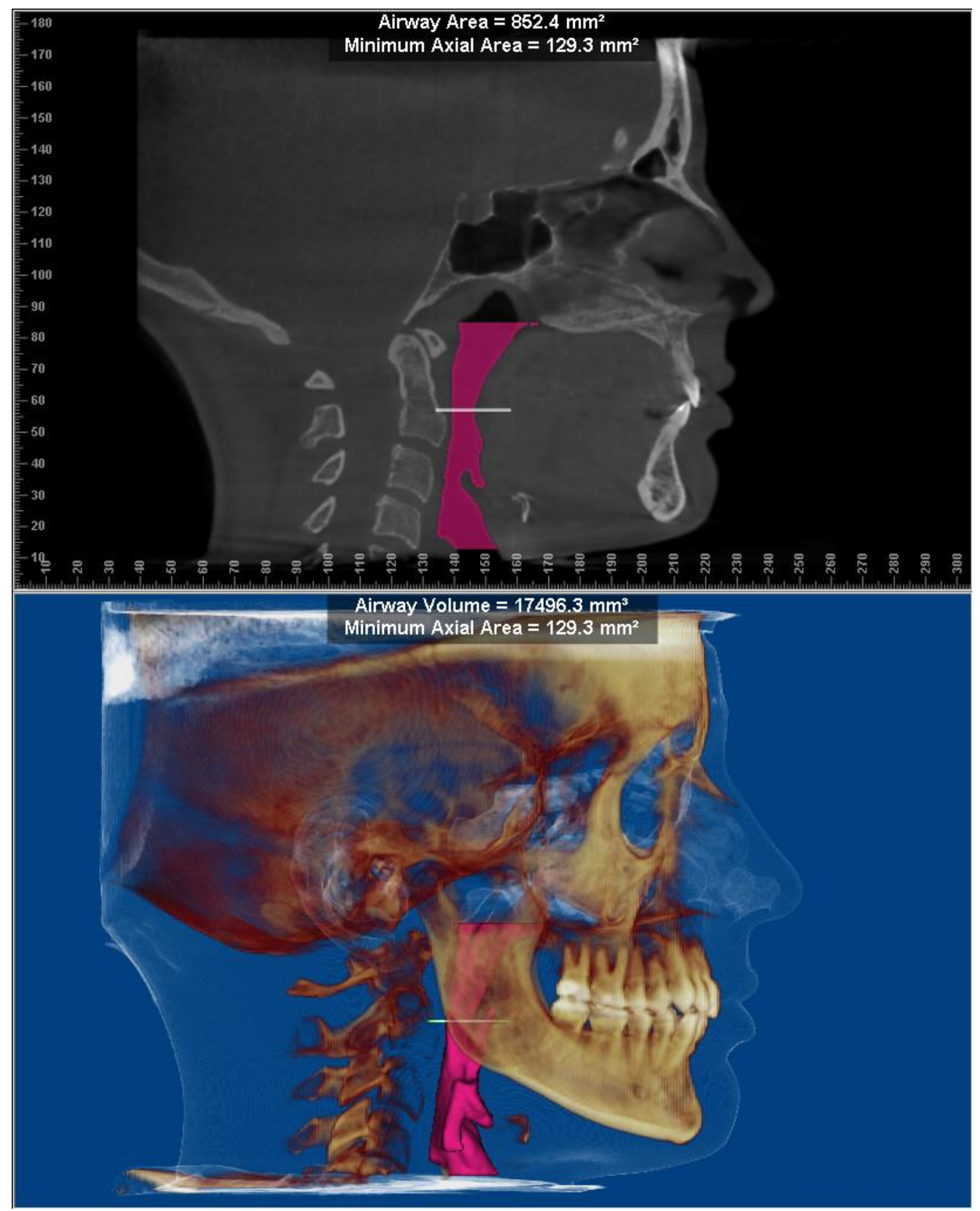

Other airway variables that correct for subject size variations were determined by

calculating Mean Cross-Sectional Area $(\mathrm{MCA}=\mathrm{AV} / \mathrm{AL})$ and Uniformity Percentage $(\mathrm{U} \%=$ mCA/MCA) in Microsoft Excel. Location of mCA was also noted by airway subregion: velopharynx, glossopharynx, or hypopharynx. 


\section{Lateral Cephalometric Tracing}

Using the Dolphin 3D Build X-Rays tool, hard and soft tissues were segmented, and an orthogonal projection was used to create a 2D lateral cephalometric radiograph. This radiographic projection is free of magnification error and can be modified with various filters to accurate depict and locate anatomical landmarks for tracing. The lateral cephalometric projection was saved to the Dolphin layout database for digitization.

\section{Digitization and Control Measurements}

A custom Dolphin analysis was created to digitize lateral cephalometric projections to a one-to-one ratio and identify traditional cephalometric landmarks to be used for the following angular measurements: SNA, SNB, ANB, MP-SN, OP-SN and NAP (Figure 15).

\section{Figure 15. Digital Tracing and Measurements}

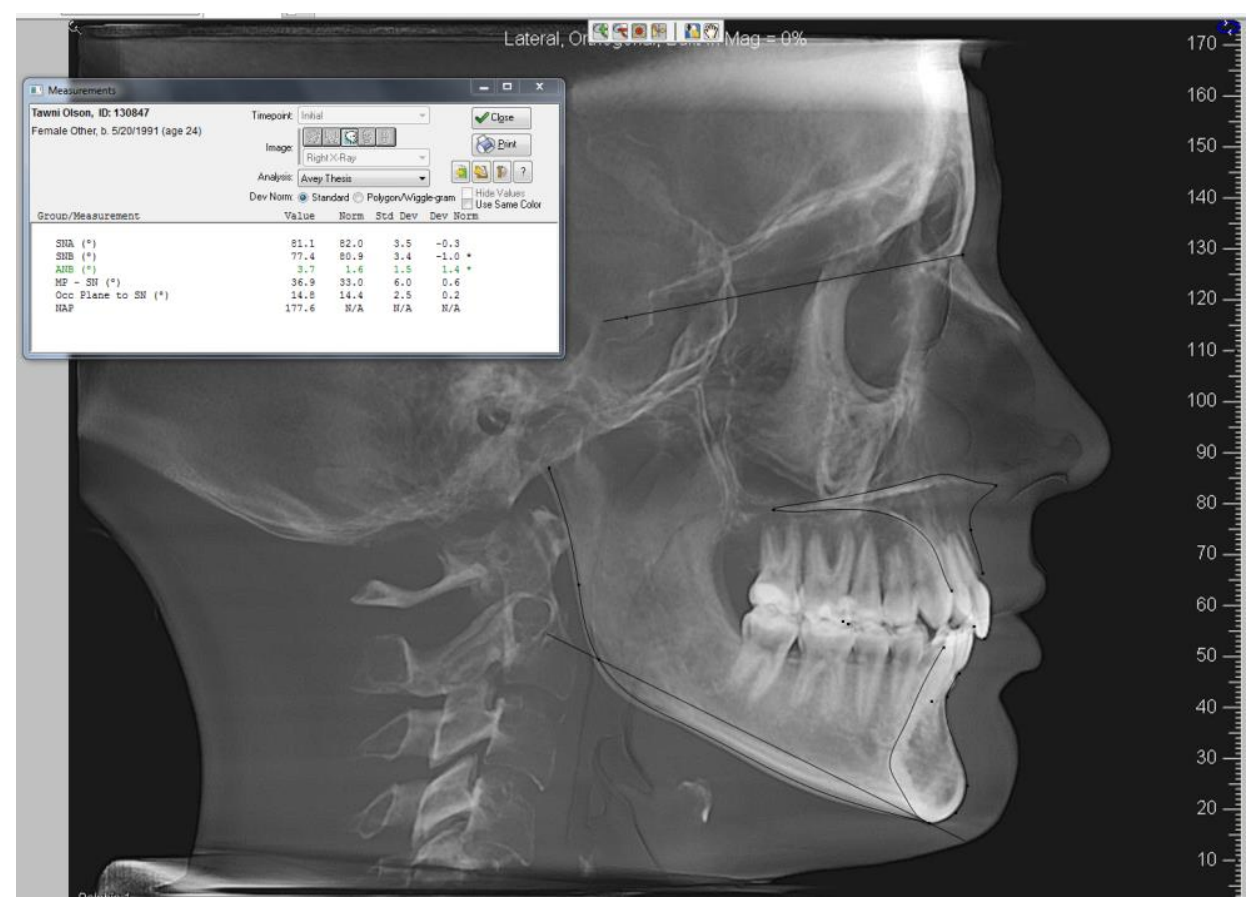




\section{Hand-Traced Six Elements Analysis}

Previously digitized lateral cephalometric projections were printed to hard copy for use in a hand-traced Six Elements analysis. Using the U1-FALL judgment and the FFA point, the FALL line was constructed and the GALL line was set to a parallel line passing through glabella. The occlusal plane and mandibular plane were duplicated from the digital tracing on the hard copy. Hypothetical optimal incisors were traced by aligning the Andrews tracing template (Figure 16) with the treatment occlusal plane and sliding until the incisor tracings were centered in the basal bone of the maxilla and mandibular symphysis.

\section{Figure 16. Andrews Tracing Template}

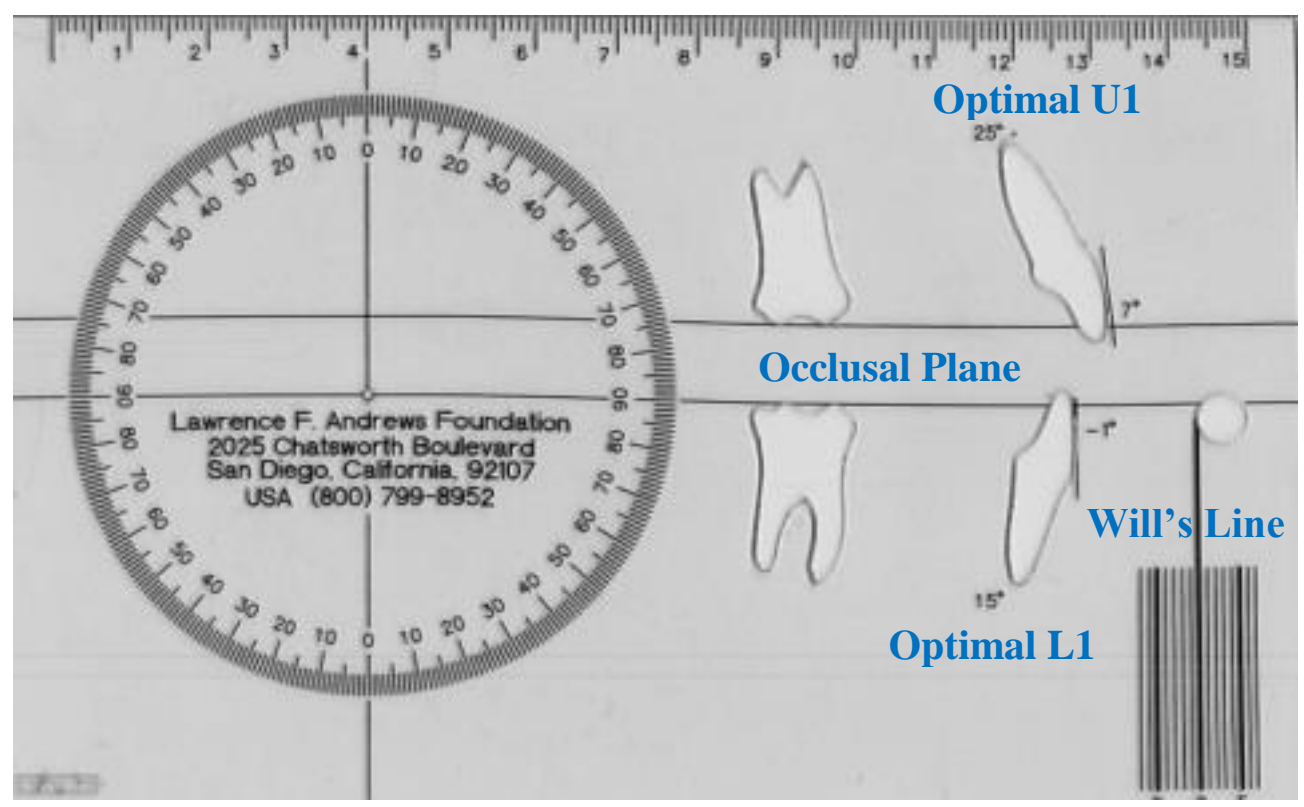

After this tracing, the distance in millimeters is measured from the FA of the optimal upper incisor to the GALL, noted as Mx-GALL. Mx-Md is calculated by measurement of the hypothetical overjet, along the occlusal plane from the lingual contour of the optimal upper 
incisor to the facial contour of the optimal upper incisor. Md-GALL is calculated by subtracting the Mx-Md value from Mx-GALL. Angular measurements for MPI and OPI were found by aligning the $90^{\circ}$ line with the GALL and finding the inclination of these lines to the nearest whole degree. The final measurement for hard-tissue pogonion prominence, Pog, was found by aligning the Andrew's tracing template to the occlusal plane and allowing the perpendicular Will's line to pass through the FA of the lower incisor. The Pog is measured in millimeters ahead or behind this line. The calculated value, Effective Pogonion Prominence (EPP), is found by addition of Md-GALL and Pog values, and is used to describe the relative position of the hard tissue chin in the face. Completed hand-traced analyses were scanned and saved a PDF files for data input. 
Figure 17. Consecutively Completed Hand-Traced Analyses

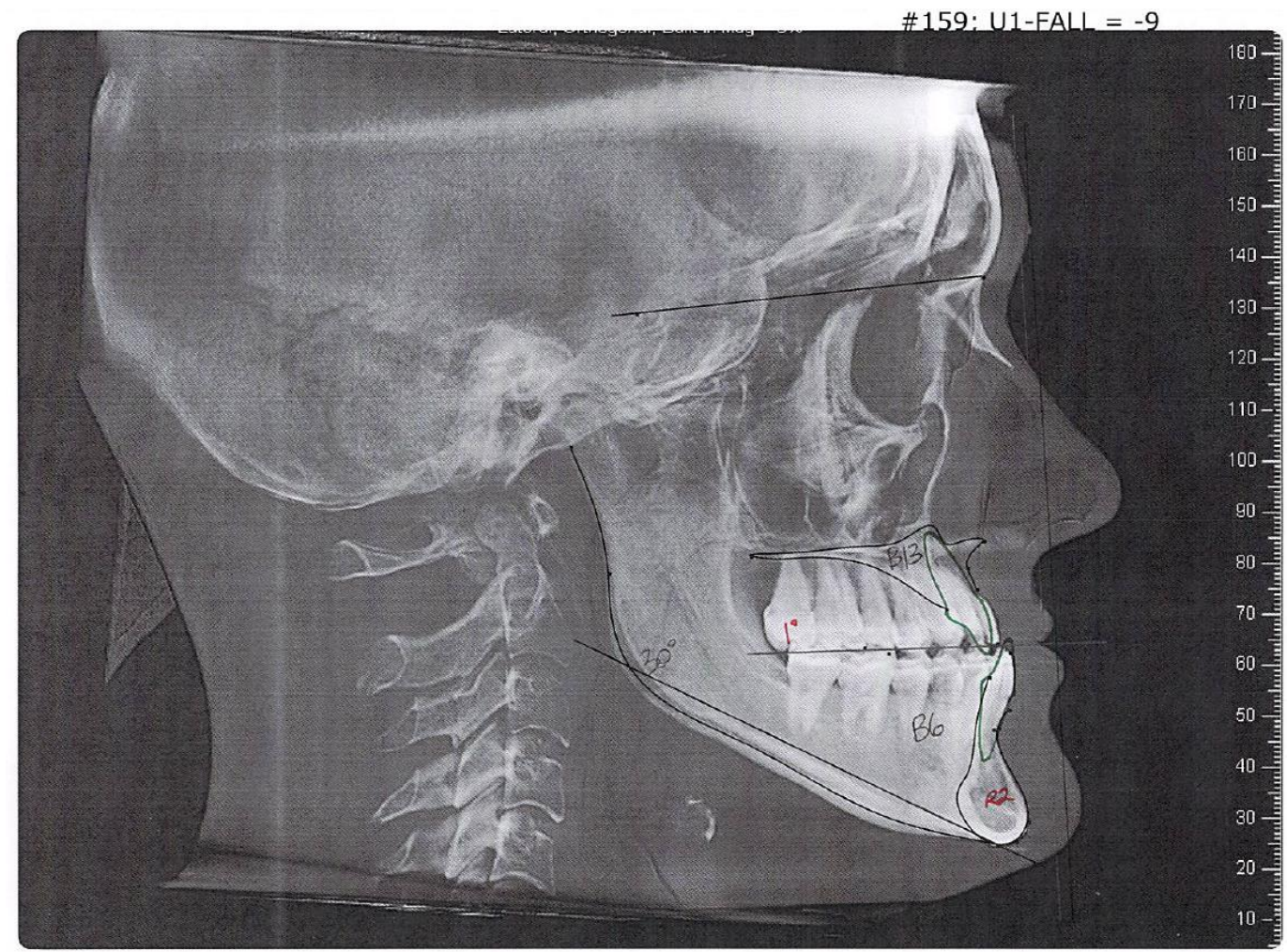

\#160; U1-FALL = -1

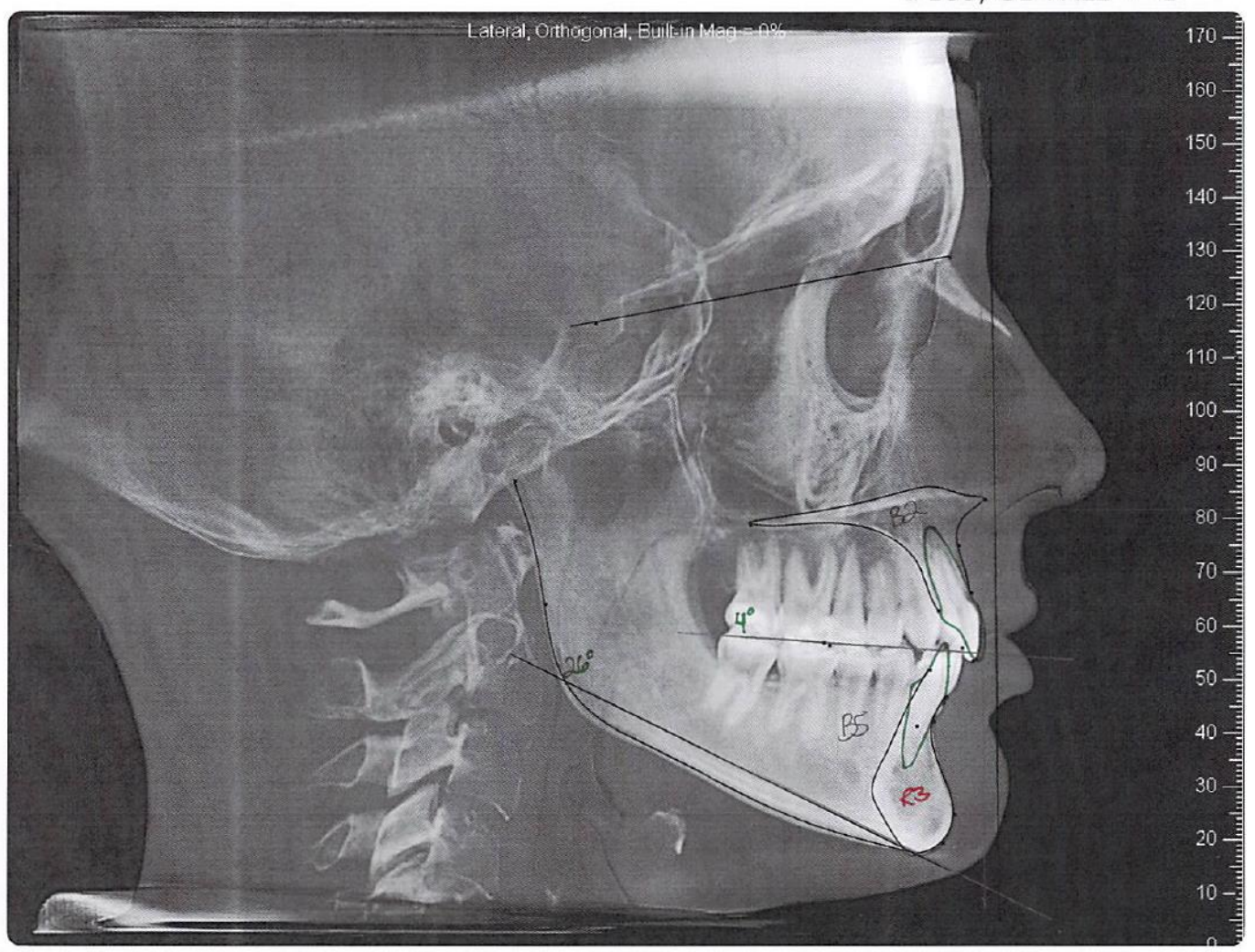




\section{Jaw Classification and Group Determination}

Using 2D lateral cephalometric tracings, subjects were divided into groups based on classification of each craniofacial variable. Table 2 lists each craniofacial variable and how subjects were divided into respective groups. Grouping limits were determined from established normative values (e.g. $\mathrm{Mx}-\mathrm{GALL}=0, \mathrm{SNA}=82, \mathrm{OP}-\mathrm{SN}=15$, etc.) and standard deviations. The addition of "severe" categories for the AP Six Elements groups was primarily to illustrate the difference between mild-moderate discrepancies that could feasibly be corrected by orthodontic camouflage or orthopedics, and more severe cases likely requiring surgical intervention. Experimental Six Elements measurements were all hand measured to the nearest whole millimeter or degree, and were grouped by integers. Control traditional measurements were all digitally calculated using the custom Dolphin Imaging analysis to the nearest tenth of a degree and rounded to the nearest whole degree for grouping. 
Table 2. Craniofacial Variable Groups

\begin{tabular}{|c|c|c|c|c|c|}
\hline Variable & $\begin{array}{l}\text { Norm } \\
\text { Values }\end{array}$ & \multicolumn{4}{|c|}{$\begin{array}{c}\text { Grouping } \\
\text { (Numerical Limits) }\end{array}$} \\
\hline Mx-GALL & 0 & $\begin{array}{c}\text { Severely Deficient } \\
(\leq-7)\end{array}$ & $\begin{array}{l}\text { Deficient } \\
(-6 \leq-3)\end{array}$ & $\begin{array}{l}\text { Optimal } \\
(-2 \leq 1)\end{array}$ & $\begin{array}{c}\text { Excessive } \\
(\geq 2)\end{array}$ \\
\hline Md-GALL & $\mathbf{0}$ & $\begin{array}{c}\text { Severely Deficient } \\
(\leq-7)\end{array}$ & $\begin{array}{l}\text { Deficient } \\
(-6 \leq-3)\end{array}$ & $\begin{array}{c}\text { Optimal } \\
(-2 \leq 1)\end{array}$ & $\begin{array}{l}\text { Excessive } \\
(\geq 2)\end{array}$ \\
\hline Mx-Md & 0 & $\begin{array}{c}\text { Category II - Severe } \\
(\geq 6)\end{array}$ & $\begin{array}{l}\text { Category II } \\
(5 \geq 2)\end{array}$ & $\begin{array}{l}\text { Category I } \\
(1 \geq-1)\end{array}$ & $\begin{array}{c}\text { Category III } \\
(\leq-2)\end{array}$ \\
\hline MPI & 25 & \multicolumn{2}{|l|}{$\begin{array}{c}\text { Flat } \\
(\leq 22)\end{array}$} & $\begin{array}{l}\text { Optimal } \\
(23 \leq 28)\end{array}$ & $\begin{array}{l}\text { Steep } \\
(\geq 29)\end{array}$ \\
\hline OPI & 7 & \multicolumn{2}{|l|}{$\begin{array}{l}\text { Flat } \\
(\leq 2)\end{array}$} & $\begin{array}{l}\text { Optimal } \\
(3 \leq 8)\end{array}$ & $\begin{array}{l}\text { Steep } \\
(\geq 9)\end{array}$ \\
\hline Pog & $\mathbf{0}$ & \multicolumn{2}{|l|}{$\begin{array}{c}\text { Deficient } \\
(\leq-2)\end{array}$} & $\begin{array}{l}\text { Optimal } \\
(-1 \leq 1)\end{array}$ & $\begin{array}{l}\text { Excessive } \\
(\geq 2)\end{array}$ \\
\hline EPP & $\mathbf{0}$ & $\begin{array}{c}\text { Severely Retrusive } \\
(\leq-7)\end{array}$ & $\begin{array}{c}\text { Retrusive } \\
(-6 \leq-3)\end{array}$ & $\begin{array}{l}\text { Optimal } \\
(-2 \leq 1)\end{array}$ & $\begin{array}{l}\text { Protrusive } \\
\quad(\geq 2)\end{array}$ \\
\hline SNA & 82 & \multicolumn{2}{|l|}{$\begin{array}{c}\text { Deficient } \\
(\leq 78)\end{array}$} & $\begin{array}{c}\text { Optimal } \\
(78<84)\end{array}$ & $\begin{array}{c}\text { Excessive } \\
(\geq 84)\end{array}$ \\
\hline SNB & 80 & \multicolumn{2}{|l|}{$\begin{array}{c}\text { Deficient } \\
(\leq 74)\end{array}$} & $\begin{array}{c}\text { Optimal } \\
(74<82)\end{array}$ & $\begin{array}{c}\text { Excessive } \\
(\geq 82)\end{array}$ \\
\hline ANB & 2 & \multicolumn{2}{|l|}{$\begin{array}{c}\text { Class II } \\
(>4)\end{array}$} & $\begin{array}{l}\text { Class I } \\
(0 \leq 4)\end{array}$ & $\begin{array}{c}\text { Class III } \\
(<0)\end{array}$ \\
\hline MP-SN & 32 & \multicolumn{2}{|l|}{$\begin{array}{l}\text { Low Angle } \\
\quad(\leq 30)\end{array}$} & $\begin{array}{c}\text { Normal } \\
(30<40)\end{array}$ & $\begin{array}{l}\text { High Angle } \\
\quad(\geq 40)\end{array}$ \\
\hline OP-SN & 15 & \multicolumn{2}{|l|}{$\begin{array}{l}\text { Low Angle } \\
\quad(\leq 10)\end{array}$} & $\begin{array}{c}\text { Normal } \\
(10<20) \\
\end{array}$ & $\begin{array}{l}\text { High Angle } \\
(\geq 20)\end{array}$ \\
\hline NAP & 180 & \multicolumn{2}{|l|}{$\begin{array}{l}\text { Convex } \\
(\leq 175)\end{array}$} & $\begin{array}{c}\text { Straight } \\
(175<180)\end{array}$ & $\begin{array}{l}\text { Concave } \\
(\geq 180)\end{array}$ \\
\hline
\end{tabular}




\section{Statistical Analysis}

The experimental (Six Elements) and control (traditional cephalometric) craniofacial variable groups were analyzed statistically to determine the relationship between jaw position and lower pharyngeal airway dimensions. Data was analyzed using one-way ANOVA to determine if significant differences existed among variable groups. For significant variables, post-hoc analysis was performed using Welch's unequal variances t-test to determine differences between pairs of groups. Significance of results was determined as p-value $<0.05(95 \%$ Confidence Interval). 


\section{CHAPTER 4: RESULTS}

\section{Sample Analysis}

Sample Size, Age, and Gender

The CBCT sample consisted of 86 total subjects from 18 to 30 years old. Of these, 68 were females and 18 were males (Figure 18). No differentiation was made for medical history, body mass index, or ethnicity. Figure 19 illustrates the frequency distribution of subject ages in this study and the consistency in airway size (AV) and shape (MCA) across ages.

Figure 18. Gender Distribution $(n=86)$

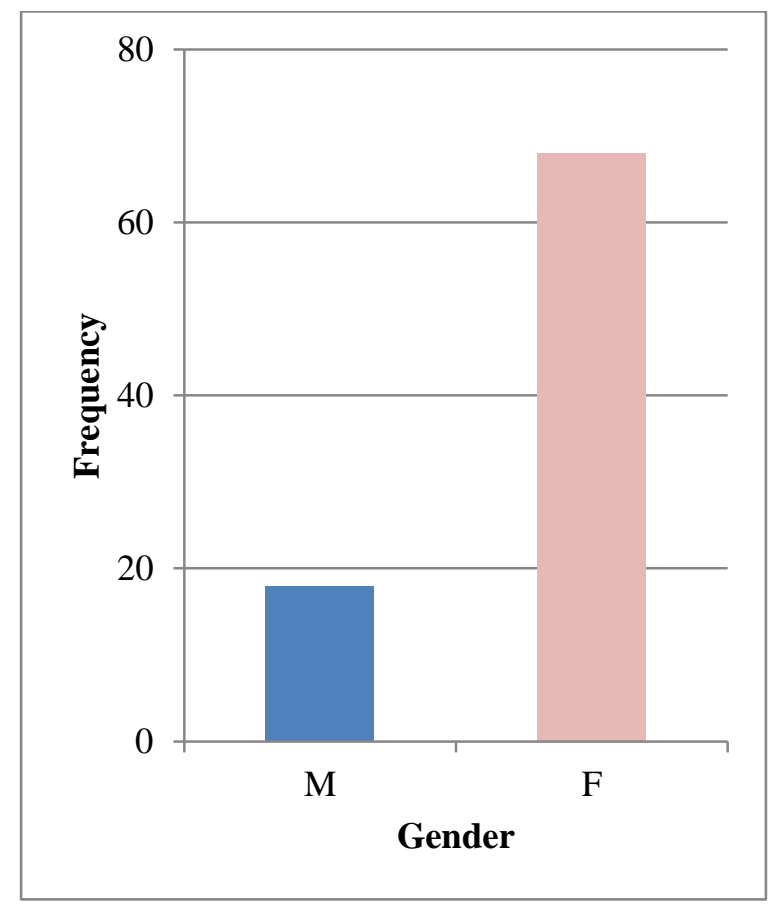


Figure 19. Age Distribution (A) and Correlation with Airway Size and Shape (B, C)
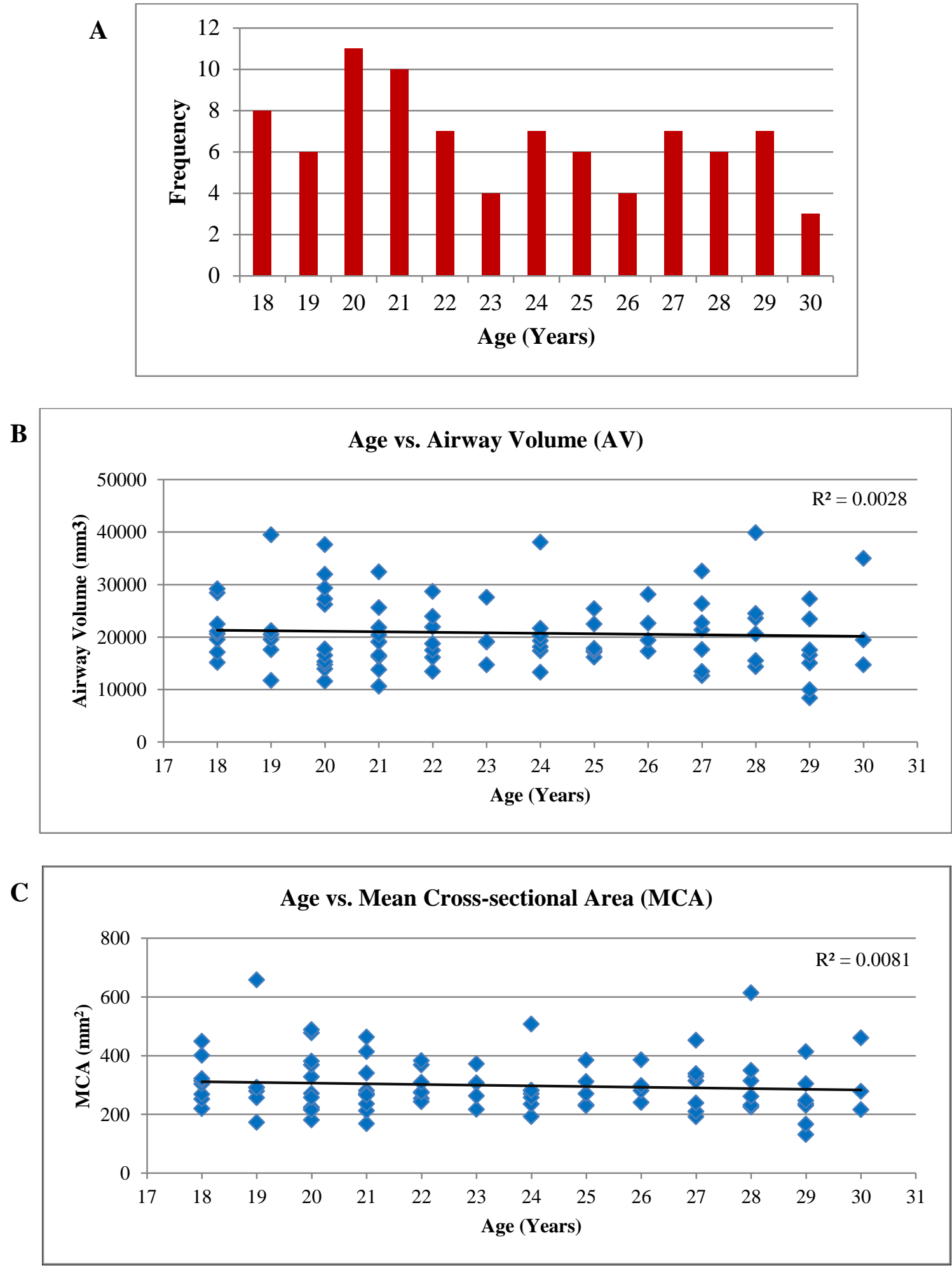
Frequency Distribution of AP Variables

Figures 20-22 show frequency distribution for AP craniofacial variables after all cephalometric tracing was completed.

Figure 20. Maxillary Craniofacial Variable Distributions $(\mathbf{n}=\mathbf{8 6})$
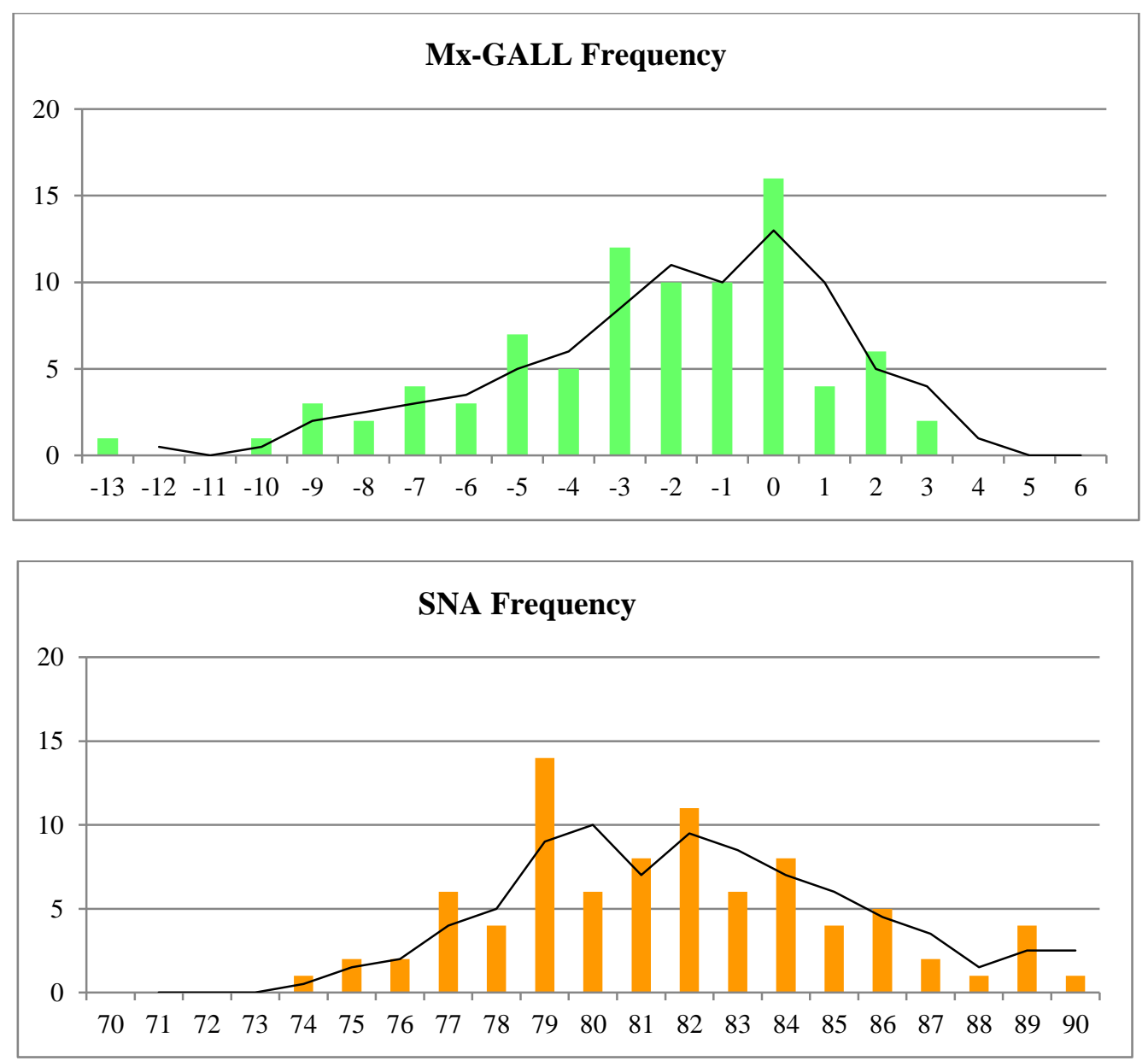
Figure 21. Mandibular Craniofacial Variable Distributions $(\mathbf{n}=86)$
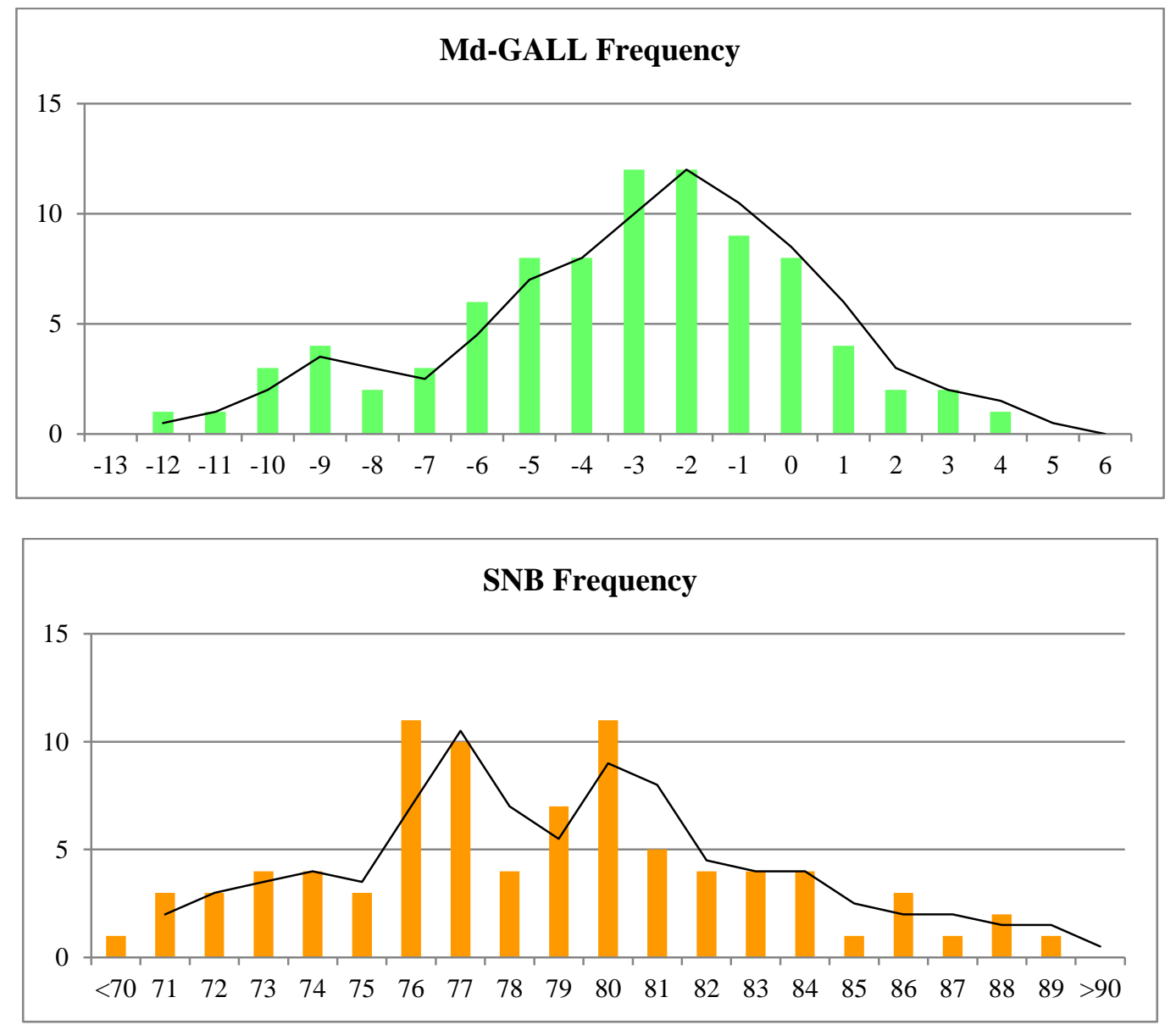

Figure 22. Inter-Jaw Craniofacial Variable Distributions $(\mathbf{n}=\mathbf{8 6})$

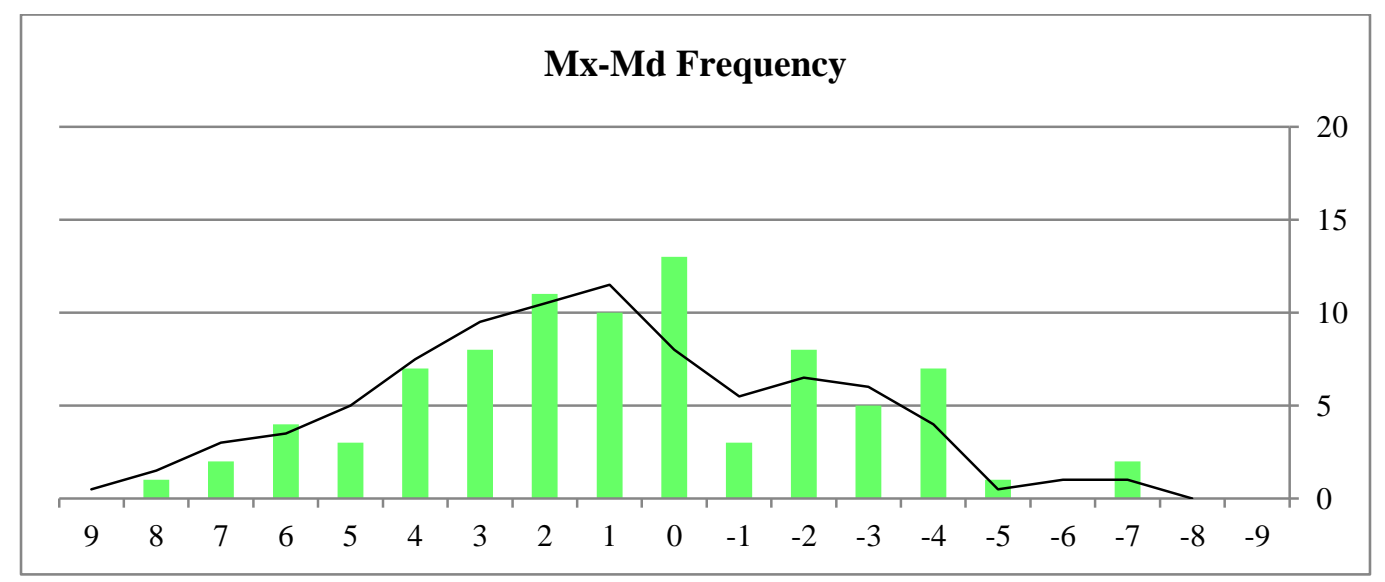




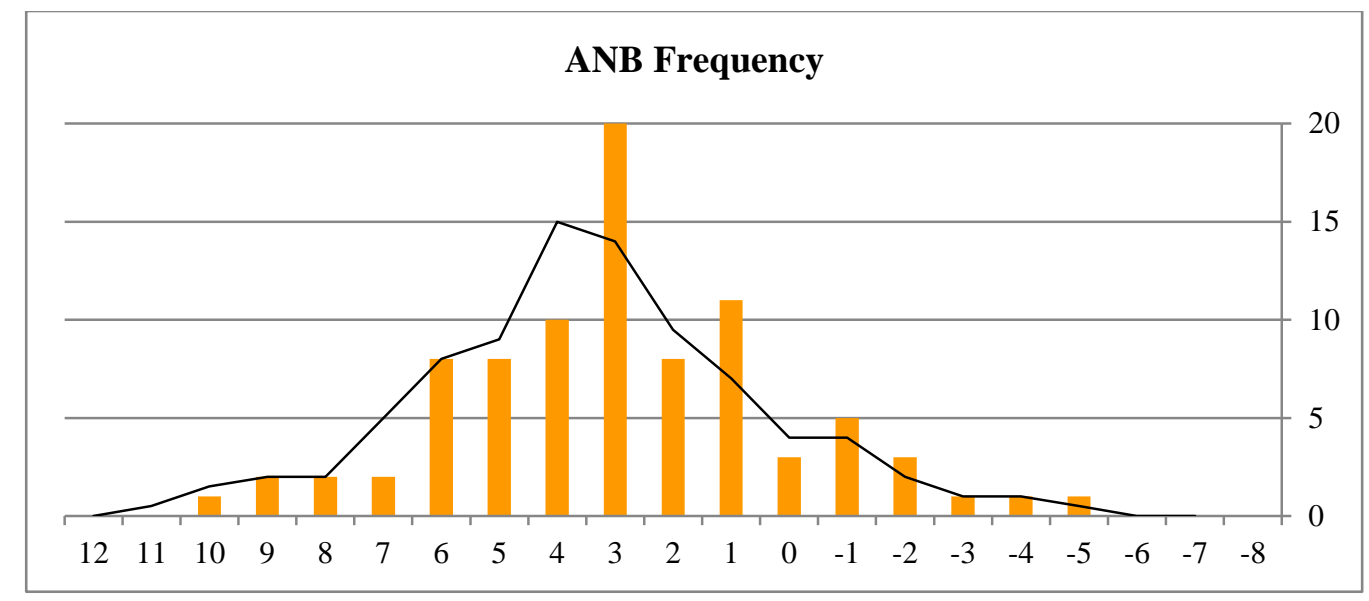

Population Averages and Ranges

Table 3 lists measures of dispersion and central tendency for all variables. The population means for airway variables were approximately $20,786 \mathrm{~mm}^{3}$ airway volume, $69 \mathrm{~mm}$ airway length, $172 \mathrm{~mm}^{2}$ minumum cross-sectional area, $299 \mathrm{~mm}^{2}$ mean cross-sectional area, and $56 \%$ uniformity.

Table 3. Population Measures for Craniofacial $(A, B)$ and Airway $(C)$ Variables $(N=86)$

\begin{tabular}{c|c|c|c|c|c|c|c|}
\multicolumn{1}{c|}{ A } & \multicolumn{1}{c}{ Craniofacial Variables (Experimental) } \\
\cline { 2 - 9 } \multicolumn{1}{c|}{} & Mx-GALL & Md-GALL & Mx-Md & MPI & OPI & Pog & EPP \\
\hline Mean & $\mathbf{- 2 . 5}$ & $\mathbf{- 3 . 3}$ & $\mathbf{0 . 9}$ & $\mathbf{2 6 . 4}$ & $\mathbf{6 . 3}$ & $\mathbf{0 . 8}$ & $\mathbf{- 2 . 5}$ \\
$(+/-)$ & 0.3 & 0.4 & 0.4 & 0.5 & 0.4 & 0.2 & 0.4 \\
\hline Minimum & -13 & -12 & -7 & 15 & 0 & -3 & -11 \\
Maximum & 3 & 4 & 10 & 40 & 19 & 6 & 8 \\
Range (R) & 16 & 16 & 17 & 25 & 19 & 9 & 19 \\
\hline
\end{tabular}

\begin{tabular}{|c|c|c|c|c|c|c|}
\multicolumn{1}{c|}{ B } & Craniofacial Variables (Control) \\
\cline { 2 - 7 } \multicolumn{1}{c|}{} & SNA & SNB & ANB & MP-SN & OP-SN & NAP \\
\hline Mean & $\mathbf{8 1 . 4}$ & $\mathbf{7 8 . 5}$ & $\mathbf{2 . 9}$ & $\mathbf{3 6 . 7}$ & $\mathbf{1 6 . 0}$ & $\mathbf{1 7 6 . 4}$ \\
$(+/-)$ & 0.4 & 0.5 & 0.3 & 0.6 & 0.6 & 0.7 \\
\hline Minimum & 67.3 & 68.2 & -5.1 & 20.2 & 4.6 & 162.9 \\
Maximum & 91.7 & 89.3 & 9.7 & 51.8 & 29.2 & 196.5 \\
Range (R) & 24.4 & 21.1 & 14.8 & 31.6 & 24.6 & 33.6 \\
\hline
\end{tabular}




\begin{tabular}{|c|c|c|c|c|c|}
\multicolumn{1}{c|}{} & \multicolumn{6}{c|}{ Airway Variables } \\
\cline { 2 - 6 } \multicolumn{1}{c|}{$\mathrm{C}$} & $\begin{array}{c}\mathrm{AV} \\
(\mathrm{mm} 3)\end{array}$ & $\begin{array}{c}\mathrm{AL} \\
(\mathrm{mm})\end{array}$ & $\begin{array}{c}\mathrm{mCA} \\
(\mathrm{mm} 2)\end{array}$ & $\begin{array}{c}\text { MCA } \\
(\mathrm{AV} / \mathrm{AL})\end{array}$ & $\begin{array}{c}\text { U\% } \\
(\mathrm{mCA} / \mathrm{MCA})\end{array}$ \\
\hline Mean & $\mathbf{2 0 7 8 5 . 6}$ & $\mathbf{6 9 . 3}$ & $\mathbf{1 7 2 . 1}$ & $\mathbf{2 9 9 . 0}$ & $\mathbf{5 5 . 8}$ \\
$(+/-)$ & 727.6 & 0.6 & 9.0 & 10.2 & 1.4 \\
\hline Minimum & 8397.5 & 53.0 & 55.1 & 131.2 & 23.8 \\
Maximum & 39878.3 & 80.0 & 473.9 & 658.1 & 83.0 \\
Range (R) & 31480.8 & 27.0 & 418.8 & 526.9 & 59.1 \\
\hline
\end{tabular}

\section{Hypothesis Testing}

\section{Maxilla}

$\mathrm{H}_{0}$ : There are no significant differences in airway dimensions among the four anteroposterior groups for the position of the maxilla relative to GALL (Severely Deficient, Deficient, Optimal, Excessive) in this sample of untreated young adult orthodontic patients.

Using one-way ANOVA testing, statistically significant differences $(p<0.05)$ were found among Mx-GALL groups for airway volume (AV) and mean cross-sectional area (MCA). There were no significant differences in airway length, minimum cross-sectional area, or uniformity percentage (Table 4). Figures 23 and 24 illustrate the differences in AV and MCA with box-and-whisker plots of minimum, maximum, median, and middle quartiles (50\%). Posthoc analysis using unequal variance t-tests was performed for significant variables, AV and MCA. T-test results indicate significant differences $(p<0.05)$ between the Mx-GALL Optimal group and all other groups for both airway variables. There were no significant differences found between any of the other groups.

Based on these results, the null hypothesis for the position of the maxilla relative to GALL is rejected. There are significant differences in airway dimensions among the four anteroposterior groups in this sample of untreated young adults. 
Table 4. Mx-GALL Group Means and ANOVA Results

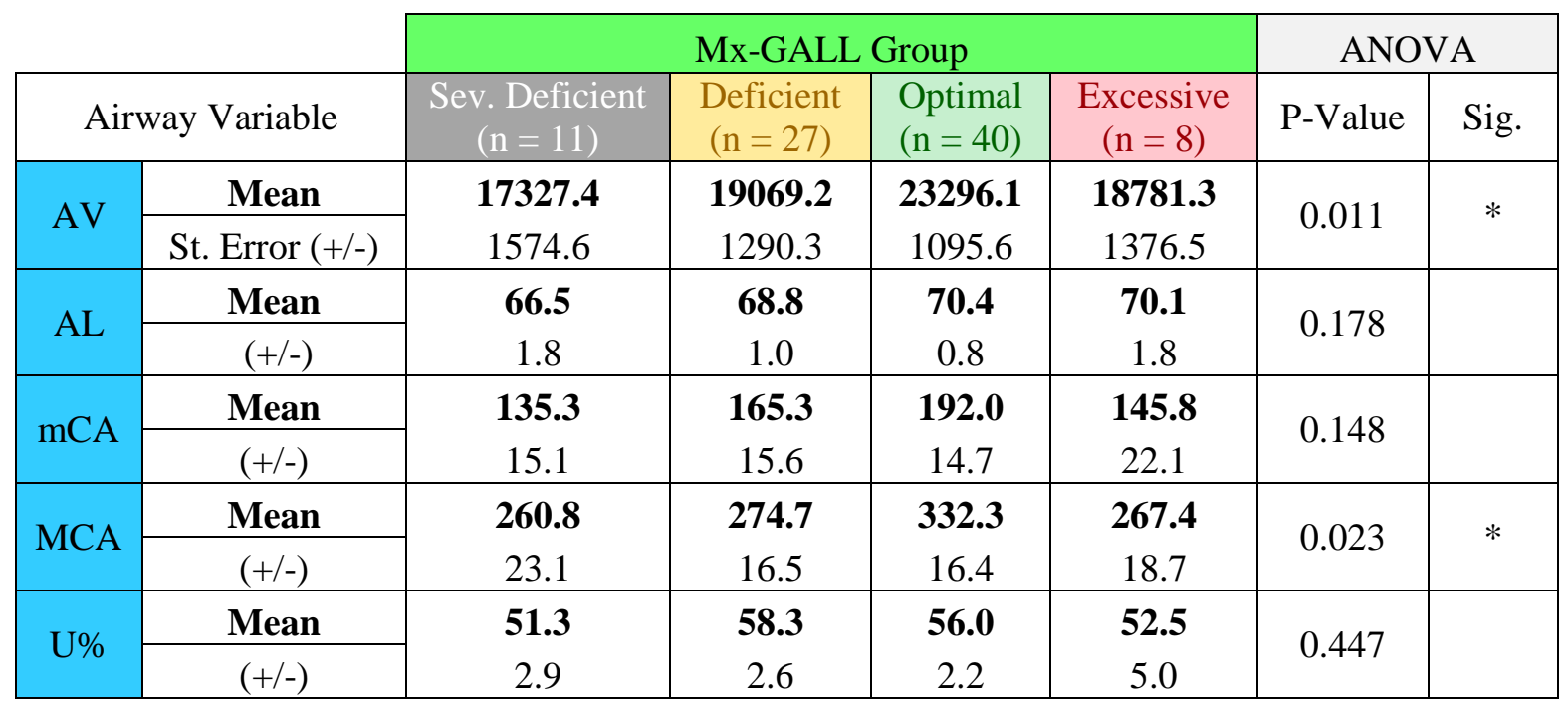

Figure 23. Mx-GALL Group vs. Airway Volume (AV) and t-test Results

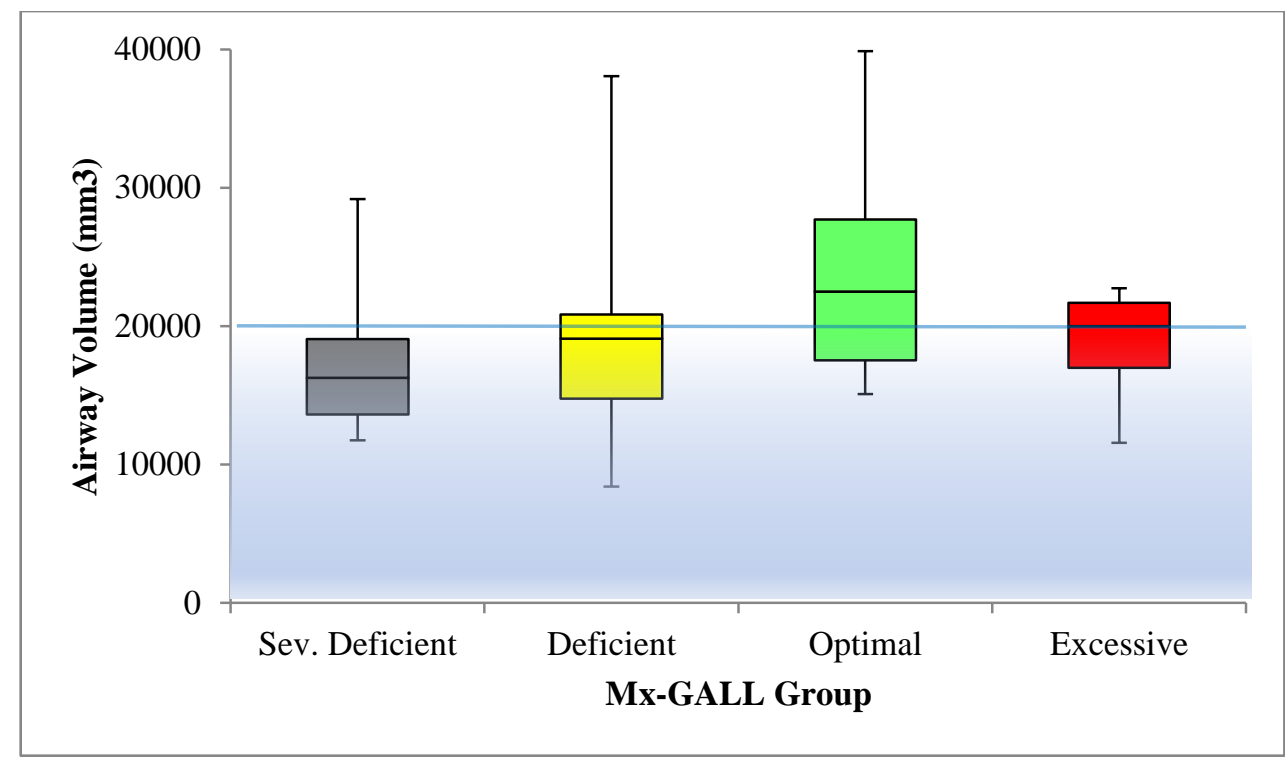

\begin{tabular}{|l|c|c|}
\hline \multicolumn{3}{|c|}{ Unequal Variances t-tests for Mean AV } \\
\hline \multicolumn{1}{|c|}{ Mx-GALL Groups } & P-value & Significance \\
\hline Sev. Deficient v. Deficient & 0.401 & \\
\hline Sev. Deficient v. Optimal & 0.005 & $*$ \\
\hline Sev. Deficient v. Excessive & 0.496 & \\
\hline Deficient v. Optimal & 0.015 & $*$ \\
\hline Deficient v. Excessive & 0.880 & \\
\hline Optimal v. Excessive & 0.020 & $*$ \\
\hline
\end{tabular}


Figure 24. Mx-GALL Group vs. Mean Cross-sectional Area (MCA) and t-test Results

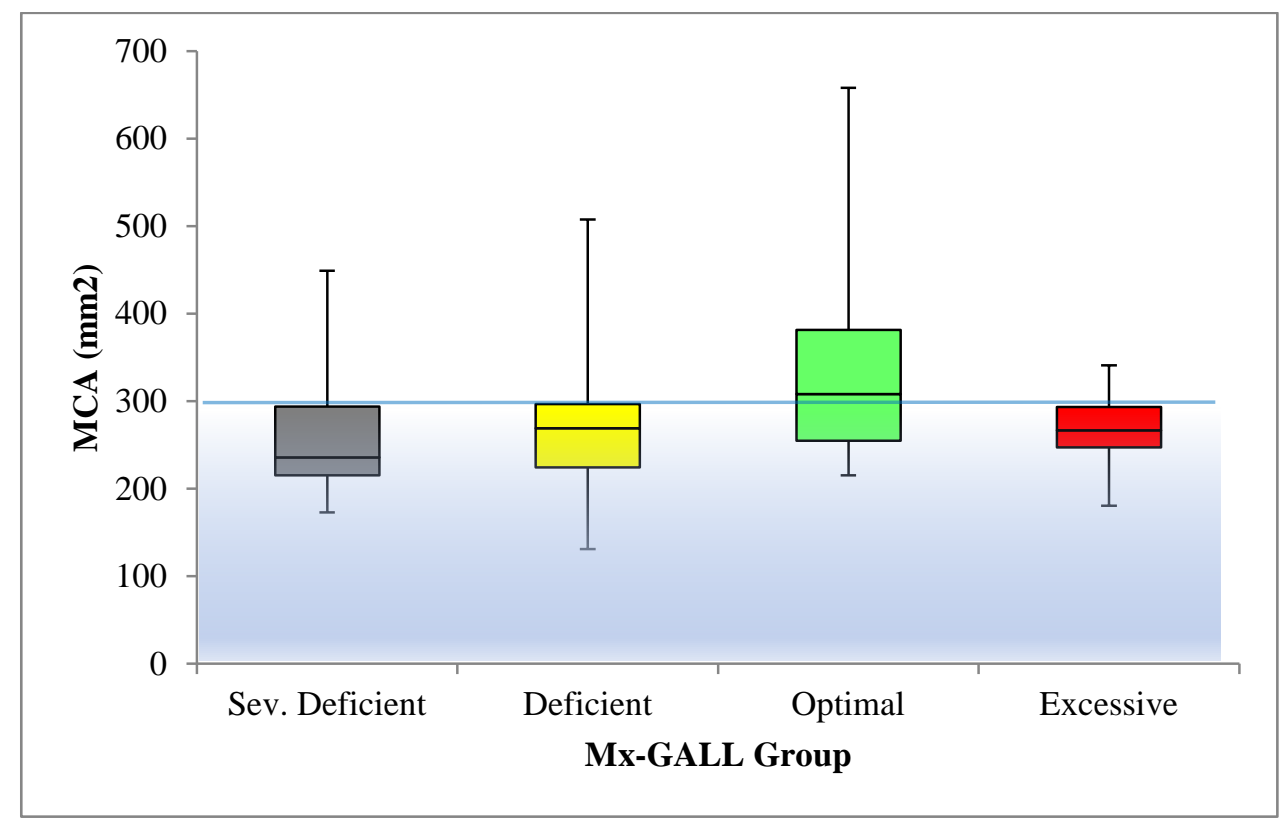

\begin{tabular}{|l|c|c|}
\hline \multicolumn{3}{|c|}{ Unequal Variances t-tests for Mean MCA } \\
\hline \multicolumn{1}{|c|}{ Mx-GALL Groups } & P-value & Significance \\
\hline Sev. Deficient v. Deficient & 0.631 & \\
\hline Sev. Deficient v. Optimal & 0.020 & $*$ \\
\hline Sev. Deficient v. Excessive & 0.826 & \\
\hline Deficient v. Optimal & 0.016 & $*$ \\
\hline Deficient v. Excessive & 0.776 & \\
\hline Optimal v. Excessive & 0.017 & $*$ \\
\hline
\end{tabular}


$\mathrm{H}_{0}$ : There are no significant differences in airway dimensions among the four anteroposterior groups for the position of the mandible relative to GALL (Severely Deficient, Deficient, Optimal, Excessive) in this sample of untreated young adult orthodontic patients.

Using one-way ANOVA testing, there were no significant differences in any airway variables (Table 5). Figure 25 illustrates variations in AV and MCA with box-and-whisker plots of minimum, maximum, median, and middle quartiles (50\%), but none of the apparent differences were statistically significant $(p>0.05)$.

Based on these results, the null hypothesis for the position of the mandible relative to GALL is accepted. There are no significant differences in airway dimensions among the four anteroposterior groups in this sample of untreated young adults.

Table 5. Md-GALL Group Means and ANOVA Results

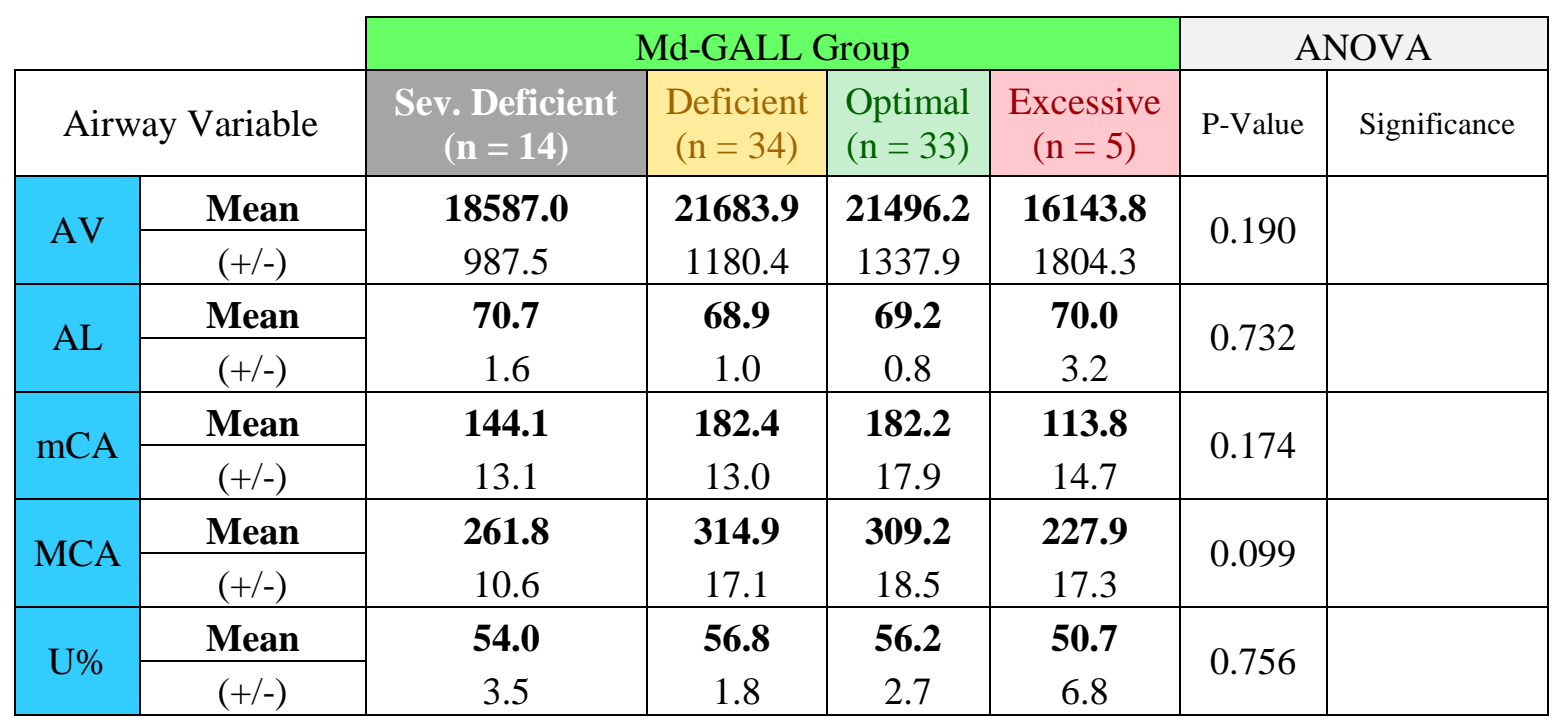


Figure 25. Md-GALL Group Comparison for AV and MCA
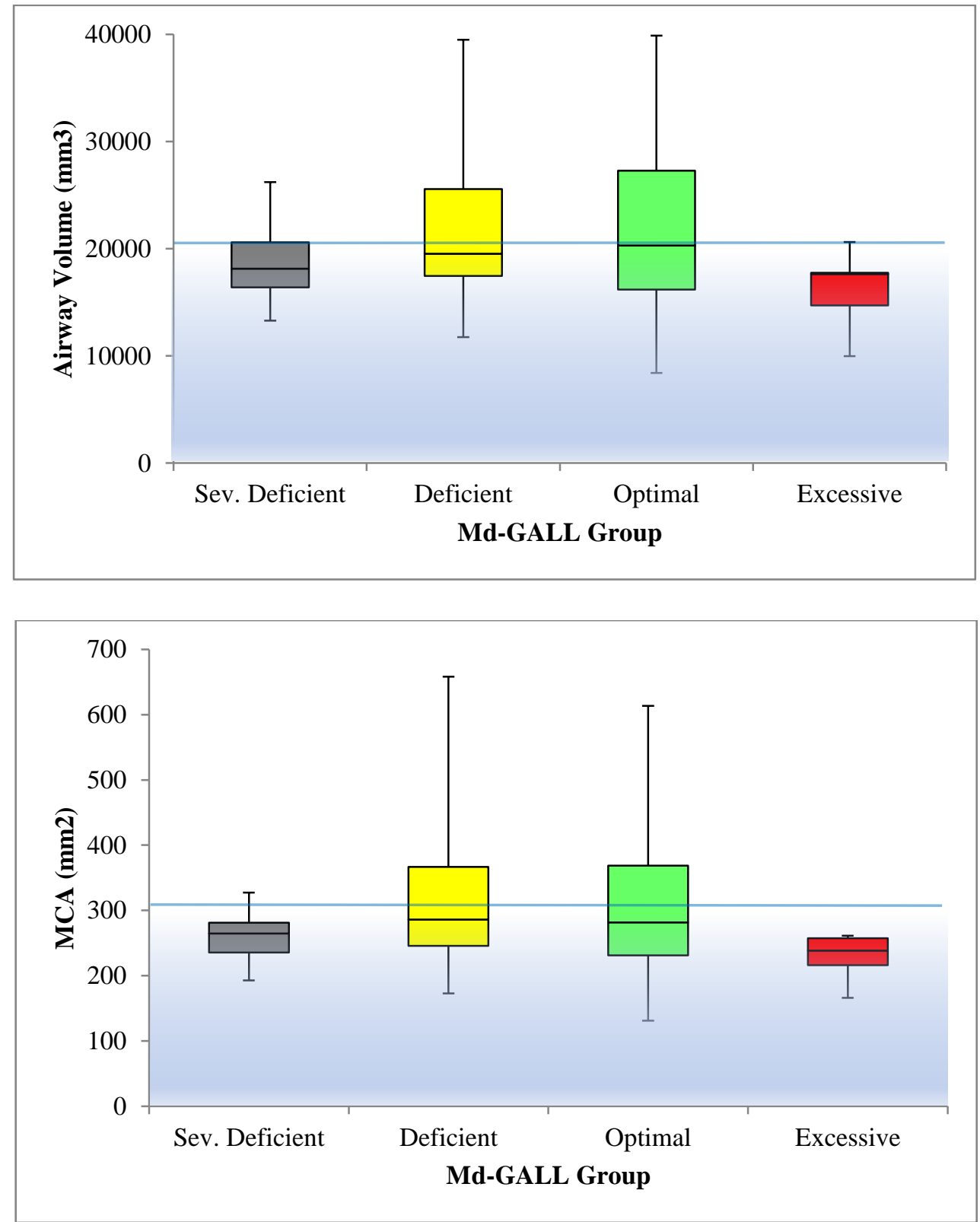
Inter-jaw Relationship

$\mathrm{H}_{0}$ : There are no significant differences in airway dimensions among the four anteroposterior groups for inter-jaw relationship (Category I, Category II, Category II - Severe, Category III) in this sample of untreated young adult orthodontic patients.

Using one-way ANOVA testing, there were no significant differences in any airway variables (Table 6). Figure 26 illustrates variations in $\mathrm{AV}, \mathrm{AL}, \mathrm{mCA}$, and MCA with box-andwhisker plots of minimum, maximum, median, and middle quartiles (50\%), but none of the apparent differences were statistically significant $(p>0.05)$.

Based on these results, the null hypothesis for inter-jaw relationship is accepted. There are no significant differences in airway dimensions among the four anteroposterior groups in this sample of untreated young adults.

Table 6. Mx-Md Group Means and ANOVA Results

\begin{tabular}{|c|c|c|c|c|c|c|c|}
\hline & & \multicolumn{4}{|c|}{ Mx-Md Group } & \multicolumn{2}{|c|}{ ANOVA } \\
\hline \multicolumn{2}{|c|}{ Airway Variable } & $\begin{array}{l}\text { Category II - } \\
\text { Severe }(n=8)\end{array}$ & $\begin{array}{c}\text { Category II } \\
(\mathrm{n}=29)\end{array}$ & $\begin{array}{c}\text { Category I } \\
(\mathrm{n}=26)\end{array}$ & $\begin{array}{c}\text { Category III } \\
(\mathrm{n}=23)\end{array}$ & P-Value & Significance \\
\hline \multirow{2}{*}{ AV } & Mean & 19745.4 & 23375.1 & 19104.8 & 19782.4 & \multirow{2}{*}{0.087} & \\
\hline & $(+/-)$ & 1222.1 & 1437.0 & 1001.7 & 1542.0 & & \\
\hline \multirow{2}{*}{$\mathrm{AL}$} & Mean & 73.1 & 70.1 & 68.1 & 68.5 & \multirow{2}{*}{0.084} & \\
\hline & $(+/-)$ & 1.9 & 1.0 & 0.8 & 1.3 & & \\
\hline \multirow{2}{*}{$\mathrm{mCA}$} & Mean & 144.8 & 201.4 & 154.8 & 164.2 & \multirow{2}{*}{0.126} & \\
\hline & $(+/-)$ & 18.5 & 18.0 & 14.3 & 16.8 & & \\
\hline \multirow{2}{*}{ MCA } & Mean & 269.0 & 334.3 & 280.2 & 286.3 & \multirow{2}{*}{0.101} & \\
\hline & $(+/-)$ & 12.3 & 21.4 & 14.1 & 20.3 & & \\
\hline \multirow{2}{*}{$\mathrm{U} \%$} & Mean & 52.9 & 58.3 & 53.4 & 56.3 & \multirow{2}{*}{0.524} & \\
\hline & $(+/-)$ & 5.3 & 1.9 & 2.9 & 3.0 & & \\
\hline
\end{tabular}


Figure 26. Mx-Md Group Comparison for AV, AL, mCA and MCA
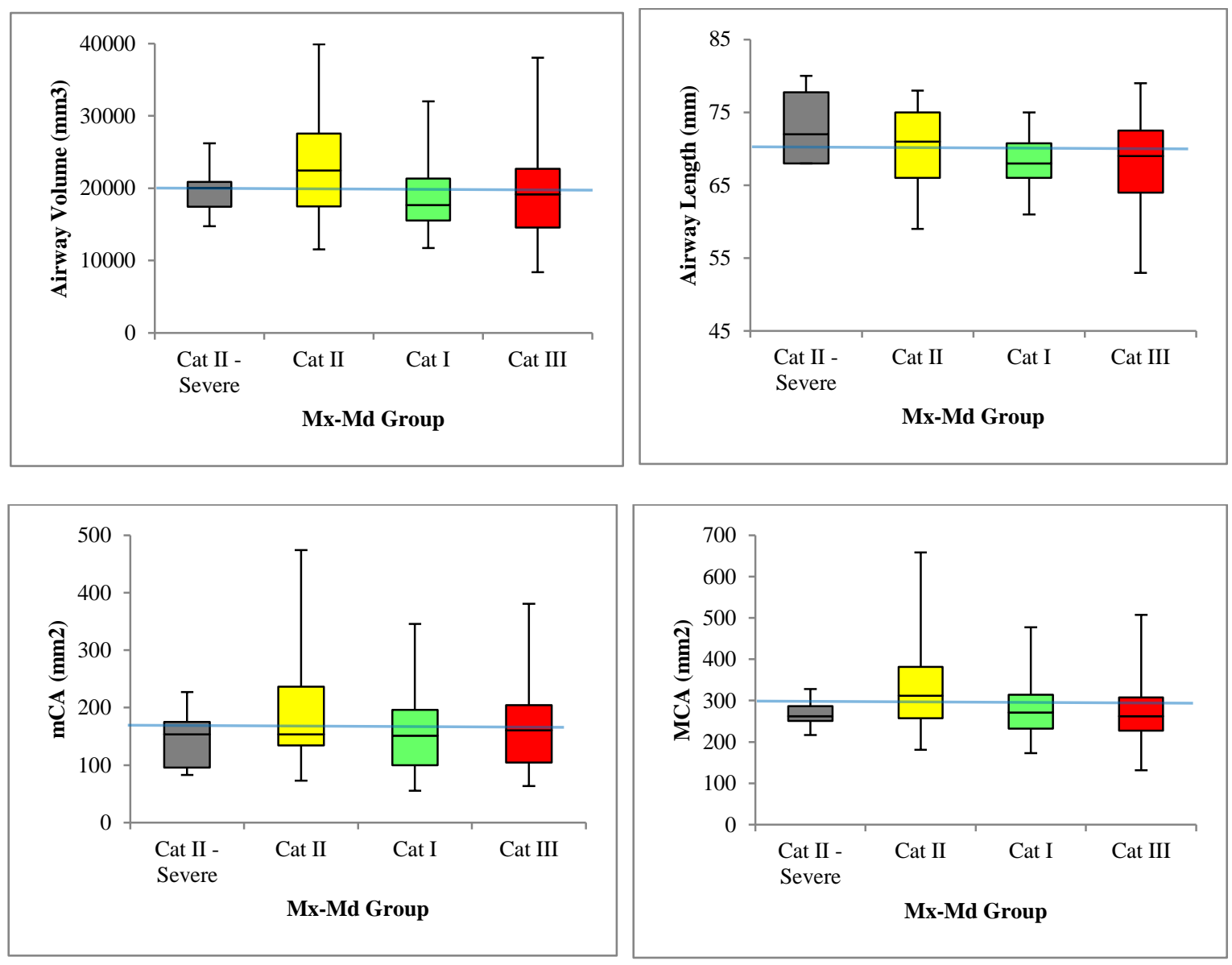


\section{Vertical Inclination}

$\mathrm{H}_{0}$ : There are no significant differences in airway dimensions among the groups for vertical inclination of the jaws relative to GALL (MPI or OPI) in this sample of untreated young adult orthodontic patients.

Using one-way ANOVA testing, there were no significant differences in any airway variables for MPI or OPI groups (Table 7). Figure 27 illustrates variations in AV and MCA across OPI groups with box-and-whisker plots of minimum, maximum, median, and middle quartiles (50\%), but none of the apparent differences were statistically significant $(p>0.05)$.

Based on these results, the null hypothesis for the vertical inclination of the jaws relative to GALL is accepted. There are no significant differences in airway dimensions among groups for MPI or OPI in this sample of untreated young adults.

Table 7. Means and ANOVA Results for MPI (A) and OPI (B)

\begin{tabular}{|c|c|c|c|c|c|c|}
\hline \multicolumn{2}{|l|}{$\mathbf{A}$} & \multicolumn{3}{|c|}{ MPI Group } & \multicolumn{2}{|c|}{ ANOVA } \\
\hline \multicolumn{2}{|c|}{ Airway Variable } & $\begin{array}{c}\text { Flat } \\
(n=20)\end{array}$ & $\begin{array}{l}\text { Optimal } \\
(\mathrm{n}=35)\end{array}$ & $\begin{array}{c}\text { Steep } \\
(\mathrm{n}=31)\end{array}$ & P-Value & Significance \\
\hline \multirow{2}{*}{$\mathrm{AV}$} & Mean & 22485.6 & 20333.8 & 20199.0 & \multirow{2}{*}{0.445} & \\
\hline & $(+/-)$ & 1920.0 & 1158.5 & 951.5 & & \\
\hline \multirow{2}{*}{$\mathrm{AL}$} & Mean & 69.2 & 69.4 & 69.4 & \multirow{2}{*}{0.990} & \\
\hline & $(+/-)$ & 1.1 & 0.8 & 1.2 & & \\
\hline \multirow{2}{*}{$\mathrm{mCA}$} & Mean & 189.6 & 167.2 & 166.3 & \multirow{2}{*}{0.572} & \\
\hline & $(+/-)$ & 24.2 & 14.5 & 11.3 & & \\
\hline \multirow{2}{*}{ MCA } & Mean & 327.1 & 291.1 & 289.9 & \multirow{2}{*}{0.326} & \\
\hline & $(+/-)$ & 30.0 & 15.1 & 12.3 & & \\
\hline \multirow{2}{*}{$\mathrm{U} \%$} & Mean & 55.4 & 55.5 & 56.3 & \multirow{2}{*}{0.958} & \\
\hline & $(+/-)$ & 3.0 & 2.5 & 2.1 & & \\
\hline
\end{tabular}




\begin{tabular}{|c|c|c|c|c|c|c|}
\hline \multicolumn{2}{|l|}{ B } & \multicolumn{3}{|c|}{ OPI Group } & \multicolumn{2}{|c|}{ ANOVA } \\
\hline \multicolumn{2}{|c|}{ Airway Variable } & $\begin{array}{c}\text { Flat } \\
(\mathrm{n}=13)\end{array}$ & $\begin{array}{l}\text { Optimal } \\
(\mathrm{n}=52)\end{array}$ & $\begin{array}{c}\text { Steep } \\
(\mathrm{n}=21)\end{array}$ & P-Value & Significance \\
\hline \multirow{2}{*}{ AV } & Mean & 19359.9 & 21771.8 & 19226.2 & \multirow{2}{*}{0.252} & \\
\hline & $(+/-)$ & 2045.2 & 1050.9 & 700.6 & & \\
\hline \multirow{2}{*}{$\mathrm{AL}$} & Mean & 68.9 & 69.3 & 69.8 & \multirow{2}{*}{0.885} & \\
\hline & $(+/-)$ & 2.0 & 0.7 & 1.1 & & \\
\hline \multirow{2}{*}{$\mathrm{mCA}$} & Mean & 164.1 & 181.6 & 153.5 & \multirow{2}{*}{0.408} & \\
\hline & $(+/-)$ & 22.9 & 12.9 & 12.0 & & \\
\hline \multirow{2}{*}{ MCA } & Mean & 277.7 & 314.0 & 275.2 & \multirow{2}{*}{0.199} & \\
\hline & $(+/-)$ & 24.6 & 15.2 & 8.9 & & \\
\hline \multirow{2}{*}{$\mathrm{U} \%$} & Mean & 57.1 & 55.8 & 54.9 & \multirow{2}{*}{0.904} & \\
\hline & $(+/-)$ & 4.4 & 1.8 & 2.9 & & \\
\hline
\end{tabular}

Figure 27. OPI Group Comparison for AV and MCA
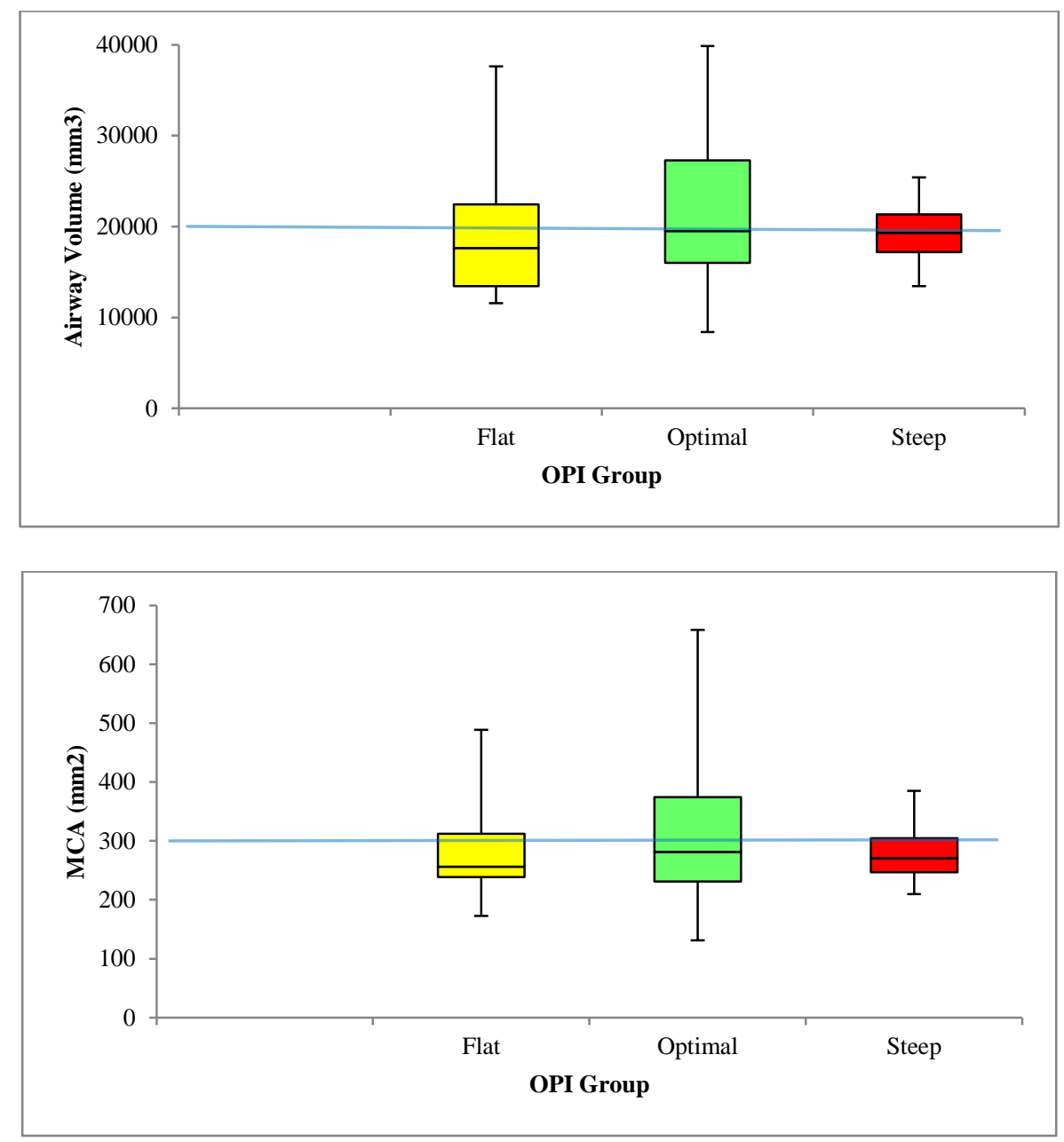


\section{Pogonion Prominence}

$\mathrm{H}_{0}$ : There are no significant differences in airway dimensions among the groups for hard tissue pogonion prominence (Pog or EPP) in this sample of untreated young adult orthodontic patients.

Using one-way ANOVA testing, there were no significant differences in any airway variables for Pog or EPP groups (Table 8). Figure 28 illustrates variations in airway volume in the EPP groups with box-and-whisker plots of minimum, maximum, median, and middle quartiles (50\%), but none of the apparent differences were statistically significant $(p>0.05)$.

Based on these results, the null hypothesis for hard tissue pogonion prominence is accepted. There are no significant differences in airway dimensions among groups for Pog or EPP in this sample of untreated young adults.

Table 8. Means and ANOVA Results for Pog (A) and EPP (B)

\begin{tabular}{|c|c|c|c|c|c|c|}
\hline \multicolumn{2}{|c|}{$\mathbf{A}$} & \multicolumn{3}{|c|}{ Pog Group } & \multicolumn{2}{|c|}{ ANOVA } \\
\hline \multicolumn{2}{|c|}{ Airway Variable } & $\begin{array}{c}\text { Deficient } \\
(\mathrm{n}=12)\end{array}$ & $\begin{array}{l}\text { Optimal } \\
(\mathrm{n}=45)\end{array}$ & $\begin{array}{c}\text { Excessive } \\
(\mathrm{n}=29)\end{array}$ & P-Value & Significance \\
\hline \multirow{2}{*}{ AV } & Mean & 22198.7 & 19527.1 & 22153.7 & \multirow{2}{*}{0.199} & \\
\hline & $(+/-)$ & 1857.3 & 947.2 & 1374.6 & & \\
\hline \multirow{2}{*}{$\mathrm{AL}$} & Mean & 71.1 & 68.8 & 69.4 & \multirow{2}{*}{0.429} & \\
\hline & $(+/-)$ & 1.7 & 0.7 & 1.1 & & \\
\hline \multirow{2}{*}{$\mathrm{mCA}$} & Mean & 176.7 & 162.6 & 184.9 & \multirow{2}{*}{0.530} & \\
\hline & $(+/-)$ & 24.5 & 11.0 & 18.2 & & \\
\hline \multirow{2}{*}{ MCA } & Mean & 312.3 & 283.1 & 318.3 & \multirow{2}{*}{0.266} & \\
\hline & $(+/-)$ & 24.6 & 13.7 & 19.2 & & \\
\hline \multirow{2}{*}{$\mathrm{U} \%$} & Mean & 54.5 & 56.4 & 55.4 & \multirow{2}{*}{0.887} & \\
\hline & $(+/-)$ & 3.8 & 2.0 & 2.5 & & \\
\hline
\end{tabular}




\begin{tabular}{|c|c|c|c|c|c|c|c|}
\hline \multicolumn{2}{|c|}{ B } & \multicolumn{4}{|c|}{ EPP Group } & \multicolumn{2}{|c|}{ ANOVA } \\
\hline \multicolumn{2}{|c|}{ Airway Variable } & $\begin{array}{l}\text { Sev. Retrusive } \\
\qquad(\mathrm{n}=10)\end{array}$ & $\begin{array}{l}\text { Retrusive } \\
(\mathrm{n}=32)\end{array}$ & $\begin{array}{l}\text { Optimal } \\
(\mathrm{n}=35)\end{array}$ & $\begin{array}{c}\text { Protrusive } \\
(\mathrm{n}=9)\end{array}$ & P-Value & Significance \\
\hline \multirow{2}{*}{$\mathrm{AV}$} & Mean & 18423.2 & 21029.2 & 21125.3 & 21223.3 & \multirow{2}{*}{0.718} & \\
\hline & $(+/-)$ & 1286.7 & 1114.8 & 1315.2 & 2391.9 & & \\
\hline \multirow{2}{*}{$\mathrm{AL}$} & Mean & 69.7 & 69.0 & 69.1 & 71.1 & \multirow{2}{*}{0.750} & \\
\hline & $(+/-)$ & 1.8 & 1.0 & 0.8 & 1.8 & & \\
\hline \multirow{2}{*}{$\mathrm{mCA}$} & Mean & 152.1 & 176.4 & 173.5 & 173.5 & \multirow{2}{*}{0.886} & \\
\hline & $(+/-)$ & 15.4 & 14.1 & 16.3 & 28.2 & & \\
\hline \multirow{2}{*}{ MCA } & Mean & 263.0 & 306.2 & 303.6 & 295.8 & \multirow{2}{*}{0.646} & \\
\hline & $(+/-)$ & 14.0 & 17.1 & 17.9 & 31.2 & & \\
\hline \multirow{2}{*}{$\mathrm{U} \%$} & Mean & 56.8 & 56.0 & 55.0 & 56.9 & \multirow{2}{*}{0.969} & \\
\hline & $(+/-)$ & 3.7 & 2.2 & 2.5 & 4.6 & & \\
\hline
\end{tabular}

Figure 28. EPP Group Comparison for Airway Volume (AV)

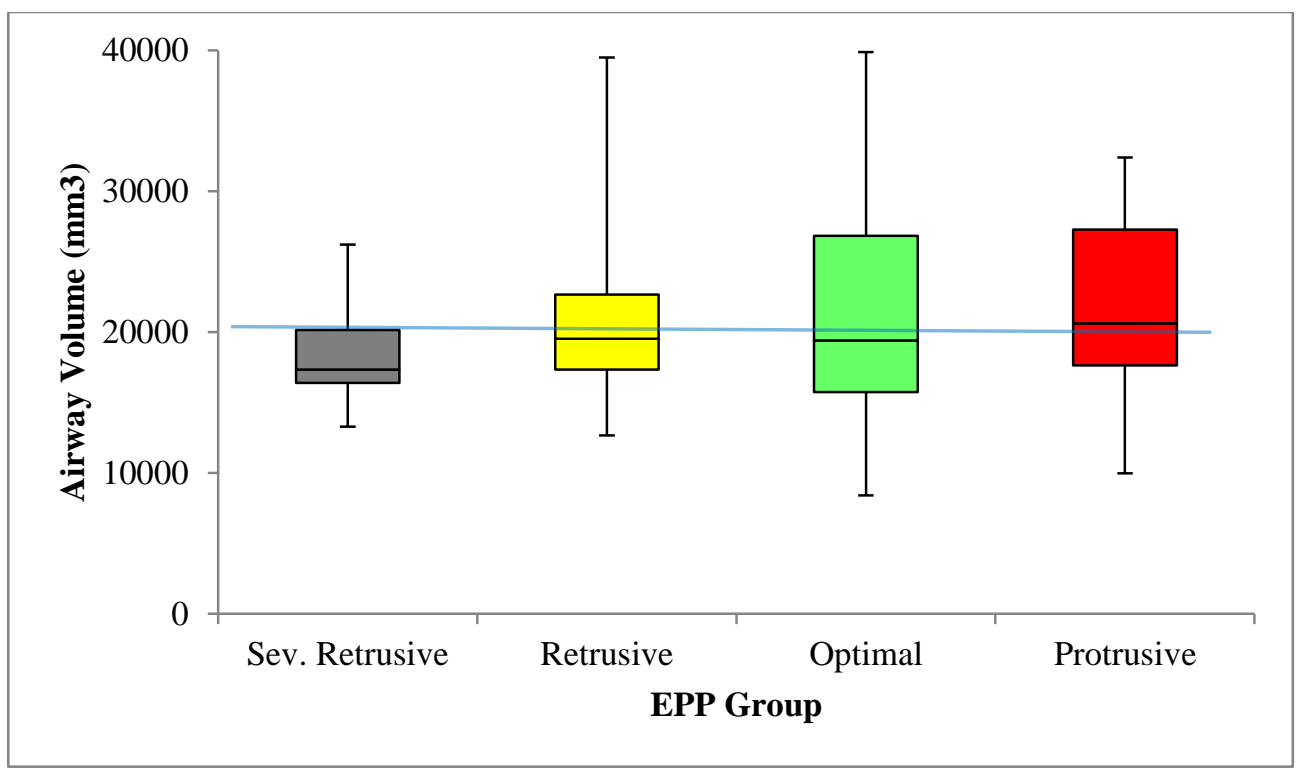




\section{Experimental vs. Control}

$\mathrm{H}_{0}$ : There are no significant differences in airway dimensions between corresponding Six Element groups and control groups in this sample of untreated young adult orthodontic patients.

None of the control craniofacial variables showed significant differences between groups utilizing one-way ANOVA testing (see Table 9). This was also true for all Six Element craniofacial variables, with the exception of Mx-GALL. Thus, there was a significant difference in airway dimensions between Mx-GALL and its corresponding cephalometric control group, SNA. These differences occurred in airway volume (AV) and mean cross-sectional area (MCA). Figure 29 shows adjacent box-and-whisker plots for Mx-GALL and SNA groups.

Based on these results, the null hypothesis for Six Elements groups versus control groups is rejected. There are significant differences in airway dimensions between groups for MxGALL and SNA in this sample of untreated young adults.

Table 9. Statistical Results for Experimental (A) and Control (B) Craniofacial Variables

\section{A}

\begin{tabular}{|c|c|c|c|c|c|c|c|}
\hline \multirow{2}{*}{$\begin{array}{c}\text { Airway } \\
\text { Variable }\end{array}$} & \multicolumn{6}{|c|}{ Craniofacial Experimental Variables ANOVA Results (P-Values) } \\
\cline { 2 - 8 } & Mx-GALL & Md-GALL & Mx-Md & MPI & OPI & Pog & EPP \\
\hline AV & 0.011 & 0.190 & 0.087 & 0.445 & 0.252 & 0.199 & 0.718 \\
\hline AL & 0.178 & 0.732 & 0.084 & 0.990 & 0.885 & 0.429 & 0.750 \\
\hline mCA & 0.148 & 0.174 & 0.126 & 0.572 & 0.408 & 0.530 & 0.886 \\
\hline MCA & 0.023 & 0.099 & 0.101 & 0.326 & 0.199 & 0.266 & 0.646 \\
\hline U\% & 0.447 & 0.756 & 0.524 & 0.958 & 0.904 & 0.887 & 0.969 \\
\hline
\end{tabular}




\begin{tabular}{|c|c|c|c|c|c|c|}
\hline \multirow{2}{*}{$\begin{array}{c}\text { Airway } \\
\text { Variable }\end{array}$} & \multicolumn{6}{|c|}{ Craniofacial Control Variables ANOVA Results (P-Values) } \\
\cline { 2 - 7 } & SNA & SNB & ANB & MP-SN & OP-SN & NAP \\
\hline AV & 0.898 & 0.140 & 0.067 & 0.987 & 0.322 & 0.233 \\
\hline AL & 0.613 & 0.198 & 0.124 & 0.062 & 0.307 & 0.222 \\
\hline mCA & 0.847 & 0.204 & 0.174 & 0.835 & 0.086 & 0.534 \\
\hline MCA & 0.742 & 0.152 & 0.102 & 0.813 & 0.192 & 0.346 \\
\hline U\% & 0.317 & 0.726 & 0.267 & 0.978 & 0.157 & 0.617 \\
\hline
\end{tabular}

*TABLE NOTE*

Green fill and number indicates statistically significant differences (Mx-GALL). Green number only indicates sub-statistical trends.

Figure 29. Comparison of Mx-GALL (left) and SNA (right) Groups for AV and MCA
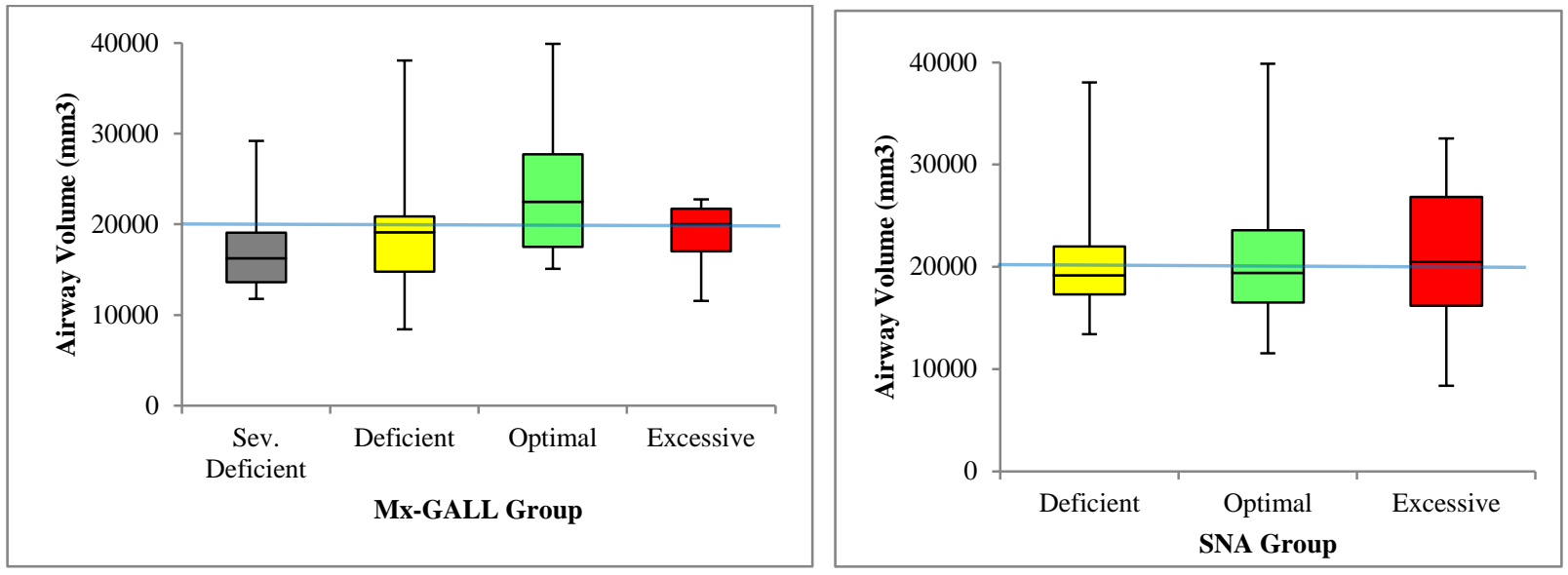

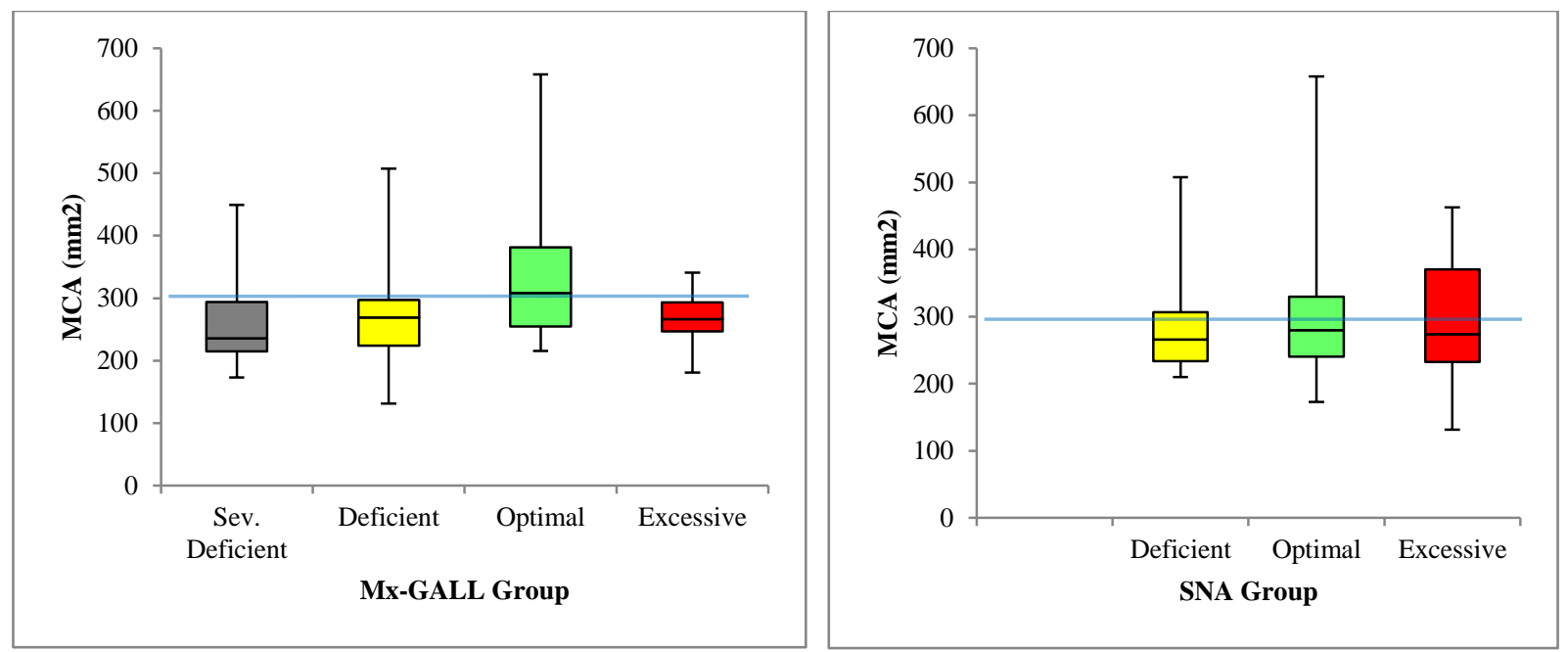

\section{Reliability of Measurements}

Because one examiner conducted all 3D airway measurement in this study, a reliability test was performed to determine the repeatability of the measures made for the airway variables in this study. A random sample of ten subjects had the airway data collection process repeated four weeks after the first assessment. The results displayed a reliability coefficient of 0.99 for $\mathrm{AV}, \mathrm{AL}$, and mCA. Therefore, the data collected in this study is considered reliable and consistent. 


\section{CHAPTER 5: DISCUSSION}

\section{Data Collection and Sample Analysis}

It should be noted that CBCT images taken from prospective orthodontic patients is not a particularly useful diagnostic tool for OSA. Such a diagnosis requires a PSG study and imaging such as supine live-motion MRI. Subjects in this study have had CBCT scans while seated upright and awake, two factors that change the airway drastically compared to sleeping. Furthermore, as noted in the limitations, the pharyngeal airway is a dynamic structure, and the actions of the breathing and swallowing as well as normal muscle tone can lead to inherently variable airway measurements from CBCT scans that only represent a snapshot of the subjects' anatomical motion. While CBCT scans have their issues, they are becoming more prevalent as readily available records for dental professionals, and a volumetric analysis of the pharyngeal airway in prospective orthodontic patients can provide a wealth of information for comparison in individuals and within a population of similar patients.

The sample size in this study was limited to ages 18-30 with the goal of having consistent airway size and shape in all subjects. The scatter plots in Figure 19 show very consistent, level relationships between age of the subject and airway volume $\left(\mathrm{R}^{2}=0.0028\right)$, and age of the subject and mean cross-sectional area $\left(\mathrm{R}^{2}=0.0081\right)$. Therefore, airway differences between craniofacial groups cannot be attributed to age discrepancies. This is a useful sample group because it represents highly motivated adult orthodontic patients that have essentially completed growth and could be candidates for orthognathic or telegnathic surgery.

Females greatly outnumbered males in this study population, which correlates well with the overall population of adults seeking orthodontic treatment. Males are reported in the 
literature to have, on average, larger and longer airways, and may have more predispositions to obstructive sleep apnea at later ages. However, in this sample of men and women 18-30, males had only slightly higher airway volume (Figure 30 ) and length, not enough to produce a statistically significant difference. Thus, this sample of males and females can be grouped together by craniofacial variables without significantly impacting group averages.

Figure 30. Airway Volume in Males $(n=18)$ and Females $(n=68)$

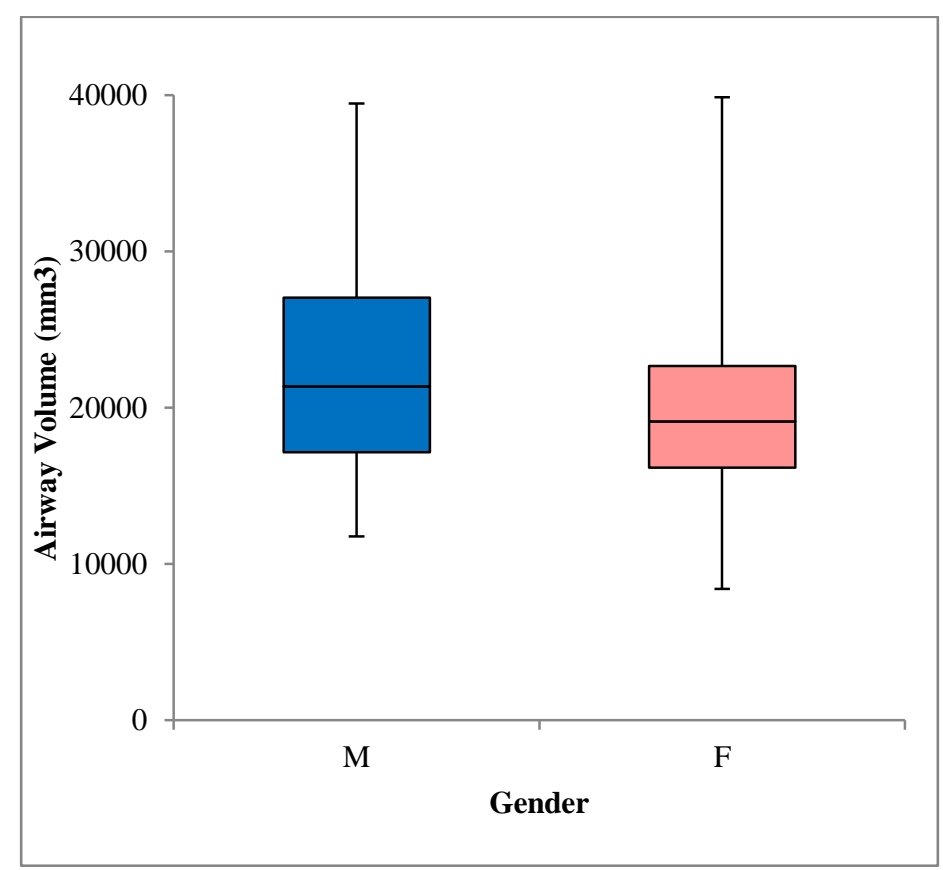




\section{Hypothesis Testing}

\section{Summary of Results}

1. $\quad \boldsymbol{R E J E C T E D : ~ T h e r e ~ a r e ~ n o ~ s i g n i f i c a n t ~ d i f f e r e n c e s ~ i n ~ a i r w a y ~ d i m e n s i o n s ~ a m o n g ~}$ the four anteroposterior groups for the position of the maxilla relative to GALL (Severely Deficient, Deficient, Optimal, Excessive) in this sample of untreated young adult orthodontic patients.

2. ACCEPTED: There are no significant differences in airway dimensions among the four anteroposterior groups for the position of the mandible relative to GALL (Severely Deficient, Deficient, Optimal, Excessive) in this sample of untreated young adult orthodontic patients.

3. ACCEPTED: There are no significant differences in airway dimensions among the four anteroposterior groups for inter-jaw relationship (Category I, Category II, Category II - Severe, Category III) in this sample of untreated young adult orthodontic patients.

4. ACCEPTED: There are no significant differences in airway dimensions among the groups for the vertical inclination of the jaws relative to GALL (MPI and OPI) in this sample of untreated young adult orthodontic patients.

5. ACCEPTED: There are no significant differences in airway dimensions among the groups for skeletal pogonion prominence (Pog or EPP) in this sample of untreated young adult orthodontic patients.

6. $\quad$ REJECTED: There are no significant differences in airway dimensions between corresponding Six Element groups and control groups in this sample of untreated young adult orthodontic patients. 


\section{Position of the Maxilla Relative to GALL}

The differences found in airway volume and mean cross-sectional area when the maxilla was optimally positioned relative to GALL were statistically significant compared to all other groups. These findings indicate that the anteroposterior position of the maxilla has a greater correlation with airway size and shape than any other craniofacial variable investigated in this study.

As shown in Figure 29, groups of subjects divided by SNA did not have a significant difference in airway size and shape. One of the biggest drawbacks of using SNA to classify the AP position of the maxilla, other than inconsistency of locating point $\mathrm{A}$, is the variability of inclination of the anterior cranial base from a plane perpendicular to GALL (SNI). This study measured SNI for each subject and found an average inclination of 10.3 degrees, and a range from -2.2 to 16.7 degrees. Two subjects in this study had an optimally positioned maxilla relative to GALL, yet, solely due to differences in SNI, had SNA values of 77 and 89, placing them in deficient and excessive SNA groups, respectively. This inherent variability explains the lack of correlation between Six Elements and control groups and underscores the importance of accurate jaw classification.

In management of OSA, it is critical to evaluate the location of the minimum crosssectional area (mCA) in patients that have smaller or thinner airways. By separating out only subjects with an airway volume of less the $17000 \mathrm{~mm}^{3}$, which amounts to the bottom $30 \%$ of the sample, this study was able to show an increase in the percentage of velopharyngeal constrictions when compared to all subjects (Figure 31). 
Figure 31. Constriction Location in Smaller Airways

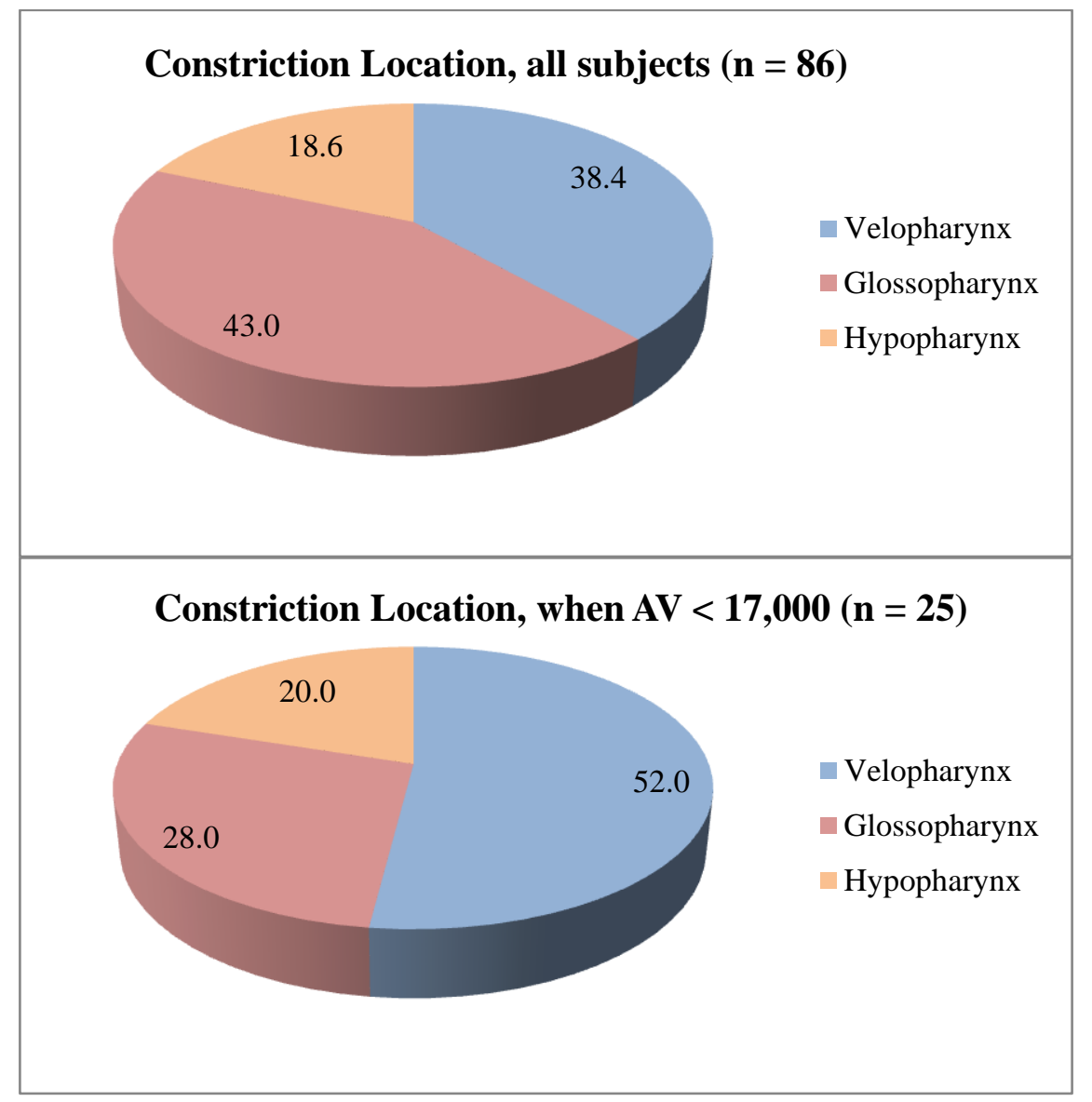

The increased prevalence of velopharyngeal constrictions in subjects with smaller airways likely corresponds with the effect of AP position of the maxilla that is not optimal. Subjects with deficient and severely deficient maxilla positions may not have adequate space posterior to the soft palate and may become more prone to airway collapsibility with aging and weight gain.

\section{Experimental vs. Control Variables}

In previous studies using $\mathrm{CBCT}$, Class II hyperdivergent patients were shown to have decreased airway dimensions. This suggests that ANB and MP-SN are variables that should 
show a significant difference between groups. In this study, there existed a similar trend with these variables, however p-values were between 0.1 and 0.05 (see Table 9) and were thus presented as a sub-significant trend. The most likely reasoning for these results is the limited age range and sample size of this investigation. It is probable that increasing the number of subjects would yield significant differences for ANB and MP-SN, which would support existing research in this field. Sub-significant trends were also found for the experimental Mx-Md groups, so it is apparent that inter-jaw relationship or craniofacial skeletal pattern is correlated to pharyngeal airway dimensions.

This study does not aim to conclude that the experimental Six Elements variables outperform or should replace traditional cephalometric measurements. Rather, it is apparent that additional information about the relationship of jaw position and the pharyngeal airway can be determined using the Six Elements approach, particularly with respect to the AP position of the maxilla. Having a reliable, patient-customized landmark such as the GALL line as a target for surgical procedures is more practical than attempting correction based on normative values for angular measurements. Since it has been established that the GALL is an excellent esthetic landmark for the position of the maxilla, this research suggests that it can also become a functional landmark that could mitigate poor esthetic results from telegnathic MMA procedures to treat OSA.

\section{Subjects with Symptoms of OSA}

Three subjects in this study had a medical history that consisted of symptoms of obstructive sleep apnea, and one subject underwent MMA surgery as a treatment for OSA. Although no subjects underwent a sleep study, and there was not a significant sample size for 
statistical analysis, all three subjects showed similar trends in certain variables. All had deficient or severely deficient Mx-GALL measurements, and average airway dimensions well below the population average noted in Table 3. These three subjects had, on average, smaller than average airway volume $\left(17026 \mathrm{~mm}^{3}\right)$, longer than average airway length $(72.7 \mathrm{~mm}), \mathrm{mCA}$ of $103.1 \mathrm{~mm}^{2}$, MCA of $234.3 \mathrm{~mm}^{2}$, and a uniformity percentage of 44.2 . These trends anecdotally support the measurement of airway dimensions utilizing CBCT and their relationship to airway collapsibility. Interestingly, one subject that had surgical intervention (Figure 32) and displayed drastic improvement in airway size and shape after increasing Mx-GALL from -9 to -1 and MdGALL from -12 to -3 .

\section{Figure 32. Subject \#196, Before (A, C) and After (B, D) MMA Procedure}
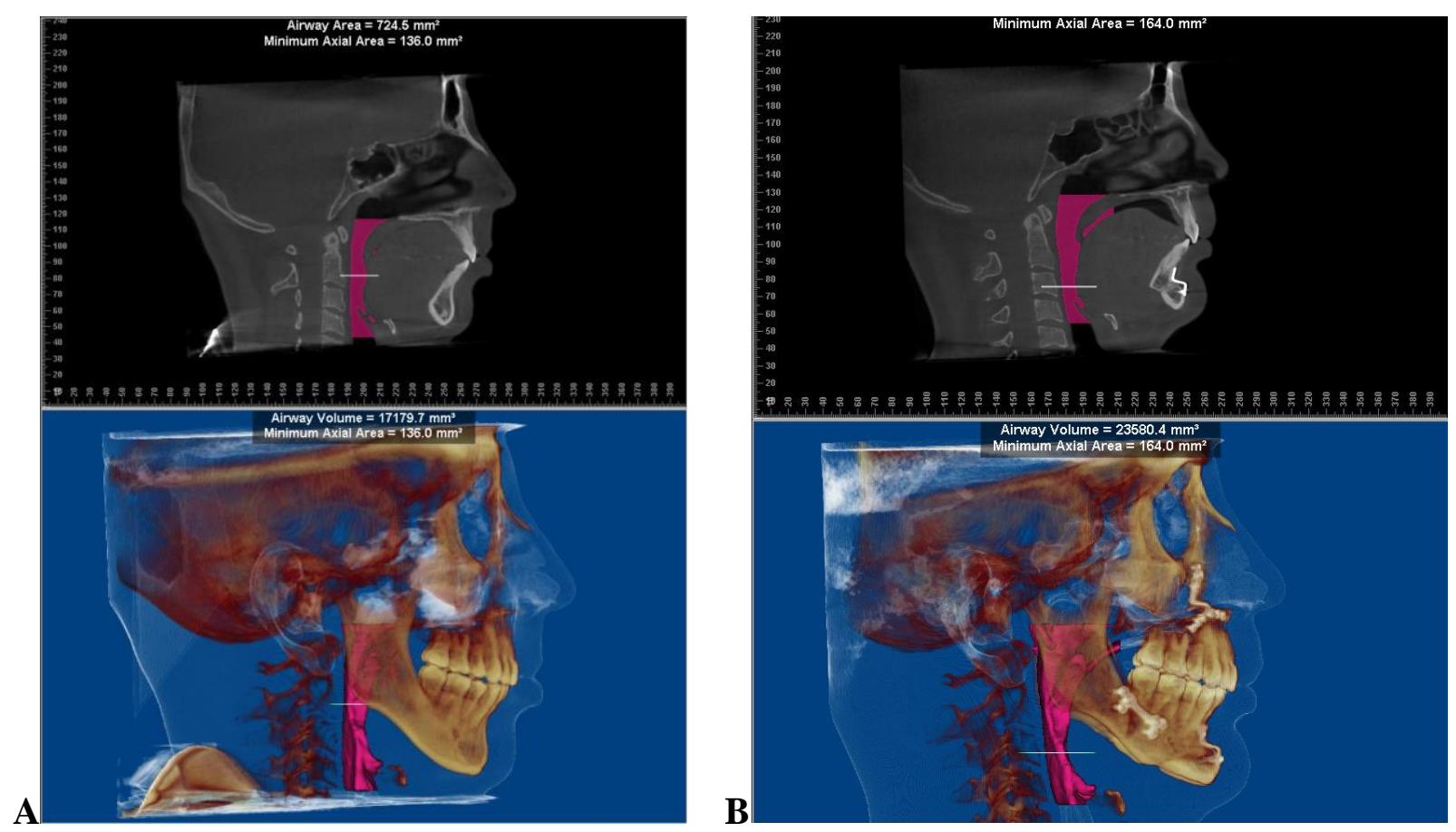

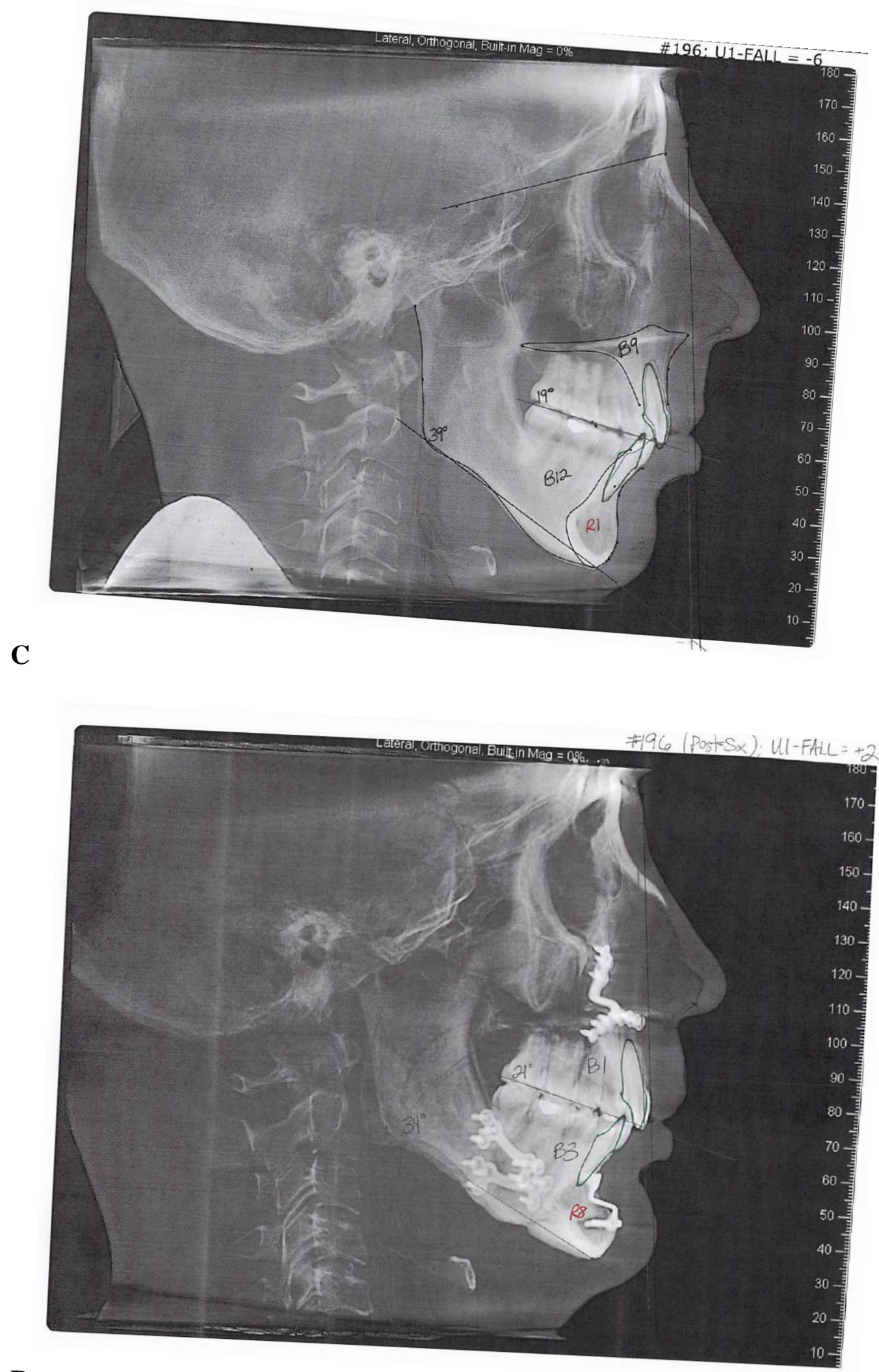

D 


\section{Clinical Implications}

The strong correlation between an optimally positioned maxilla relative to GALL and increased airway dimensions elucidated in this study has significant clinical implications, primarily in surgical treatment planning. An adult patient with a skeletal Class II pattern as well as a deficient maxilla may benefit much more from a double-jaw advancement procedure (MMA) using the GALL line as a landmark, than from a one-jaw mandibular advancement to match the deficient maxillary position. This potential benefit would not only be esthetic, but also functional in terms of airway dimensions that gradually shrink in adults. In obstructive sleep apnea patients that cannot tolerate CPAP and for whom MMA is a viable treatment option, surgeons now have a defendable landmark in the GALL for optimized advancement of the maxillomandibular complex during orthognathic and telegnathic surgery.

While the findings of this study should not be taken as predictive for other age groups, careful attention should be paid to the potential influence on the airway when treatment planning adolescents for extractions or orthopedic appliances that would restrict forward growth of the maxilla. More research is absolutely indicated in this area. 


\section{CHAPTER 6: SUMMARY AND CONCLUSIONS}

\section{Summary}

The specific aim of this study was to utilize cone-beam computed tomography to investigate pharyngeal airway morphology relative to various AP jaw positions as described by

Element II. Secondarily, the investigators wanted to explore maxilla-mandibular vertical inclination and hard tissue pogonion prominence, and compare these craniofacial variables with established cephalometric controls from existing literature. The final 86 subjects used in this study represent an unbiased sample, as it is composed of every CBCT scan available from Dr. Shipley's i-CAT database that met the inclusion and exclusion criteria. 3D airway measurements were recorded after precise head orientation and 2D cephalometric tracing was used to divide subjects into groups based on each craniofacial variable. Statistical analysis was performed for all groups, and the only craniofacial variable showing statistically significant differences between groups was Mx-GALL. This finding, confirmed with post-hoc group analysis, led the investigator to reject the null hypothesis that there are no significant differences in airway dimensions among the four anteroposterior groups for the position of the maxilla relative to GALL in this sample of untreated young adult orthodontic patients. This study has also shown a significant difference between Mx-GALL and SNA for classifying the position of the maxilla and its relationship to pharyngeal airway morphology. 


\section{Conclusions}

Based on the results of this study, the following conclusions have been reached:

- The anteroposterior position of the maxilla relative to GALL has a significant correlation with pharyngeal airway size and shape.

- Subjects with an optimally positioned maxilla had airways with a significantly higher volume and larger average axial area than subjects in every other group for maxillary position.

- This is a novel and clinically relevant finding that can have a significant influence on surgical and non-surgical treatment planning.

- No other craniofacial variable has a statistically significant correlation with pharyngeal airway size and shape. 


\section{CHAPTER 7: RECOMMENDATIONS FOR FUTURE RESEARCH}

\section{Large-Scale Reproduction of This Study}

The novel and clinically relevant findings of this study warrant future research in this area. This study should be repeated with a larger sample size, and could include adolescents and older adults, provided subjects are age-matched and grouped accordingly to account for agerelated changes to the airway. The largest obstacle to large-scale studies with this experiment design and methods is the U1-FALL judgment, which is typically limited to the clinical setting of Six Elements orthodontists. As an alternative, prospective subjects should be positioned in adjusted natural head position and a LASER-generated horizontal plane can be traced clinically with three radiopaque markers prior to imaging with $\mathrm{CBCT}$. This would not only expand the potential pool of CBCT databases, but it would allow extremely accurate and unbiased CBCT head orientation and the GALL line could be consistently constructed by dropping a vertical plane at glabella. A larger scale study would also allow multivariate analysis of several craniofacial variable groups in combination and refine the relationship between jaw position and airway dimensions.

\section{OSA Patients and Craniofacial Variables}

A more robust recommendation for future research would need to include collaboration from a sleep physician and sleep laboratory, and would involve recruiting subjects with diagnosed OSA and comparing craniofacial Six Elements variables of this group to a group of non-OSA controls. If MMA surgery was indicated and performed, pre- and post-treatment comparisons could be made for craniofacial variables that changed or improved towards optimal. 


\section{REFERENCES}

1. Maxillomandibular Expansion and Advacement for the Treatment of Sleep-Disordered Breathing in Children and Adults. Holty, Jon-Erik C and Guilleminault, Christian. 2012, Seminars in Orthodontics, pp. 162-170.

2. Three-dimensional upper-airway changes with maxillomandibular advancement for obstructive sleep apnea treatment. Schendel, Stephen A, Broujerdi, Joseph A and

Jacobson, Richard L. 2014, Am J Orthod Dentofacial Orthop, pp. 385-393.

3. Primary and Secondary Telegnathic Maxillomandibular Advancement, With or Without Adjunctive Procedures, for Obstructive Sleep Apnea in Adults: A Literature Review and Treatment Recommendations. Prinsell, Jeffrey R. 2012, J Oral Maxillofac Surg, pp. 1659-1677.

4. AP relationship of the maxillary central incisors to the forehead in adult white females.

Andrews, Will A. 2008, Angle Orthod, pp. 662-669.

5. The effects of computer-aided anteroposterior maxillary incisor movement on ratings of facial attractiveness. Schlosser, JB, Preston, CD and Lampasso, J. 2005, Am J Orthod Dentofacial Orthop, pp. 17-24.

6. Melvin L. Moss and the functional matrix. Moss-Salentijn, L. 1997, J Dent Res, Vol. 76, pp. 1814-1817.

7. Respiratory function in relation to facial morphology and the dentition. Linder-Aronson, $\mathbf{S}$. 1979, Br J Orthod, Vol. 6, pp. 59-71.

8. Influence of respiratory pattern on craniofacial growth. McNamara, J. 1981, Angle Orthod, Vol. 51, pp. 269-300.

9. Lavigne, Gilles J, Cistulli, Peter A and Smith, Michael T. Sleep Medicine for Dentists. Hanover Park : Quintessence Publishing Co, 2009.

10. Sleep disorders and their classification - an overview. Levy, P, Viot-Blanc, V and Pepin, J. 2006, Progress in Respiratory Research, Vol. 35, pp. 1-12.

11. Three-dimensional cone beam computed tomography definition of the anatomical subregions of the upper airway: a validation study. Guijarro-Martinez, R and Swennen, GRJ. 2013, Int J Oral Maxillofac Surg, Vol. 42, pp. 1140-1149.

12. Use of 3-dimensional computed tomograph scan to evaluate upper airway patency for 
patients undergoing sleep-disordered breathing surgery. Li, Hseuh-Yu, et al. 129, 2003, Otolaryngol Head Neck Surg, pp. 336-342.

13. Airway Growth and Development: A Computerized 3-Dimensional Analysis. Schendel, $\mathbf{S}$, Jacobson, R and Khalessi, S. 2012, J Oral Maxillofac Surg, Vol. 70, pp. 2174-2183.

14. Gender- and age-based differences in computerized tomographic measurements of the oropharynx. Shigeta, Y, et al. 2008, Oral Surg Oral Med Oral Pathol Oral Radiol Endod, Vol. 106, pp. 563-70.

15. Postsurgical volumetric airway changes in 2-jaw orthognathic surgery patients. Hart, $\mathbf{P}$. Sheamus, et al. 147, 2015, Am J Orthod Dentofacial Orthop, pp. 536-546.

16. Evaluation of the human airway using cone-beam computerized tomography. Tso, HH, et al. 5, 2009, Oral Surg Oral Med Oral Pathol Oral Radiol Endod, Vol. 108, pp. 768-776.

17. Cone-beam computerized tomography imaging and analysis of the upper airway: a systematic review of the literature. Guijarro-Martinez, R and Swennen, GRJ. 2011, Int J Oral Maxillofac Surg, Vol. 40, pp. 1227-1237.

18. Reliability of upper airway linear, area, and volumetric measurements in cone-beam computed tomography. Mattos, CT, et al. 2014, Am J Orthod Dentofacial Orthop, Vol. 145, pp. 188-97.

19. Comparison of cone-beam CT parameters and sleep questionnaires in sleep apnea patients and control subjects. Enciso, R, et al. 2, 2010, Oral Surg Oral Med Oral Pathol Oral Radiol Endod, Vol. 109, pp. 285-293.

20. Three-Dimensional Computed Tomographic Analysis of Airway Anatomy in Patients with Obstructive Sleep Apnea. Abramson, Z, et al. 2010, J Oral Maxillofac Surg, Vol. 68, pp. 354-362.

21. Correlation between severity of sleep apnea and upper airway morphology based on advanced anatomical and functional imaging. Vos, W, et al. 2007, J Biomech, Vol. 40, pp. 2207-2213.

22. Three-dimensional analysis of pharyngeal airway in preadolescent children with different anteroposterior skeletal patterns. Kim, YJ, et al. 2010, Am J Orthod Dentofacial Orthop, Vol. 137, pp. 306.e1-306.e11.

23. An airway study of different maxillary and mandibular sagittal positions. El, $\mathbf{H}$ and Palomo, 
JM. 2, 2011, Europ J Orthod, Vol. 35, pp. 262-270.

24. Pharyngeal airway characterization in adolescents related to facial skeletal pattern: A preliminary study. Claudino, LV, et al. 2013, Am J Orthod Dentofacial Orthop, Vol. 143, pp. 799-809.

25. A Comparison of Airway Dimensions among Different Skeletal Craniofacial Patterns.

Sparks, Ronnie J. s.l. : WVU Department of Orthodontics - unpublished research, 2012.

26. The "Wits" appraisal of jaw disharmony. Jacobson, A. 1975, Am J Orthod, Vol. 67, pp. 125138.

27. Analysis of factors affecting angle ANB. Hussels, W and Nanda, R. 1984, Am J Orthod, Vol. 85, pp. 411-423.

28. The use of linear and angluar measurements of maxillo-mandibular anteroposterior discrepancies. Ferrario, V, et al. 1999, Clin Orthod Res, Vol. 2, pp. 34-41.

29. The Six Elements of Orofacial Harmony. Andrews, LF. 2000, The Andrews J Orthod and Orofac Harmony, Vol. 1, pp. I-X.

30. Article 2: Six Element Diagnostic Record. Andrews, LF. 2001, The Andrews J Orthod and Orofac Harmony, Vol. 2, pp. 15-20.

31. Imaging software accuracy for 3-dimensional analysis of the upper airway. Weissheimer, A, et al. 2012, Am J Orthod Dentofacial Orthop, Vol. 142, pp. 801-13.

32. Three-dimensional airway evaluation in 387 subjects from one university orthodontic clinic using cone beam computed tomography. Chiang, CC, et al. 2012, Angle Orthod, Vol. 82, pp. 985-992.

33. Three-dimensional analysis of the airway with cone-beam computed tomography.

Stratemann, S, et al. 2011, Am J Orthod Dentofacial Orthop, Vol. 140, pp. 607-15.

34. Airway volume for different dentofacial skeletal patterns. El, H and Palomo, JM. 2011, Am J Orthod Dentofacial Orthop, Vol. 139, pp. e511-e521.

35. Head Orientation in CBCT-generated Cephalograms. Cevidanes, L, et al. 2009, Angle Orthod, Vol. 79, pp. 971-977.

36. Three-dimensional changes of the hyoid bone and airway volumes related to its relationship with horizontoal anatomic planes after bimaxillary surgery in skeletal Class III patients. Kim, MA, et al. 2013, Angle Orthod, Vol. 83, pp. 623-629. 
37. Precision of identifying cephalometric landmarks with cone beam computed tomography in vivo. Hassan, B, et al. 2013, Europ J Orthod, Vol. 35, pp. 38-44.

38. Predicting the Pharyngeal Airway Space After Mandibular Setback Surgery. Chen, F, et al. 2005, J Oral Maxillofac Surg, Vol. 63, pp. 1509-1514.

39. Evaluation of cross-section airway configuration of obstructive sleep apnea. Ogawa, T, Shintaku, WH and Clark, GT. 2007, Oral Surg Oral Med Oral Pathol Oral Radiol Endod, Vol. 103, pp. 102-8.

40. Andrews, LF. Straight Wire: The Concept and Appliance. San Diego : L.A. Wells Co., 1989. pp. 3-40. 


\title{
APPENDICES
}

\section{Appendix A - IRB Exemption}

\section{W. West VrginiaUniversity. \\ Office of Research Integrity and Compliance \\ 886 CHESNUT RIDGE ROAD MORGANTOWN, WV 25606}

\section{Acknowledgement Letter Exempt Initial Protocol Review}

\author{
Action Date \\ $12 / 07 / 2015$ \\ To \\ Timothy Tremont \\ From \\ WVU Office of Research Integrity and Compliance \\ Approval Date \\ $12 / 07 / 2015$ \\ Expiration Date \\ $12 / 06 / 2018$ \\ Subject \\ Acknowledgement Letter Exempt Initial Protocol Review \\ Protocol Number \\ 1506711157 \\ Title \\ Anteroposterior Jaw Position and Pharyngeal Airway Morphology in Young Adult \\ Patients: A CBCT Study
}

The above-referenced study was reviewed by the West Virginia University Institutional Review Board IRB and was granted exemption in accordance with 45 CFR 46.101.

- This research study was granted an exemption in accordance with Research on existing data, documents, records, pathological specimens, or diagnostic specimens [45 CFR 46.101(4)]. In accordance with the Health Insurance Portability and Accountability Act, a waiver of research authorization has been granted. Please fulfill the subject accounting requirements associated with the granting of this waiver. All exemptions are only good for three years. If this research extends more than three years beyond the approved date, then the researcher will have to request another exemption. The following documents have been acknowledged for use in this study and are available in the WVU+kc system:

Documents reviewed and/or approved as part of this submission:

HIPAA Waiver Form.docx: 2015-07-24-04:00

Letter of Permission to Conduct Research.pdf: 2015-07-24-04:00

List of Variables.JPG: 2015-11-16-05:00

Documents for use in this study have been acknowledged and are available in the WVUkc system in the Notes and Attachments section of your protocol. 
The Office of Research Integrity and Compliance is here to provide assistance to you from the initial submission of an IRB protocol and all subsequent activity. Please feel free to contact us by phone at 304.293.7073 with any question you may have. Thank you.

WVU Office of Research Integrity and Compliance

Date: $12 / 07 / 2015$

Signed:

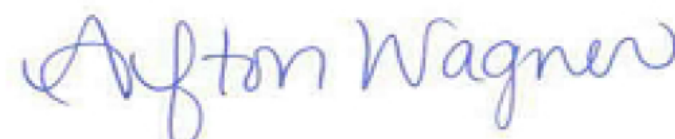

Afton Wagner IRB Administrator 


\section{Appendix B - Statistics}

Raw Data

Subject \# Age Gender U1-FALL Mx-GALL Md-GALL Mx-Md MPI OPI Pog EPP SNA SNB

ANB MP-SN OP-SN NAP AV AL mCA MCA U\% Location of Constriction

\begin{tabular}{|c|c|c|c|c|c|c|c|c|c|c|}
\hline \multirow[t]{2}{*}{104} & 18 & $\mathrm{~F}$ & -4 & -8 & $-4 \quad-4$ & 22 & 4 & 3 & $-1 \quad 81$ & 84 \\
\hline & -3 & 27 & 9 & 193 & 29180.465 .0 & 212.9 & 448.9 & 47.4 & \multicolumn{2}{|c|}{ Hypopharynx (HP) } \\
\hline \multirow[t]{2}{*}{113} & 18 & $\mathrm{~F}$ & 3 & 0 & $-1 \quad 1$ & 29 & 4 & 0 & $-1 \quad 82$ & 80 \\
\hline & 2 & 39 & 11 & 178 & 15164.669 .0 & 82.3 & 219.8 & 37.4 & \multicolumn{2}{|c|}{ Glossopharynx (GP) } \\
\hline \multirow[t]{2}{*}{117} & 18 & $\mathrm{~F}$ & 2 & -4 & $-10 \quad 6$ & 28 & 6 & 1 & $-9 \quad 79$ & 73 \\
\hline & 6 & 38 & 14 & 172 & 20615.868 .0 & 227.3 & 303.2 & 75.0 & \multicolumn{2}{|c|}{ Hypopharynx (HP) } \\
\hline \multirow[t]{2}{*}{121} & 18 & M & 2 & -3 & $-4 \quad 1$ & 33 & 11 & -1 & $-5 \quad 89$ & 83 \\
\hline & 6 & 38 & 15 & 168 & 21065.167 .0 & 217.6 & 314.4 & 69.2 & \multicolumn{2}{|c|}{ Glossopharynx (GP) } \\
\hline \multirow[t]{2}{*}{130} & 18 & $\mathrm{~F}$ & 7 & 3 & $-3 \quad 6$ & 31 & 11 & 0 & $-3 \quad 79$ & 71 \\
\hline & 9 & 48 & 28 & 163 & 19571.573 .0 & 149.6 & 268.1 & 55.8 & \multicolumn{2}{|c|}{ Glossopharynx (GP) } \\
\hline \multirow[t]{2}{*}{132} & 18 & $\mathrm{~F}$ & 4 & 0 & $\begin{array}{ll}-2 & 2\end{array}$ & 17 & 2 & 3 & $1 \quad 84$ & 82 \\
\hline & 2 & 26 & 9 & 180 & 28459.771 .0 & 271.5 & 400.8 & 67.7 & \multicolumn{2}{|c|}{ Velopharynx (VP) } \\
\hline \multirow[t]{2}{*}{134} & 18 & $\mathrm{~F}$ & 4 & -2 & $-6 \quad 4$ & 19 & 3 & 0 & $-6 \quad 82$ & 77 \\
\hline & 4 & 30 & 12 & 174 & 22508.570 .0 & 192.7 & 321.6 & 59.9 & \multicolumn{2}{|c|}{ Velopharynx (VP) } \\
\hline \multirow[t]{2}{*}{144} & 18 & M & 2 & -3 & $-10 \quad 7$ & 29 & 2 & -1 & $-11 \quad 81$ & 76 \\
\hline & 5 & 39 & 12 & 172 & 17134.068 .0 & 156.8 & 252.0 & 62.2 & \multicolumn{2}{|c|}{ Glossopharynx (GP) } \\
\hline \multirow[t]{2}{*}{109} & 19 & M & 4 & -1 & $-4 \quad 3$ & 21 & 4 & -1 & $-5 \quad 81$ & 77 \\
\hline & 4 & 34 & 15 & 172 & 39486.960 .0 & 369.0 & 658.1 & 56.1 & \multicolumn{2}{|c|}{ Hypopharynx (HP) } \\
\hline \multirow[t]{2}{*}{123} & 19 & $\mathrm{~F}$ & 4 & -2 & $-3 \quad 1$ & 22 & 4 & 2 & $-1 \quad 80$ & 77 \\
\hline & 3 & 34 & 15 & 178 & 17607.163 .0 & 169.4 & 279.5 & 60.6 & \multicolumn{2}{|c|}{ Velopharynx (VP) } \\
\hline \multirow[t]{2}{*}{135} & 19 & M & 0 & -7 & $\begin{array}{ll}-6 & -1\end{array}$ & 20 & 0 & 5 & $-1 \quad 79$ & 80 \\
\hline & -2 & 27 & 5 & 193 & 11758.068 .0 & 76.5 & 172.9 & 44.2 & \multicolumn{2}{|c|}{ Velopharynx (VP) } \\
\hline \multirow[t]{2}{*}{137} & 19 & $\mathrm{~F}$ & 2 & -1 & $-1 \quad 0$ & 23 & 5 & 0 & $-1 \quad 81$ & 78 \\
\hline & 3 & 35 & 21 & 177 & 19539.467 .0 & 196.4 & 291.6 & 67.3 & \multicolumn{2}{|c|}{ Glossopharynx (GP) } \\
\hline 142 & 19 & $\mathrm{~F}$ & 0 & -3 & $-3 \quad 0$ & 20 & 8 & 4 & $1 \quad 84$ & 81 \\
\hline & 3 & 29 & 14 & 179 & 21221.073 .0 & 160.3 & 290.7 & 55.1 & Glossophary & (GP) \\
\hline 155 & 19 & M & 5 & -3 & $-10 \quad 7$ & 15 & 1 & 6 & $-4 \quad 89$ & 82 \\
\hline & 6 & 20 & 5 & 176 & 20505.580 .0 & 82.9 & 256.3 & 32.3 & Velopharyn & VP) \\
\hline 118 & 20 & M & 6 & 1 & $-3 \quad 4$ & 22 & 1 & 0 & $\begin{array}{ll}-3 & 83\end{array}$ & 79 \\
\hline & 4 & 33 & 12 & 175 & 37607.777 .0 & 340.0 & 488.4 & 69.6 & Hypopharyn & (HP) \\
\hline 126 & 20 & $\mathrm{~F}$ & 8 & 3 & $-1 \quad 4$ & 27 & 1 & 2 & $1 \quad 84$ & 81 \\
\hline & 3 & 37 & 9 & 177 & 11569.964 .0 & 72.6 & 180.8 & 40.2 & Hypopharyn & (HP) \\
\hline 128 & 20 & $\mathrm{~F}$ & -4 & 2 & $\begin{array}{ll}3 & -1\end{array}$ & 22 & 3 & 5 & $8 \quad 84$ & 81 \\
\hline & 3 & 34 & 15 & 182 & 17756.169 .0 & 107.8 & 257.3 & 41.9 & Glossophary & (GP) \\
\hline 139 & 20 & $\mathrm{~F}$ & 4 & -1 & $\begin{array}{ll}-2 & 1\end{array}$ & 30 & 8 & -1 & $-3 \quad 82$ & 77 \\
\hline & 5 & 41 & 20 & 172 & 31991.667 .0 & 345.8 & 477.5 & 72.4 & Velopharyn & VP) \\
\hline 143 & 20 & $\mathrm{~F}$ & 4 & 1 & $-4 \quad 5$ & 29 & 6 & 2 & $\begin{array}{ll}-2 & 78\end{array}$ & 72 \\
\hline & 6 & 44 & 19 & 171 & 29353.177 .0 & 209.8 & 381.2 & 55.0 & Glossophary & (GP) \\
\hline 148 & 20 & $\mathrm{~F}$ & 0 & -3 & $\begin{array}{ll}-5 & 2\end{array}$ & 27 & 8 & 1 & $-4 \quad 92$ & 89 \\
\hline & 3 & 27 & 9 & 176 & 14779.166 .0 & 134.3 & 223.9 & 60.0 & Velopharyn & VP) \\
\hline
\end{tabular}




\begin{tabular}{|c|c|c|c|c|c|c|c|c|c|c|}
\hline \multirow[t]{2}{*}{149} & 20 & $\mathrm{~F}$ & 3 & 0 & -1 & 23 & 2 & 0 & 82 & 80 \\
\hline & 1 & 35 & 16 & 179 & 16517.261 .0 & 164.2 & 270.8 & 60.6 & \multicolumn{2}{|c|}{ Glossopharynx (GP) } \\
\hline \multirow[t]{2}{*}{151} & 20 & M & 8 & 1 & $-7 \quad 8$ & 30 & 4 & -2 & $-9 \quad 80$ & 73 \\
\hline & 7 & 44 & 18 & 167 & 26209.480 .0 & 170.5 & 327.6 & 52.0 & \multicolumn{2}{|c|}{ Glossopharynx (GP) } \\
\hline \multirow[t]{2}{*}{157} & 20 & $\mathrm{~F}$ & 4 & 0 & $0 \quad 0$ & 20 & 5 & 5 & $5 \quad 86$ & 83 \\
\hline & 3 & 29 & 10 & 179 & 27263.374 .0 & 255.0 & 368.4 & 69.2 & \multicolumn{2}{|c|}{ Glossopharynx (GP) } \\
\hline \multirow[t]{2}{*}{162} & 20 & $\mathrm{~F}$ & -4 & -7 & $\begin{array}{ll}-3 & -4\end{array}$ & 23 & 6 & 1 & $\begin{array}{ll}-2 & 82\end{array}$ & 82 \\
\hline & -1 & 32 & 15 & 183 & 13965.464 .0 & 120.4 & 218.2 & 55.2 & \multicolumn{2}{|c|}{ Glossopharynx (GP) } \\
\hline \multirow[t]{2}{*}{169} & 20 & $\mathrm{~F}$ & 3 & 0 & $0 \quad 0$ & 28 & 8 & -1 & $\begin{array}{ll}-1 & 79\end{array}$ & 76 \\
\hline & 3 & 42 & 22 & 173 & 15297.071 .0 & 93.8 & 215.5 & 43.5 & \multicolumn{2}{|c|}{ Velopharynx (VP) } \\
\hline \multirow[t]{2}{*}{120} & 21 & M & 7 & -1 & $-4 \quad 3$ & 28 & 5 & -2 & $-6 \quad 84$ & 80 \\
\hline & 4 & 36 & 12 & 173 & 25619.262 .0 & 261.1 & 413.2 & 63.2 & \multicolumn{2}{|c|}{ Hypopharynx (HP) } \\
\hline \multirow[t]{2}{*}{150} & 21 & $\mathrm{~F}$ & -5 & -9 & $-9 \quad 0$ & 20 & 6 & 5 & $-4 \quad 83$ & 83 \\
\hline & 1 & 27 & 13 & 183 & 19084.268 .0 & 141.5 & 280.7 & 50.4 & \multicolumn{2}{|c|}{ Hypopharynx (HP) } \\
\hline \multirow[t]{2}{*}{152} & 21 & $\mathrm{~F}$ & 0 & -4 & $0 \quad-4$ & 27 & 7 & 0 & $0 \quad 85$ & 84 \\
\hline & 1 & 35 & 15 & 178 & 10611.763 .0 & 63.3 & 168.4 & 37.6 & \multicolumn{2}{|c|}{ Velopharynx (VP) } \\
\hline \multirow[t]{2}{*}{153} & 21 & $\mathrm{~F}$ & 0 & -2 & $1 \quad-3$ & 24 & 6 & 3 & $4 \quad 88$ & 85 \\
\hline & 3 & 32 & 17 & 179 & 32405.570 .0 & 336.8 & 462.9 & 72.8 & \multicolumn{2}{|c|}{ Velopharynx (VP) } \\
\hline \multirow[t]{2}{*}{156} & 21 & $\mathrm{~F}$ & -4 & -7 & $-9 \quad 2$ & 32 & 10 & 0 & $-9 \quad 75$ & 72 \\
\hline & 4 & 46 & 20 & 174 & 13792.965 .0 & 107.8 & 212.2 & 50.8 & \multicolumn{2}{|c|}{ Velopharynx (VP) } \\
\hline 163 & 21 & $\mathrm{~F}$ & 7 & 2 & $-1 \quad 3$ & 27 & 3 & -2 & $\begin{array}{ll}-3 & 83\end{array}$ & 77 \\
\hline & 6 & 38 & 15 & 167 & 21811.864 .0 & 211.5 & 340.8 & 62.1 & Velopharyn & (P) \\
\hline 164 & 21 & $\mathrm{~F}$ & 2 & -1 & $-1 \quad 0$ & 32 & 11 & 0 & $\begin{array}{ll}-1 & 84\end{array}$ & 79 \\
\hline & 5 & 44 & 22 & 169 & 16520.561 .0 & 197.8 & 270.8 & 73.0 & Velopharyn & (P) \\
\hline 165 & 21 & M & -5 & -9 & $\begin{array}{ll}-5 & -4\end{array}$ & 30 & 13 & 0 & $-5 \quad 85$ & 84 \\
\hline & 1 & 34 & 17 & 177 & 16263.369 .0 & 127.6 & 235.7 & 54.1 & Glossophary & (GP) \\
\hline 166 & 21 & $\mathrm{~F}$ & -3 & -3 & $\begin{array}{ll}-5 & 2\end{array}$ & 24 & 4 & 4 & $-1 \quad 79$ & 76 \\
\hline & 3 & 36 & 18 & 179 & 19099.671 .0 & 145.2 & 269.0 & 54.0 & Glossophary & (GP) \\
\hline 180 & 21 & $\mathrm{~F}$ & 4 & 2 & $0 \quad 2$ & 32 & 10 & 0 & $0 \quad 79$ & 74 \\
\hline & 5 & 47 & 25 & 169 & 20423.277 .0 & 131.3 & 265.2 & 49.5 & Velopharyn & (P) \\
\hline 140 & 22 & $\mathrm{~F}$ & 4 & -4 & $0 \quad-4$ & 33 & 14 & 2 & $2 \quad 79$ & 77 \\
\hline & 2 & 44 & 26 & 177 & 21928.871 .0 & 189.3 & 308.9 & 61.3 & Glossophary & (GP) \\
\hline 159 & 22 & $\mathrm{~F}$ & -9 & -13 & $\begin{array}{ll}-6 & -7\end{array}$ & 30 & 1 & 2 & $-4 \quad 81$ & 86 \\
\hline & -5 & 32 & 5 & 197 & 13454.453 .0 & 86.6 & 253.9 & 34.1 & Glossophary & (GP) \\
\hline 160 & 22 & $\mathrm{~F}$ & -1 & -2 & $\begin{array}{ll}-5 & 3\end{array}$ & 26 & 4 & 3 & $-2 \quad 81$ & 77 \\
\hline & 4 & 37 & 15 & 178 & 17496.372 .0 & 129.3 & 243.0 & 53.2 & Velopharyn & JP) \\
\hline 167 & 22 & $\mathrm{~F}$ & 0 & -6 & $-9 \quad 3$ & 31 & 12 & -1 & $-10 \quad 86$ & 80 \\
\hline & 6 & 37 & 16 & 168 & 16133.159 .0 & 191.1 & 273.4 & 69.9 & Velopharyn & /P) \\
\hline 171 & 22 & $\mathrm{~F}$ & 0 & -1 & $\begin{array}{ll}-2 & 1\end{array}$ & 25 & 4 & 3 & $1 \quad 78$ & 76 \\
\hline & 3 & 38 & 19 & 180 & 23973.365 .0 & 173.5 & 368.8 & 47.0 & Velopharyn & (P) \\
\hline 172 & 22 & $\mathrm{~F}$ & 1 & -4 & $\begin{array}{ll}-7 & 3\end{array}$ & 28 & 10 & -1 & $\begin{array}{ll}-8 & 82\end{array}$ & 76 \\
\hline & 6 & 38 & 19 & 168 & 18763.468 .0 & 147.6 & 275.9 & 53.5 & Glossophary & (GP) \\
\hline 185 & 22 & $\mathrm{~F}$ & 1 & -1 & $1 \quad-2$ & 30 & 5 & 1 & 283 & 82 \\
\hline & 1 & 39 & 15 & 180 & 28693.475 .0 & 211.1 & 382.6 & 55.2 & Glossophary & (GP) \\
\hline 146 & 23 & M & -2 & -5 & -116 & 20 & 3 & 5 & $-6 \quad 79$ & 76 \\
\hline & 3 & 32 & 12 & 181 & 14736.068 .0 & 83.3 & 216.7 & 38.4 & Glossophary & (GP) \\
\hline 154 & 23 & $\mathrm{~F}$ & 2 & -1 & $1 \quad-2$ & 24 & 2 & 0 & 187 & 88 \\
\hline & -1 & 29 & 7 & 182 & 19164.373 .0 & 217.8 & 262.5 & 83.0 & Glossophary & (GP) \\
\hline
\end{tabular}




\begin{tabular}{|c|c|c|c|c|c|c|c|c|c|c|}
\hline \multirow[t]{2}{*}{173} & 23 & $\mathrm{~F}$ & 5 & 1 & $-3 \quad 4$ & 29 & 6 & -2 & $\begin{array}{ll}-5 & 87\end{array}$ & 80 \\
\hline & 7 & 38 & 13 & 166 & 27557.174 .0 & 218.1 & 372.4 & 58.6 & \multicolumn{2}{|c|}{ Hypopharynx (HP) } \\
\hline \multirow[t]{2}{*}{192} & 23 & $\mathrm{~F}$ & -6 & -10 & $-6 \quad-4$ & 32 & 4 & 2 & $-4 \quad 67$ & 71 \\
\hline & -4 & 46 & 17 & 195 & 19049.962 .0 & 194.6 & 307.3 & 63.3 & \multicolumn{2}{|c|}{ Glossopharynx (GP) } \\
\hline \multirow[t]{2}{*}{161} & 24 & $\mathrm{~F}$ & -1 & -5 & $\begin{array}{ll}-2 & -3\end{array}$ & 30 & 9 & 0 & $\begin{array}{ll}-2 & 82\end{array}$ & 81 \\
\hline & 1 & 39 & 17 & 179 & 20286.172 .0 & 167.1 & 281.8 & 59.3 & \multicolumn{2}{|c|}{ Hypopharynx (HP) } \\
\hline \multirow[t]{2}{*}{189} & 24 & $\mathrm{M}$ & 0 & -3 & $0 \quad-3$ & 26 & 5 & -2 & $-2 \quad 75$ & 77 \\
\hline & -1 & 42 & 19 & 181 & 38056.175 .0 & 380.6 & 507.4 & 75.0 & \multicolumn{2}{|c|}{ Velopharynx (VP) } \\
\hline \multirow[t]{2}{*}{191} & 24 & $\mathrm{~F}$ & 5 & -2 & $-2 \quad 0$ & 26 & 7 & -1 & $-3 \quad 76$ & 74 \\
\hline & 2 & 40 & 20 & 177 & 18129.767 .0 & 161.4 & 270.6 & 59.6 & \multicolumn{2}{|c|}{ Velopharynx (VP) } \\
\hline \multirow[t]{2}{*}{195} & 24 & $\mathrm{~F}$ & 3 & -2 & $\begin{array}{ll}-2 & 0\end{array}$ & 26 & 6 & -2 & $-4 \quad 89$ & 87 \\
\hline & 2 & 30 & 9 & 175 & 17369.774 .0 & 97.5 & 234.7 & 41.5 & \multicolumn{2}{|c|}{ Glossopharynx (GP) } \\
\hline \multirow[t]{2}{*}{197} & 24 & M & -4 & -8 & $-9 \quad 1$ & 23 & 4 & 2 & $\begin{array}{ll}-7 & 79\end{array}$ & 78 \\
\hline & 1 & 31 & 14 & 180 & 13300.269 .0 & 76.4 & 192.8 & 39.6 & \multicolumn{2}{|c|}{ Velopharynx (VP) } \\
\hline \multirow[t]{2}{*}{204} & 24 & M & 5 & 2 & $\begin{array}{ll}-8 & 10\end{array}$ & 23 & 5 & 3 & $-5 \quad 85$ & 75 \\
\hline & 10 & 36 & 14 & 163 & 21660.077 .0 & 187.9 & 281.3 & 66.8 & \multicolumn{2}{|c|}{ Velopharynx (VP) } \\
\hline \multirow[t]{2}{*}{212} & 24 & $\mathrm{~F}$ & 3 & 0 & $\begin{array}{ll}-3 & 3\end{array}$ & 27 & 12 & 0 & $-3 \quad 78$ & 72 \\
\hline & 6 & 43 & 26 & 168 & 19307.475 .0 & 125.2 & 257.4 & 48.6 & \multicolumn{2}{|c|}{ Hypopharynx (HP) } \\
\hline \multirow[t]{2}{*}{181} & 25 & $\mathrm{~F}$ & 6 & 0 & $-4 \quad 4$ & 35 & 14 & -2 & $-6 \quad 81$ & 73 \\
\hline & 8 & 48 & 24 & 164 & 17820.366 .0 & 122.5 & 270.0 & 45.4 & \multicolumn{2}{|c|}{ Glossopharynx (GP) } \\
\hline 196 & 25 & M & -6 & -9 & -123 & 39 & 19 & 1 & -1177 & 68 \\
\hline & 9 & 51 & 29 & 163 & 17179.774 .0 & 136.0 & 232.2 & 58.6 & Glossophary & (GP) \\
\hline 198 & 25 & $\mathrm{~F}$ & 6 & -2 & $\begin{array}{ll}-4 & 2\end{array}$ & 32 & 8 & -2 & $\begin{array}{ll}-6 & 83\end{array}$ & 79 \\
\hline & 4 & 42 & 17 & 170 & 17436.976 .0 & 144.1 & 229.4 & 62.8 & Glossophary & (GP) \\
\hline 205 & 25 & $\mathrm{~F}$ & 0 & -5 & $-6 \quad 1$ & 29 & 10 & 0 & $\begin{array}{ll}-6 & 79\end{array}$ & 76 \\
\hline & 3 & 39 & 18 & 176 & 25412.466 .0 & 311.3 & 385.0 & 80.8 & Velopharyn & VP) \\
\hline 215 & 25 & $\mathrm{~F}$ & 5 & 0 & $-1 \quad 1$ & 23 & 6 & 1 & $0 \quad 83$ & 80 \\
\hline & 3 & 33 & 17 & 177 & 16182.170 .0 & 55.1 & 231.2 & 23.8 & Hypopharyr & HP) \\
\hline 216 & 25 & $\mathrm{~F}$ & -1 & -2 & $-6 \quad 4$ & 28 & 2 & 0 & $\begin{array}{ll}-6 & 78\end{array}$ & 76 \\
\hline & 2 & 40 & 13 & 179 & 22463.572 .0 & 153.5 & 312.0 & 49.2 & Velopharyn & VP) \\
\hline 193 & 26 & $\mathrm{~F}$ & -1 & -5 & $-3 \quad-2$ & 22 & 8 & 3 & $0 \quad 79$ & 77 \\
\hline & 2 & 34 & 19 & 180 & 19400.869 .0 & 162.6 & 281.2 & 57.8 & Glossophary & (GP) \\
\hline 194 & 26 & $\mathrm{~F}$ & 4 & 0 & $-2 \quad 2$ & 30 & 11 & -3 & $\begin{array}{ll}-5 & 79\end{array}$ & 75 \\
\hline & 5 & 43 & 23 & 169 & 22636.976 .0 & 137.6 & 297.9 & 46.2 & Glossophary & (GP) \\
\hline 219 & 26 & $\mathrm{~F}$ & 4 & -1 & $-1 \quad 0$ & 26 & 8 & -1 & $-2 \quad 82$ & 79 \\
\hline & 3 & 35 & 17 & 175 & 28153.873 .0 & 135.1 & 385.7 & 35.0 & Glossophary & (GP) \\
\hline 223 & 26 & $\mathrm{~F}$ & 4 & -3 & $\begin{array}{ll}-3 & 0\end{array}$ & 30 & 9 & -2 & $-5 \quad 80$ & 76 \\
\hline & 5 & 42 & 22 & 172 & 17307.372 .0 & 72.5 & 240.4 & 30.2 & Glossophar & (GP) \\
\hline 203 & 27 & M & 6 & 0 & $2 \quad-2$ & 22 & 0 & 2 & $4 \quad 77$ & 78 \\
\hline & -1 & 37 & 13 & 186 & 17642.974 .0 & 160.3 & 238.4 & 67.2 & Glossophar & (GP) \\
\hline 206 & 27 & $\mathrm{~F}$ & 2 & -5 & $\begin{array}{ll}-5 & 0\end{array}$ & 30 & 13 & 2 & $\begin{array}{ll}-3 & 76\end{array}$ & 73 \\
\hline & 3 & 44 & 25 & 176 & 13436.164 .0 & 109.1 & 209.9 & 52.0 & Hypopharyı & $\mathrm{HP})$ \\
\hline 225 & 27 & $\mathrm{~F}$ & 6 & 0 & $0 \quad 0$ & 29 & 10 & -1 & $\begin{array}{ll}-1 & 80\end{array}$ & 76 \\
\hline & 4 & 41 & 22 & 173 & 21354.268 .0 & 194.7 & 314.0 & 62.0 & Velopharyn & VP) \\
\hline 228 & 27 & $\mathrm{~F}$ & 2 & -3 & $-4 \quad 1$ & 21 & 2 & 1 & $\begin{array}{ll}-3 & 79\end{array}$ & 80 \\
\hline & -1 & 31 & 12 & 184 & 12656.866 .0 & 114.0 & 191.8 & 59.4 & Hypopharyı & HP) \\
\hline 229 & 27 & M & 4 & 0 & $\begin{array}{ll}-5 & 5\end{array}$ & 25 & 4 & 5 & $0 \quad 84$ & 80 \\
\hline & 4 & 35 & 14 & 175 & 26393.678 .0 & 149.0 & 338.4 & 44.0 & Velopharyn & VP) \\
\hline
\end{tabular}




\begin{tabular}{|c|c|c|c|c|c|c|c|c|c|c|}
\hline \multirow[t]{2}{*}{236} & 27 & $\mathrm{~F}$ & 4 & 0 & $\begin{array}{ll}-2 & 2\end{array}$ & 27 & 6 & 2 & 86 & 81 \\
\hline & 5 & 36 & 13 & 174 & 32575.972 .0 & 361.0 & 452.4 & 79.8 & \multicolumn{2}{|c|}{ Glossopharynx (GP) } \\
\hline \multirow[t]{2}{*}{237} & 27 & $\mathrm{~F}$ & 8 & 2 & $-3 \quad 5$ & 20 & 2 & 0 & $\begin{array}{ll}-3 & 81\end{array}$ & 76 \\
\hline & 5 & 36 & 17 & 172 & 22745.169 .0 & 236.6 & 329.6 & 71.8 & \multicolumn{2}{|c|}{ Glossopharynx (GP) } \\
\hline \multirow[t]{2}{*}{214} & 28 & $\mathrm{~F}$ & 4 & -4 & $3 \quad-7$ & 31 & 8 & -1 & $2 \quad 77$ & 79 \\
\hline & -2 & 43 & 21 & 184 & 20633.079 .0 & 123.5 & 261.2 & 47.3 & \multicolumn{2}{|c|}{ Velopharynx (VP) } \\
\hline \multirow[t]{2}{*}{217} & 28 & $\mathrm{~F}$ & 3 & 0 & $-2 \quad 2$ & 22 & 3 & -1 & $\begin{array}{ll}-3 & 82\end{array}$ & 79 \\
\hline & 3 & 33 & 11 & 175 & 15500.067 .0 & 112.1 & 231.3 & 48.5 & \multicolumn{2}{|c|}{ Velopharynx (VP) } \\
\hline \multirow[t]{2}{*}{231} & 28 & $\mathrm{~F}$ & 2 & -5 & $\begin{array}{ll}-2 & -3\end{array}$ & 23 & 4 & 1 & $-1 \quad 77$ & 79 \\
\hline & -2 & 35 & 15 & 187 & 14387.764 .0 & 151.5 & 224.8 & 67.4 & \multicolumn{2}{|c|}{ Velopharynx (VP) } \\
\hline \multirow[t]{2}{*}{232} & 28 & $\mathrm{~F}$ & 0 & 0 & $-2 \quad 2$ & 21 & 5 & 3 & $1 \quad 82$ & 78 \\
\hline & 4 & 32 & 16 & 176 & 39878.365 .0 & 473.9 & 613.5 & 77.2 & \multicolumn{2}{|c|}{ Velopharynx (VP) } \\
\hline \multirow[t]{2}{*}{233} & 28 & $\mathrm{~F}$ & -2 & -7 & $\begin{array}{ll}-7 & 0\end{array}$ & 32 & 13 & 0 & $\begin{array}{ll}-7 & 80\end{array}$ & 77 \\
\hline & 3 & 39 & 21 & 174 & 23572.775 .0 & 207.9 & 314.3 & 66.1 & \multicolumn{2}{|c|}{ Velopharynx (VP) } \\
\hline \multirow[t]{2}{*}{234} & 28 & $\mathrm{~F}$ & 6 & -1 & $\begin{array}{ll}-5 & 4\end{array}$ & 23 & 3 & 1 & $-4 \quad 77$ & 75 \\
\hline & 2 & 35 & 16 & 181 & 24493.070 .0 & 204.5 & 349.9 & 58.4 & \multicolumn{2}{|c|}{ Glossopharynx (GP) } \\
\hline \multirow[t]{2}{*}{238} & 29 & $\mathrm{~F}$ & 2 & -3 & $\begin{array}{ll}-1 & -2\end{array}$ & 24 & 4 & 0 & $-1 \quad 85$ & 84 \\
\hline & 1 & 30 & 10 & 180 & 8397.564 .0 & 82.9 & 131.2 & 63.2 & \multicolumn{2}{|c|}{ Velopharynx (VP) } \\
\hline \multirow[t]{2}{*}{239} & 29 & $\mathrm{~F}$ & -2 & -6 & $\begin{array}{ll}-2 & -4\end{array}$ & 25 & 8 & 1 & $-1 \quad 86$ & 86 \\
\hline & 0 & 32 & 13 & 181 & 16592.672 .0 & 100.8 & 230.5 & 43.7 & \multicolumn{2}{|c|}{ Hypopharynx (HP) } \\
\hline \multirow[t]{2}{*}{241} & 29 & M & -2 & -5 & $\begin{array}{ll}-3 & -2\end{array}$ & 29 & 8 & 2 & $\begin{array}{ll}-1 & 89\end{array}$ & 88 \\
\hline & 1 & 27 & 9 & 181 & 27281.766 .0 & 232.1 & 413.4 & 56.1 & \multicolumn{2}{|c|}{ Glossopharynx (GP) } \\
\hline \multirow[t]{2}{*}{243} & 29 & $\mathrm{~F}$ & 6 & -2 & $-8 \quad 6$ & 40 & 12 & 1 & $\begin{array}{ll}-7 & 79\end{array}$ & 71 \\
\hline & 8 & 52 & 21 & 167 & 17530.671 .0 & 99.8 & 246.9 & 40.4 & \multicolumn{2}{|c|}{ Glossopharynx (GP) } \\
\hline \multirow[t]{2}{*}{246} & 29 & $\mathrm{~F}$ & 1 & -2 & $0 \quad-2$ & 25 & 9 & 1 & $1 \quad 77$ & 74 \\
\hline & 3 & 40 & 24 & 176 & 23445.777 .0 & 80.5 & 304.5 & 26.4 & \multicolumn{2}{|c|}{ Hypopharynx (HP) } \\
\hline 248 & 29 & $\mathrm{~F}$ & 4 & 0 & $1 \quad-1$ & 23 & 5 & -2 & $-1 \quad 82$ & 80 \\
\hline & 3 & 38 & 19 & 173 & 15092.664 .0 & 107.5 & 235.8 & 45.6 & Velopharyn & VP) \\
\hline 249 & 29 & $\mathrm{~F}$ & 3 & -3 & $2 \quad-5$ & 31 & 7 & 0 & $2 \quad 86$ & 86 \\
\hline & 0 & 38 & 16 & 182 & 9974.360 .0 & 108.4 & 166.2 & 65.2 & Glossophary & (GP) \\
\hline 230 & 30 & M & 2 & -3 & $\begin{array}{ll}-5 & 2\end{array}$ & 27 & 6 & 3 & $\begin{array}{ll}-2 & 80\end{array}$ & 80 \\
\hline & 0 & 36 & 14 & 182 & 34986.076 .0 & 350.6 & 460.3 & 76.2 & Glossophary & (GP) \\
\hline 242 & 30 & $\mathrm{~F}$ & -3 & -6 & $\begin{array}{ll}-3 & -3\end{array}$ & 28 & 6 & -2 & $-5 \quad 74$ & 74 \\
\hline & 1 & 40 & 20 & 182 & 19466.970 .0 & 197.4 & 278.1 & 71.0 & Hypopharyr & HP) \\
\hline 250 & 30 & $\mathrm{~F}$ & 8 & 2 & $4 \quad-2$ & 22 & 4 & 0 & $4 \quad 84$ & 83 \\
\hline & 1 & 34 & 12 & 180 & 14712.768 .0 & 69.2 & 216.4 & 32.0 & Velopharyn & VP) \\
\hline
\end{tabular}


Six Elements Group Allocation

\begin{tabular}{|c|c|c|c|c|c|c|}
\hline Subject \# & Mx-GALL Group & Md-GALL Group & Mx-Md Group & MPI Group & OPI Group & EPP Group \\
\hline 104 & Severely Deficient & Deficient & Category III & Flat & Optimal & Optimal \\
\hline 113 & Optimal Range & Optimal Range & Category I & Steep & Optimal & Optimal \\
\hline 117 & Deficient & Severely Deficient & Category II - Severe & Optimal & Optimal & Severely Retrusive \\
\hline 121 & Deficient & Deficient & Category I & Steep & Steep & Retrusive \\
\hline 130 & Excessive & Deficient & Category II - Severe & Steep & Steep & Retrusive \\
\hline 132 & Optimal Range & Optimal Range & Category II & Flat & Flat & Optimal \\
\hline 134 & Optimal Range & Deficient & Category II & Flat & Optimal & Retrusive \\
\hline 144 & Deficient & Severely Deficient & Category II - Severe & Steep & Flat & Severely Retrusive \\
\hline 109 & Optimal Range & Deficient & Category II & Flat & Optimal & Retrusive \\
\hline 123 & Optimal Range & Deficient & Category I & Flat & Optimal & Optimal \\
\hline 135 & Severely Deficient & Deficient & Category I & Flat & Flat & Optimal \\
\hline 137 & Optimal Range & Optimal Range & Category I & Optimal & Optimal & Optimal \\
\hline 142 & Deficient & Deficient & Category I & Flat & Optimal & Optimal \\
\hline 155 & Deficient & Severely Deficient & Category II - Severe & Flat & Flat & Retrusive \\
\hline 118 & Optimal Range & Deficient & Category II & Flat & Flat & Retrusive \\
\hline 126 & Excessive & Optimal Range & Category II & Optimal & Flat & Optimal \\
\hline 128 & Excessive & Excessive & Category I & Flat & Optimal & Protrusive \\
\hline 139 & Optimal Range & Optimal Range & Category I & Steep & Optimal & Retrusive \\
\hline 143 & Optimal Range & Deficient & Category II & Steep & Optimal & Optimal \\
\hline 148 & Deficient & Deficient & Category II & Optimal & Optimal & Retrusive \\
\hline 149 & Optimal Range & Optimal Range & Category I & Optimal & Flat & Optimal \\
\hline 151 & Optimal Range & Severely Deficient & Category II - Severe & Steep & Optimal & Severely Retrusive \\
\hline 157 & Optimal Range & Optimal Range & Category I & Flat & Optimal & Protrusive \\
\hline 162 & Severely Deficient & Deficient & Category III & Optimal & Optimal & Optimal \\
\hline 169 & Optimal Range & Optimal Range & Category I & Optimal & Optimal & Optimal \\
\hline 120 & Optimal Range & Deficient & Category II & Optimal & Optimal & Retrusive \\
\hline 150 & Severely Deficient & Severely Deficient & Category I & Flat & Optimal & Retrusive \\
\hline 152 & Deficient & Optimal Range & Category III & Optimal & Optimal & Optimal \\
\hline 153 & Optimal Range & Optimal Range & Category III & Optimal & Optimal & Protrusive \\
\hline 156 & Severely Deficient & Severely Deficient & Category II & Steep & Steep & Severely Retrusive \\
\hline 163 & Excessive & Optimal Range & Category II & Optimal & Optimal & Retrusive \\
\hline 164 & Optimal Range & Optimal Range & Category I & Steep & Steep & Optimal \\
\hline 165 & Severely Deficient & Deficient & Category III & Steep & Steep & Retrusive \\
\hline 166 & Deficient & Deficient & Category II & Optimal & Optimal & Optimal \\
\hline 180 & Excessive & Optimal Range & Category II & Steep & Steep & Optimal \\
\hline 140 & Deficient & Optimal Range & Category III & Steep & Steep & Protrusive \\
\hline 159 & Severely Deficient & Deficient & Category III & Steep & Flat & Retrusive \\
\hline 160 & Optimal Range & Deficient & Category II & Optimal & Optimal & Optimal \\
\hline
\end{tabular}




\begin{tabular}{|c|c|c|c|c|c|c|}
\hline 167 & Deficient & Severely Deficient & Category II & Steep & Steep & Severely Retrusive \\
\hline 171 & Optimal Range & Optimal Range & Category I & Optimal & Optimal & Optimal \\
\hline 172 & Deficient & Severely Deficient & Category II & Optimal & Steep & Severely Retrusive \\
\hline 185 & Optimal Range & Optimal Range & Category III & Steep & Optimal & Protrusive \\
\hline 146 & Deficient & Severely Deficient & Category II - Severe & Flat & Optimal & Retrusive \\
\hline 154 & Optimal Range & Optimal Range & Category III & Optimal & Flat & Optimal \\
\hline 173 & Optimal Range & Deficient & Category II & Steep & Optimal & Retrusive \\
\hline 192 & Severely Deficient & Deficient & Category III & Steep & Optimal & Retrusive \\
\hline 161 & Deficient & Optimal Range & Category III & Steep & Steep & Optimal \\
\hline 189 & Deficient & Optimal Range & Category III & Optimal & Optimal & Optimal \\
\hline 191 & Optimal Range & Optimal Range & Category I & Optimal & Optimal & Retrusive \\
\hline 195 & Optimal Range & Optimal Range & Category I & Optimal & Optimal & Retrusive \\
\hline 197 & Severely Deficient & Severely Deficient & Category I & Optimal & Optimal & Severely Retrusive \\
\hline 204 & Excessive & Severely Deficient & Category II - Severe & Optimal & Optimal & Retrusive \\
\hline 212 & Optimal Range & Deficient & Category II & Optimal & Steep & Retrusive \\
\hline 181 & Optimal Range & Deficient & Category II & Steep & Steep & Retrusive \\
\hline 196 & Severely Deficient & Severely Deficient & Category II & Steep & Steep & Severely Retrusive \\
\hline 198 & Optimal Range & Deficient & Category II & Steep & Optimal & Retrusive \\
\hline 205 & Deficient & Deficient & Category I & Steep & Steep & Retrusive \\
\hline 215 & Optimal Range & Optimal Range & Category I & Optimal & Optimal & Optimal \\
\hline 216 & Optimal Range & Deficient & Category II & Optimal & Flat & Retrusive \\
\hline 193 & Deficient & Deficient & Category III & Flat & Optimal & Optimal \\
\hline 194 & Optimal Range & Optimal Range & Category II & Steep & Steep & Retrusive \\
\hline 219 & Optimal Range & Optimal Range & Category I & Optimal & Optimal & Optimal \\
\hline 223 & Deficient & Deficient & Category I & Steep & Steep & Retrusive \\
\hline 203 & Optimal Range & Excessive & Category III & Flat & Flat & Protrusive \\
\hline 206 & Deficient & Deficient & Category I & Steep & Steep & Retrusive \\
\hline 225 & Optimal Range & Optimal Range & Category I & Steep & Steep & Optimal \\
\hline 228 & Deficient & Deficient & Category I & Flat & Flat & Retrusive \\
\hline 229 & Optimal Range & Deficient & Category II & Optimal & Optimal & Optimal \\
\hline 236 & Optimal Range & Optimal Range & Category II & Optimal & Optimal & Optimal \\
\hline 237 & Excessive & Deficient & Category II & Flat & Flat & Retrusive \\
\hline 214 & Deficient & Excessive & Category III & Steep & Optimal & Protrusive \\
\hline 217 & Optimal Range & Optimal Range & Category II & Flat & Optimal & Retrusive \\
\hline 231 & Deficient & Optimal Range & Category III & Optimal & Optimal & Optimal \\
\hline 232 & Optimal Range & Optimal Range & Category II & Flat & Optimal & Optimal \\
\hline 233 & Severely Deficient & Severely Deficient & Category I & Steep & Steep & Severely Retrusive \\
\hline 234 & Optimal Range & Deficient & Category II & Optimal & Optimal & Retrusive \\
\hline 238 & Deficient & Optimal Range & Category III & Optimal & Optimal & Optimal \\
\hline 239 & Deficient & Optimal Range & Category III & Optimal & Optimal & Optimal \\
\hline 241 & Deficient & Deficient & Category III & Steep & Optimal & Optimal \\
\hline
\end{tabular}




\begin{tabular}{|c|c|c|c|c|c|c|}
\hline 243 & Optimal Range & Severely Deficient & Category II - Severe & Steep & Steep & Severely Retrusive \\
\hline 246 & Optimal Range & Optimal Range & Category III & Optimal & Steep & Optimal \\
\hline 248 & Optimal Range & Optimal Range & Category I & Optimal & Optimal & Optimal \\
\hline 249 & Deficient & Excessive & Category III & Steep & Optimal & Protrusive \\
\hline 230 & Deficient & Deficient & Category II & Optimal & Optimal & Optimal \\
\hline 242 & Deficient & Deficient & Category III & Optimal & Optimal & Retrusive \\
\hline 250 & Excessive & Excessive & Category III & Flat & Optimal & Protrusive \\
\hline
\end{tabular}

\section{Control Group Allocation}

\begin{tabular}{|c|c|c|c|c|c|c|}
\hline Subject \# & SNA Group & SNB Group & ANB Group & MP-SN Group & OP-SN Group & NAP Group \\
\hline 104 & Optimal Range & Excessive & Class III & Low Angle & Low Angle & Concave \\
\hline 113 & Optimal Range & Optimal Range & Class I & Normal & Normal & Straight \\
\hline 117 & Optimal Range & Deficient & Class II & Normal & Normal & Convex \\
\hline 121 & Excessive & Excessive & Class II & Normal & Normal & Convex \\
\hline 130 & Optimal Range & Deficient & Class II & High Angle & High Angle & Convex \\
\hline 132 & Optimal Range & Optimal Range & Class I & Low Angle & Low Angle & Straight \\
\hline 134 & Optimal Range & Optimal Range & Class II & Low Angle & Normal & Convex \\
\hline 144 & Optimal Range & Optimal Range & Class II & Normal & Normal & Convex \\
\hline 109 & Optimal Range & Optimal Range & Class II & Normal & Normal & Convex \\
\hline 123 & Optimal Range & Optimal Range & Class I & Normal & Normal & Straight \\
\hline 135 & Optimal Range & Optimal Range & Class III & Low Angle & Low Angle & Concave \\
\hline 137 & Optimal Range & Optimal Range & Class I & Normal & High Angle & Straight \\
\hline 142 & Optimal Range & Optimal Range & Class I & Low Angle & Normal & Straight \\
\hline 155 & Excessive & Excessive & Class II & Low Angle & Low Angle & Straight \\
\hline 118 & Optimal Range & Optimal Range & Class I & Normal & Normal & Convex \\
\hline 126 & Optimal Range & Optimal Range & Class I & Normal & Low Angle & Straight \\
\hline 128 & Optimal Range & Optimal Range & Class I & Normal & Normal & Concave \\
\hline 139 & Optimal Range & Optimal Range & Class II & High Angle & Normal & Convex \\
\hline 143 & Optimal Range & Deficient & Class II & High Angle & Normal & Convex \\
\hline 148 & Excessive & Excessive & Class I & Low Angle & Low Angle & Straight \\
\hline 149 & Optimal Range & Optimal Range & Class I & Normal & Normal & Straight \\
\hline 151 & Optimal Range & Deficient & Class II & High Angle & Normal & Convex \\
\hline 157 & Excessive & Excessive & Class I & Low Angle & Low Angle & Straight \\
\hline 162 & Optimal Range & Excessive & Class III & Normal & Normal & Concave \\
\hline 169 & Optimal Range & Optimal Range & Class I & High Angle & High Angle & Convex \\
\hline 120 & Excessive & Optimal Range & Class I & Normal & Normal & Convex \\
\hline 150 & Optimal Range & Excessive & Class I & Low Angle & Normal & Concave \\
\hline 152 & Excessive & Excessive & Class I & Normal & Normal & Straight \\
\hline 153 & Excessive & Excessive & Class I & Normal & Normal & Straight \\
\hline 156 & Deficient & Deficient & Class I & High Angle & High Angle & Convex \\
\hline
\end{tabular}




\begin{tabular}{|c|c|c|c|c|c|c|}
\hline 163 & Optimal Range & Optimal Range & Class II & Normal & Normal & Convex \\
\hline 164 & Optimal Range & Optimal Range & Class II & High Angle & High Angle & Convex \\
\hline 165 & Excessive & Excessive & Class I & Normal & Normal & Straight \\
\hline 166 & Optimal Range & Optimal Range & Class I & Normal & Normal & Straight \\
\hline 180 & Optimal Range & Deficient & Class II & High Angle & High Angle & Convex \\
\hline 140 & Optimal Range & Optimal Range & Class I & High Angle & High Angle & Straight \\
\hline 159 & Optimal Range & Excessive & Class III & Normal & Low Angle & Concave \\
\hline 160 & Optimal Range & Optimal Range & Class I & Normal & Normal & Straight \\
\hline 167 & Excessive & Optimal Range & Class II & Normal & Normal & Convex \\
\hline 171 & Optimal Range & Optimal Range & Class I & Normal & Normal & Straight \\
\hline 172 & Optimal Range & Optimal Range & Class II & Normal & Normal & Convex \\
\hline 185 & Optimal Range & Optimal Range & Class I & Normal & Normal & Straight \\
\hline 146 & Optimal Range & Optimal Range & Class I & Normal & Normal & Concave \\
\hline 154 & Excessive & Excessive & Class III & Low Angle & Low Angle & Concave \\
\hline 173 & Excessive & Optimal Range & Class II & Normal & Normal & Convex \\
\hline 192 & Deficient & Deficient & Class III & High Angle & Normal & Concave \\
\hline 161 & Optimal Range & Optimal Range & Class I & Normal & Normal & Straight \\
\hline 189 & Deficient & Optimal Range & Class III & High Angle & Normal & Concave \\
\hline 191 & Deficient & Optimal Range & Class I & Normal & High Angle & Straight \\
\hline 195 & Excessive & Excessive & Class I & Low Angle & Low Angle & Convex \\
\hline 197 & Optimal Range & Optimal Range & Class I & Normal & Normal & Concave \\
\hline 204 & Excessive & Optimal Range & Class II & Normal & Normal & Convex \\
\hline 212 & Deficient & Deficient & Class II & High Angle & High Angle & Convex \\
\hline 181 & Optimal Range & Deficient & Class II & High Angle & High Angle & Convex \\
\hline 196 & Deficient & Deficient & Class II & High Angle & High Angle & Convex \\
\hline 198 & Optimal Range & Optimal Range & Class I & High Angle & Normal & Convex \\
\hline 205 & Optimal Range & Optimal Range & Class I & Normal & Normal & Straight \\
\hline 215 & Optimal Range & Optimal Range & Class I & Normal & Normal & Straight \\
\hline 216 & Deficient & Optimal Range & Class I & Normal & Normal & Straight \\
\hline 193 & Optimal Range & Optimal Range & Class I & Normal & Normal & Straight \\
\hline 194 & Optimal Range & Optimal Range & Class II & High Angle & High Angle & Convex \\
\hline 219 & Optimal Range & Optimal Range & Class I & Normal & Normal & Convex \\
\hline 223 & Optimal Range & Optimal Range & Class II & High Angle & High Angle & Convex \\
\hline 203 & Deficient & Optimal Range & Class III & Normal & Normal & Concave \\
\hline 206 & Deficient & Deficient & Class I & High Angle & High Angle & Straight \\
\hline 225 & Optimal Range & Optimal Range & Class I & High Angle & High Angle & Convex \\
\hline 228 & Optimal Range & Optimal Range & Class III & Normal & Normal & Concave \\
\hline 229 & Excessive & Optimal Range & Class II & Normal & Normal & Convex \\
\hline 236 & Excessive & Optimal Range & Class II & Normal & Normal & Convex \\
\hline 237 & Optimal Range & Optimal Range & Class II & Normal & Normal & Convex \\
\hline 214 & Deficient & Optimal Range & Class III & High Angle & High Angle & Concave \\
\hline
\end{tabular}




\begin{tabular}{|l|llllll|}
217 & Optimal Range & Optimal Range & Class I & Normal & Normal & Straight \\
231 & Deficient & Optimal Range & Class III & Normal & Normal & Concave \\
232 & Optimal Range & Optimal Range & Class II & Normal & Normal & Straight \\
233 & Optimal Range & Optimal Range & Class I & Normal & High Angle & Convex \\
234 & Deficient & Optimal Range & Class I & Normal & Normal & Concave \\
238 & Excessive & Excessive & Class I & Low Angle & Normal & Straight \\
239 & Excessive & Excessive & Class I & Normal & Normal & Concave \\
241 & Excessive & Excessive & Class I & Low Angle & Low Angle & Concave \\
243 & Optimal Range & Deficient & Class II & High Angle & High Angle & Convex \\
246 & Deficient & Optimal Range & Class I & Normal & High Angle & Straight \\
248 & Optimal Range & Optimal Range & Class I & Normal & Normal & Convex \\
249 & Excessive & Excessive & Class III & Normal & Normal & Concave \\
230 & Optimal Range & Optimal Range & Class I & Normal & Normal & Concave \\
242 & Deficient & Deficient & Class I & High Angle & Normal & Concave \\
250 & Optimal Range & Excessive & Class I & Normal & Normal & Straight \\
\hline
\end{tabular}

\section{Mx-GALL ANOVA and t-test Analyses}

\section{*For additional statistics, see supplemental excel spreadsheet}

\begin{tabular}{|c|c|c|c|c|c|c|c|c|c|c|}
\hline \multicolumn{4}{|c|}{ AV } & \multicolumn{7}{|c|}{ One-Way ANOVA: Airway Volume (AV) } \\
\hline Deficient & Deficient & Optimal & Excessive & & & & & & & \\
\hline 13454.4 & 17307.3 & 16182.1 & 14712.7 & Groups & Sev. Deficient & Deficient & Optimal & Excessive & & \\
\hline 13300.2 & 20505.5 & 23445.7 & 11569.9 & Count & 11.00 & 27.00 & 40.00 & 8.00 & & \\
\hline 11758.0 & 10611.7 & 28153.8 & 17756.1 & Sum & 190601.10 & 514868.40 & 931842.20 & 150250.30 & & \\
\hline 29180.4 & 14736.0 & 15164.6 & 20423.2 & Average & 17327.37 & 19069.20 & 23296.06 & 18781.29 & & \\
\hline 19084.2 & 16592.6 & 17530.6 & 19571.5 & Variance & 27273727.71 & 44951813.15 & 48015501.33 & 15158805.28 & & \\
\hline 13792.9 & 20633.0 & 17369.7 & 21811.8 & SS & 272737277.12 & 1168747141.94 & 1872604551.76 & 106111636.99 & & \\
\hline 16263.3 & 13436.1 & 15297.0 & 21660.0 & & & & & & & \\
\hline 13965.4 & 18763.4 & 26393.6 & 22745.1 & $\begin{array}{l}\text { Source of } \\
\text { Variation } \\
\end{array}$ & SS & $d f$ & $M S$ & $F$ & $P$-value & $F$ crit \\
\hline 17179.7 & 19099.6 & 17820.3 & & $\begin{array}{l}\text { Between } \\
\text { Groups } \\
\text { Within }\end{array}$ & 495328997.55 & 3.00 & 165109665.85 & 3.959 & 0.011 & 2.716 \\
\hline 19049.9 & 21221.0 & 15092.6 & & Groups & 3420200607.81 & 82.00 & 41709763.51 & & & \\
\hline 23572.7 & 27281.7 & 22636.9 & & & & & & & & \\
\hline & 19400.8 & 23973.3 & & Total & 3915529605.36 & 85.00 & & & SIGNIFICAN & \\
\hline & 20286.1 & 15500.0 & & & & & & & & \\
\hline & 12656.8 & 19307.4 & & & & & & & & \\
\hline & 14779.1 & 22463.5 & & & & & & & & \\
\hline & 21928.8 & 26209.4 & & & & & & Unequal V & ances T-Test & Mean AV \\
\hline & 17134.0 & 17496.3 & & & & & & $\begin{array}{c}\text { Mx-GALL } \\
\text { Groups } \\
\end{array}$ & P-value & Significance \\
\hline & 8397.5 & 29353.1 & & & & & & $\begin{array}{l}\text { Sev. Deficient } \\
\text { v. Deficient }\end{array}$ & 0.401 & \\
\hline
\end{tabular}




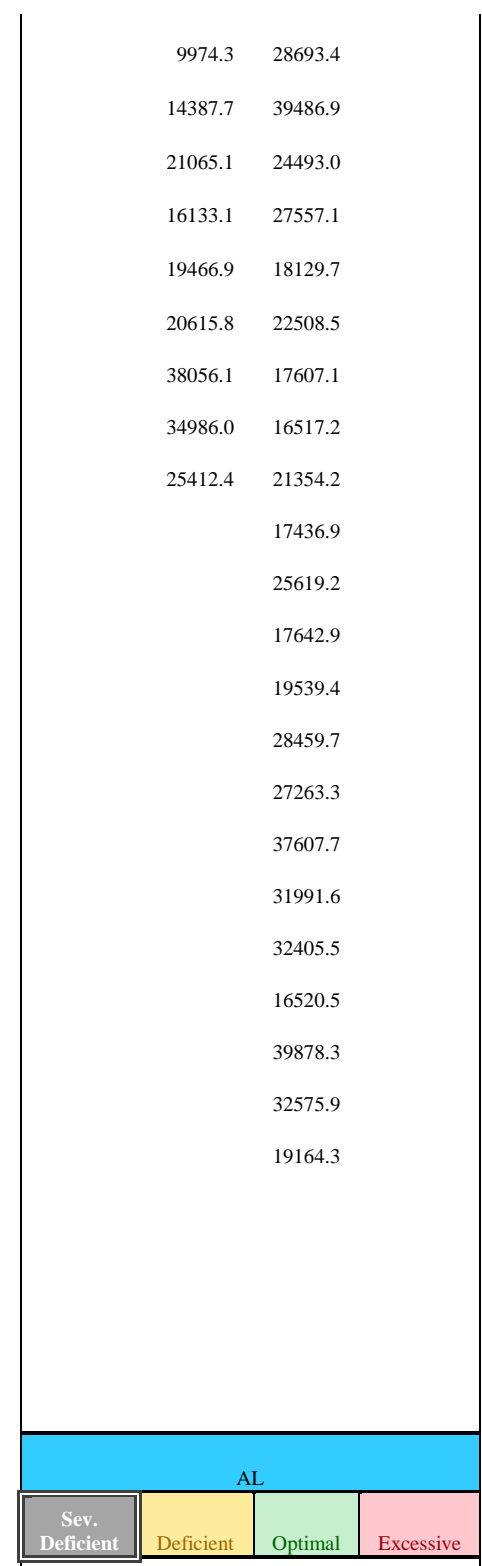

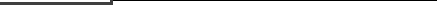

\begin{tabular}{|llll}
53.0 & 72.0 & 70.0 & 68.0 \\
69.0 & 80.0 & 77.0 & 64.0 \\
68.0 & 63.0 & 73.0 & 69.0 \\
65.0 & 68.0 & 69.0 & 77.0 \\
68.0 & 72.0 & 71.0 & 73.0 \\
65.0 & 79.0 & 74.0 & 64.0 \\
69.0 & 64.0 & 71.0 & 77.0 \\
64.0 & 68.0 & 78.0 & 69.0 \\
74.0 & 71.0 & 66.0 & \\
62.0 & 73.0 & 64.0 & \\
75.0 & 66.0 & 76.0 &
\end{tabular}

\begin{tabular}{|l|l|l|}
$\begin{array}{l}\text { Sev. Deficient } \\
\text { v. Optimal }\end{array}$ & 0.005 & $*$ \\
\hline $\begin{array}{l}\text { Sev. Deficient } \\
\text { v. Excessive }\end{array}$ & 0.496 & \\
\hline $\begin{array}{l}\text { Deficient v. } \\
\text { Optimal }\end{array}$ & 0.015 & $*$ \\
\hline $\begin{array}{l}\text { Deficient v. } \\
\text { Excessive }\end{array}$ & 0.880 & \\
\hline $\begin{array}{l}\text { Optimal v. } \\
\text { Excessive }\end{array}$ & 0.020 & $*$ \\
\hline
\end{tabular}

One-Way ANOVA: Airway Length (AL)

\begin{tabular}{|c|c|c|c|c|c|c|}
\hline Groups & Sev. Deficient & Deficient & Optimal & Excessive & & \\
\hline Count & 11.00 & 27.00 & 40.00 & 8.00 & & \\
\hline Sum & 732.00 & 1857.00 & 2814.00 & 561.00 & & \\
\hline Average & 66.55 & 68.78 & 70.35 & 70.13 & & \\
\hline Variance & 35.87 & 26.64 & 26.75 & 26.41 & & \\
\hline SS & 358.73 & 692.67 & 1043.10 & 184.88 & & \\
\hline $\begin{array}{l}\text { Source of } \\
\text { Variation }\end{array}$ & SS & $d f$ & $M S$ & $F$ & $P$-value & $F_{\text {crit }}$ \\
\hline $\begin{array}{l}\text { Between } \\
\text { Groups }\end{array}$ & 140.17 & 3.00 & 46.72 & 1.681 & 0.178 & 2.716 \\
\hline $\begin{array}{l}\text { Within } \\
\text { Groups }\end{array}$ & 2279.37 & 82.00 & 27.80 & & & \\
\hline
\end{tabular}




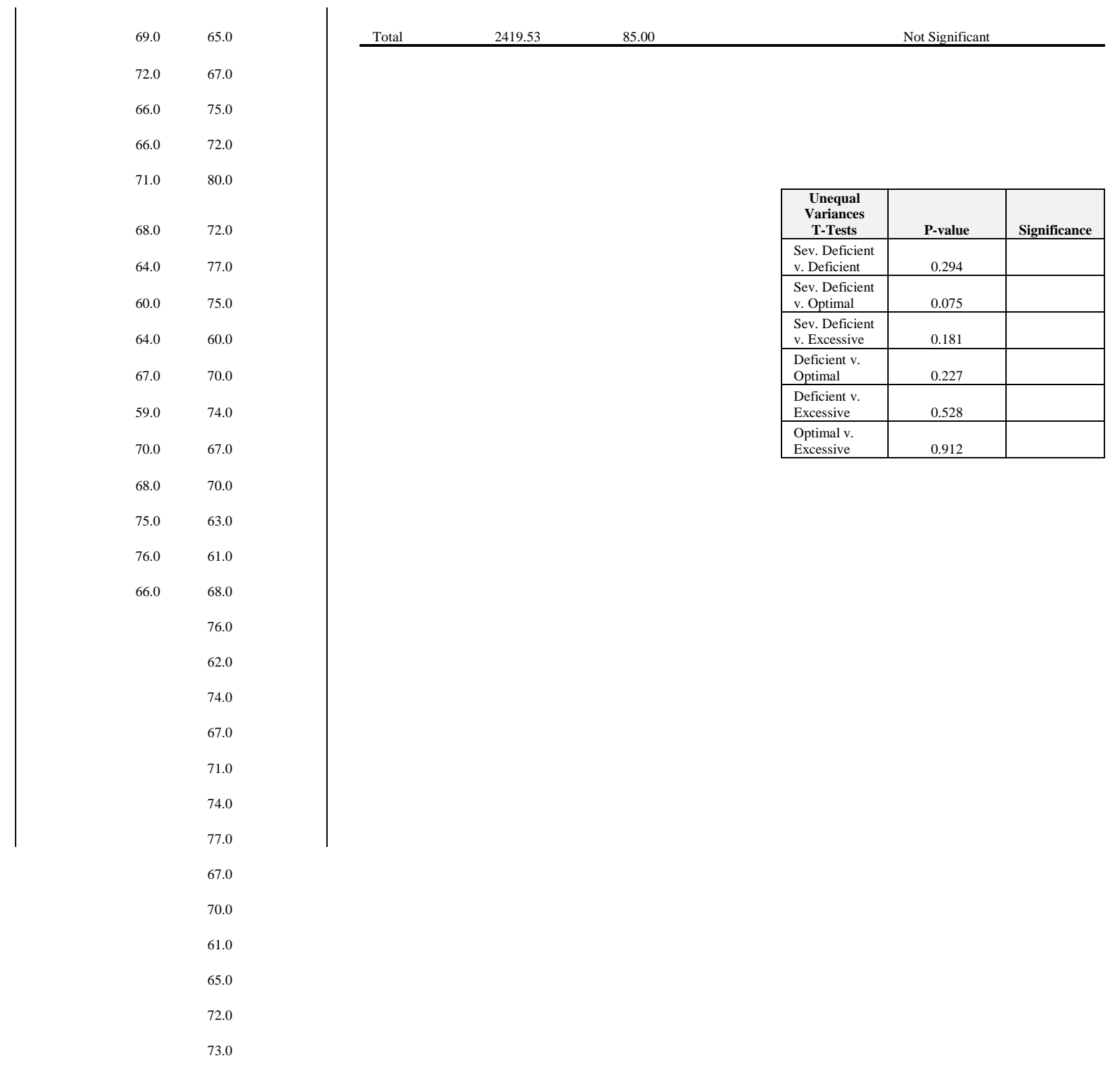

\begin{tabular}{|c|c|c|c|}
\hline \multicolumn{4}{|c|}{$\mathrm{mCA}$} \\
\hline $\begin{array}{l}\text { Sev. } \\
\text { Deficient }\end{array}$ & Deficient & Optimal & Excessive \\
\hline 86.6 & 72.5 & 55.1 & 69.2 \\
\hline 76.4 & 82.9 & 80.5 & 72.6 \\
\hline 76.5 & 63.3 & 135.1 & 107.8 \\
\hline
\end{tabular}

One-Way ANOVA: Minimum Cross-sectional Area (mCA)

\begin{tabular}{lrrrr}
\hline \multirow{2}{*}{ Groups } & Sev. Deficient & Deficient & Optimal & \multicolumn{1}{c}{ Excessive } \\
\hline \multirow{2}{*}{ Count } & 11.00 & 27.00 & 40.00 & 8.00 \\
Sum & 1488.20 & 4463.40 & 7681.20 & 1166.50
\end{tabular}




\begin{tabular}{|c|c|c|c|c|c|c|c|c|c|c|}
\hline 212.9 & 83.3 & 82.3 & 131.3 & Average & 135.29 & 165.31 & 192.03 & 145.81 & & \\
\hline 141.5 & 100.8 & 99.8 & 149.6 & Variance & 2518.38 & 6598.11 & 8617.31 & 3889.72 & & \\
\hline 107.8 & 123.5 & 97.5 & 211.5 & SS & 25183.83 & 171550.87 & 336074.94 & 27228.03 & & \\
\hline 127.6 & 109.1 & 93.8 & 187.9 & & & & & & & \\
\hline 120.4 & 147.6 & 149.0 & 236.6 & $\begin{array}{l}\text { Source of } \\
\text { Variation }\end{array}$ & SS & $d f$ & $M S$ & $F$ & $P$-value & F crit \\
\hline 136.0 & 145.2 & 122.5 & & $\begin{array}{l}\text { Between } \\
\text { Groups } \\
\text { Within }\end{array}$ & 37564.84 & 3.00 & 12521.61 & 1.833 & 0.148 & 2.716 \\
\hline 194.6 & 160.3 & 107.5 & & Groups & 560037.67 & 82.00 & 6829.73 & & & \\
\hline 207.9 & 232.1 & 137.6 & & & & & & & & \\
\hline & 162.6 & 173.5 & & Total & 597602.51 & \multicolumn{2}{|l|}{85.00} & \multicolumn{3}{|c|}{ Not Significant } \\
\hline & 167.1 & 112.1 & & & & & & & & \\
\hline & 114.0 & 125.2 & & & & & & & & \\
\hline & 134.3 & 153.5 & & & & & & & & \\
\hline & 189.3 & 170.5 & & & & & & & & \\
\hline & 156.8 & 129.3 & & & & & & $\begin{array}{c}\text { Unequal } \\
\text { Variances } \\
\text { T-Tests } \\
\end{array}$ & P-value & Significance \\
\hline & 82.9 & 209.8 & & & & & & $\begin{array}{l}\text { Sev. Deficient } \\
\text { v. Deficient }\end{array}$ & 0.178 & \\
\hline & 108.4 & 211.1 & & & & & & $\begin{array}{l}\text { Sev. Deficient } \\
\text { v. Optimal }\end{array}$ & 0.011 & * \\
\hline & 151.5 & 369.0 & & & & & & $\begin{array}{l}\text { Sev. Deficient } \\
\text { v. Excessive } \\
\end{array}$ & 0.700 & \\
\hline & 217.6 & 204.5 & & & & & & $\begin{array}{l}\text { Deficient v. } \\
\text { Optimal }\end{array}$ & 0.218 & \\
\hline & 191.1 & 218.1 & & & & & & $\begin{array}{l}\text { Deficient } v \text {. } \\
\text { Excessive }\end{array}$ & 0.482 & \\
\hline & 197.4 & 161.4 & & & & & & $\begin{array}{l}\text { Optimal v. } \\
\text { Excessive }\end{array}$ & 0.103 & \\
\hline & 227.3 & 192.7 & & & & & & & & \\
\hline & 380.6 & 169.4 & & & & & & & & \\
\hline & 350.6 & 164.2 & & & & & & & & \\
\hline & 311.3 & 194.7 & & & & & & & & \\
\hline & & 144.1 & & & & & & & & \\
\hline & & 261.1 & & & & & & & & \\
\hline & & 160.3 & & & & & & & & \\
\hline & & 196.4 & & & & & & & & \\
\hline & & 271.5 & & & & & & & & \\
\hline & & 255.0 & & & & & & & & \\
\hline & & 340.0 & & & & & & & & \\
\hline & & 345.8 & & & & & & & & \\
\hline & & 336.8 & & & & & & & & \\
\hline & & 197.8 & & & & & & & & \\
\hline & & 473.9 & & & & & & & & \\
\hline & & 361.0 & & & & & & & & \\
\hline & & 217.8 & & & & & & & & \\
\hline
\end{tabular}




\begin{tabular}{|c|c|c|c|c|c|c|c|c|c|c|}
\hline \multicolumn{4}{|c|}{ MCA } & \multicolumn{3}{|c|}{$\begin{array}{l}\text { One-Way ANOVA: Mean Cross-sectional Area } \\
\text { (MCA) }\end{array}$} & \multirow{3}{*}{\multicolumn{2}{|c|}{ Excessive }} & & \\
\hline $\begin{array}{c}\text { Sev. } \\
\text { Deficient } \\
\end{array}$ & Deficient & Optimal & Excessive & & & & & & & \\
\hline 253.9 & 240.4 & 231.2 & 216.4 & Groups & Sev. Deficient & Deficient & & & & \\
\hline 192.8 & 256.3 & 304.5 & 180.8 & Count & 11.00 & 27.00 & 40.00 & 8.00 & & \\
\hline 172.9 & 168.4 & 385.7 & 257.3 & Sum & 2868.93 & 7416.03 & 13291.19 & 2139.56 & & \\
\hline 448.9 & 216.7 & 219.8 & 265.2 & Average & 260.81 & 274.67 & 332.28 & 267.45 & & \\
\hline 280.7 & 230.5 & 246.9 & 268.1 & Variance & 5883.63 & 7357.21 & 10744.35 & 2810.02 & & \\
\hline 212.2 & 261.2 & 234.7 & 340.8 & SS & 58836.27 & 191287.36 & 419029.46 & 19670.12 & & \\
\hline 235.7 & 209.9 & 215.5 & 281.3 & & & & & & & \\
\hline 218.2 & 275.9 & 338.4 & 329.6 & $\begin{array}{l}\text { Source of } \\
\text { Variation }\end{array}$ & SS & $d f$ & $M S$ & $F$ & $P$-value & F crit \\
\hline 232.2 & 269.0 & 270.0 & & $\begin{array}{l}\text { Between } \\
\text { Groups } \\
\text { Within } \\
\text { Growns }\end{array}$ & 84294.56 & 3.00 & 28098.19 & 3.345 & 0.023 & 2.716 \\
\hline $\begin{array}{l}307.3 \\
314.3\end{array}$ & $\begin{array}{l}290.7 \\
413.4\end{array}$ & $\begin{array}{l}235.8 \\
297.9\end{array}$ & & Groups & 688823.21 & 82.00 & 8400.28 & & & \\
\hline & 281.2 & 368.8 & & Total & 773117.77 & 85.00 & & & SIGNIFICAN & \\
\hline & 281.8 & 231.3 & & & & & & & & \\
\hline & 191.8 & 257.4 & & & & & & & & \\
\hline & 223.9 & 312.0 & & & & & & & & \\
\hline & 308.9 & 327.6 & & & & & & Unequal Va & inces T-Tests & Iean MCA \\
\hline & 252.0 & 243.0 & & & & & & $\begin{array}{c}\text { Mx-GALL } \\
\text { Groups }\end{array}$ & P-value & Significance \\
\hline & 131.2 & 381.2 & & & & & & $\begin{array}{l}\text { Sev. Deficient } \\
\text { v. Deficient }\end{array}$ & 0.631 & \\
\hline & 166.2 & 382.6 & & & & & & $\begin{array}{l}\text { Sev. Deficient } \\
\text { v. Optimal }\end{array}$ & 0.020 & $*$ \\
\hline & 224.8 & 658.1 & & & & & & $\begin{array}{l}\text { Sev. Deficient } \\
\text { v. Excessive }\end{array}$ & 0.826 & \\
\hline & 314.4 & 349.9 & & & & & & $\begin{array}{l}\text { Deficient v. } \\
\text { Optimal }\end{array}$ & 0.016 & $*$ \\
\hline & 273.4 & 372.4 & & & & & & $\begin{array}{l}\text { Deficient v. } \\
\text { Excessive }\end{array}$ & 0.776 & \\
\hline & 278.1 & 270.6 & & & & & & $\begin{array}{l}\text { Optimal v. } \\
\text { Excessive } \\
\end{array}$ & 0.017 & $*$ \\
\hline & 303.2 & 321.6 & & & & & & & & \\
\hline & 507.4 & 279.5 & & & & & & & & \\
\hline & 460.3 & 270.8 & & & & & & & & \\
\hline & 385.0 & 314.0 & & & & & & & & \\
\hline & & 229.4 & & & & & & & & \\
\hline & & 413.2 & & & & & & & & \\
\hline & & 238.4 & & & & & & & & \\
\hline & & 291.6 & & & & & & & & \\
\hline & & 400.8 & & & & & & & & \\
\hline & & 368.4 & & & & & & & & \\
\hline & & 488.4 & & & & & & & & \\
\hline & & 477.5 & & & & & & & & \\
\hline & & 462.9 & & & & & & & & \\
\hline
\end{tabular}




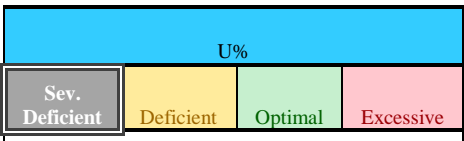

\begin{tabular}{|c|c|c|c|}
\hline 34.1 & 30.2 & 23.8 & 32.0 \\
\hline 39.6 & 32.3 & 26.4 & 40.2 \\
\hline 44.2 & 37.6 & 35.0 & 41.9 \\
\hline 47.4 & 38.4 & 37.4 & 49.5 \\
\hline 50.4 & 43.7 & 40.4 & 55.8 \\
\hline 50.8 & 47.3 & 41.5 & 62.1 \\
\hline 54.1 & 52.0 & 43.5 & 66.8 \\
\hline 55.2 & 53.5 & 44.0 & 71.8 \\
\hline 58.6 & 54.0 & 45.4 & \\
\hline 63.3 & 55.1 & 45.6 & \\
\hline \multirow[t]{19}{*}{66.1} & 56.1 & 46.2 & \\
\hline & 57.8 & 47.0 & \\
\hline & 59.3 & 48.5 & \\
\hline & 59.4 & 48.6 & \\
\hline & 60.0 & 49.2 & \\
\hline & 61.3 & 52.0 & \\
\hline & 62.2 & 53.2 & \\
\hline & 63.2 & 55.0 & \\
\hline & 65.2 & 55.2 & \\
\hline & 67.4 & 56.1 & \\
\hline & 69.2 & 58.4 & \\
\hline & 69.9 & 58.6 & \\
\hline & 71.0 & 59.6 & \\
\hline & 75.0 & 59.9 & \\
\hline & 75.0 & 60.6 & \\
\hline & 76.2 & 60.6 & \\
\hline & 80.8 & 62.0 & \\
\hline & & 62.8 & \\
\hline & & 63.2 & \\
\hline
\end{tabular}

One-Way ANOVA: Uniformity Percentage (U\%)

\begin{tabular}{lrrrr}
\hline Groups & Sev. Deficient & \multicolumn{1}{c}{ Deficient } & \multicolumn{1}{c}{ Optimal } & Excessive \\
\hline Count & 11.00 & 27.00 & 40.00 & 8.00 \\
Sum & 564.01 & 1573.20 & 2239.48 & 419.97 \\
Average & 51.27 & 58.27 & 55.99 & 52.50 \\
Variance & 93.86 & 180.84 & 194.32 & 196.14 \\
SS & 938.61 & 4701.84 & 7578.59 & 1372.96 \\
\hline
\end{tabular}

\begin{tabular}{lrrrrrr}
\hline $\begin{array}{l}\text { Source of } \\
\text { Variation }\end{array}$ & SS & df & MS & $F$ & P-value & F crit \\
\hline Between & 478.35 & 3.00 & 159.45 & 0.896 & $\mathbf{0 . 4 4 7}$ & 2.716 \\
$\begin{array}{l}\text { Groups } \\
\text { Within }\end{array}$ & 14592.01 & 82.00 & 177.95 & & \\
Groups & & & & & \\
& & & & & \\
& & & & & \\
Total & 15070.36 & 85.00 & & & & \\
\hline
\end{tabular}

Total

85.00

Not Significant

\begin{tabular}{|l|c|l|}
\hline \multicolumn{1}{|c|}{$\begin{array}{c}\text { Unequal } \\
\text { Variances } \\
\text { T-Tests }\end{array}$} & P-value & Significance \\
\hline $\begin{array}{l}\text { Sev. Deficient } \\
\text { v. Deficient }\end{array}$ & 0.085 & \\
\hline $\begin{array}{l}\text { Sev. Deficient } \\
\text { v. Optimal }\end{array}$ & 0.211 & \\
\hline $\begin{array}{l}\text { Sev. Deficient } \\
\text { v. Excessive }\end{array}$ & 0.835 & \\
\hline $\begin{array}{l}\text { Deficient v. } \\
\text { Optimal }\end{array}$ & 0.505 & \\
\hline $\begin{array}{l}\text { Deficient v. } \\
\text { Excessive }\end{array}$ & 0.324 & \\
\hline $\begin{array}{l}\text { Optimal v. } \\
\text { Excessive }\end{array}$ & 0.534 & \\
\hline
\end{tabular}




\begin{tabular}{|l|l|}
67.2 \\
67.3 \\
67.7 \\
69.2 \\
69.6 \\
72.4 \\
72.8 \\
73.0 \\
77.2 \\
79.8 \\
83.0
\end{tabular}

